DOE/ID-10326

Distribution Category UC-122

\title{
MICROBIAL ENHANCED OIL RECOVERY AND WETTABILITY RESEARCH PROGRAM
}

DOE/ID--10326

DE91 002248

FY 1990 Annual Report

July 1991

Work Performed Under Contract No. DE-AC07-76ID01570

\author{
Prepared for \\ U.S. Department of Energy \\ Assistant Secretary for Fossil Energy \\ I. Aoki, Project Manager \\ Idaho Operations Office \\ and \\ Edith Allison, Project Manager \\ Bartlesville Project Office
}

\author{
Prepared by \\ EG\&G Idaho, Inc. \\ Idaho National Engineering Laboratory \\ Idaho Falls, ID 83415
}

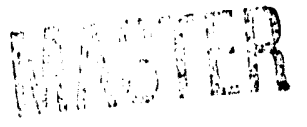




\section{ABSTRACT}

This report covers research results for FY 1990 for the microbial enhanced 011 recovery (MEOR) and wettability research program conducted by EG\&G Idaho, Inc. at the Idaho National Engineering Laboratory (INEL) for the U.S. Department of Energy (DOE). The research program is funded by the Office of Fossil Energy and managed by the Idaho Opeations Office and the Bartlesville Project Office. The objective of the multi-year MEOR project is to develop microbial enhanced oil recovery (MEOR) systems for application to reservoirs containing medium to heavy crude oils and the design and implementation of an industry cost-shared field demonstration project of the MEOR technology. An understanding of the controlling mechanisms will first be developed through the use of laboratory scale testing to determine the ability of microbially mediated processes to recover oil under reservoir conditions and to develop the design criteria for scale-up to the field. Concurrently with this work, the isolation and characterization of microbial species collected from various locations including target oil field environments is underway to develop more effective oil recovery systems for specific applications. The wettability research is a multi-year collaborative effort with the New Mexico Petroleum Recovery Research Center (NMPRRC) at the New Mexico Institue of Mining and Technology, Socorro, NM to evaluate reservoir wettabiltiy and its effects on oil recovery. Results from the wettability research will be applied to determine if alteration of wettability is a significant contributing mechanism for MEOR systems.

Eight facultatively anaerobic surfactant producing isolates able to function in the reservoir conditions of the Minnelusa A Sands of the Powder River Basin in Wyoming have been isolated from naturally occurring oil-laden environments. The isolates have been characterized according to morphology, thermostability, halotolerance, growth substrates, affinity to crude $0 i 1 /$ brine interfaces, degradative effects on crude oils, and biochemical profiles. 
The MEOR research at the INEL in FY 1990 has focused on the elucidation of microbial mechanisms by which crude oil may be recovered from a reservoir and the chemical and physical properties of the reservoir that may impact the effectiveness of MEOR. During FY 1990, Bacillus licheniformis JF-2 (ATCC 39307) has been used as a benchmark organism to quantify MEOR of medium weight crude oils (17.5 to $\left.38.1^{\circ} \mathrm{API}\right)$. Bacillus licheniformis was chosen because of its past and current use in the field of MEOR. The capacity for oil recovery of Bacillus licheniformis JF-2 utilizing a sucrose-based nutrient has been elucidated using Berea sandstone cores (permeability 85 to $400 \mathrm{md}$ ). Depending on method of injection (washed or unwashed cells) and type of 011 , recoveries up to $28 \%$ of the original oil-in-place have been achieved. Spacial distribution of cells after microbial flooding has been analyzed with scanning electron microscopy. These data indicate complete distribution of cells with a predominance of organisms located distal to the point of injection. $0 i 1$ recovery appears to be surfactant mediated. The effect of microbial surfactants on the interfacial tensions (IFT) of aqueous/crude oil systems has been measured utilizing an interfacial tensiometer based on real time digital imaging of a hanging drop (designed and constructed at the INEL). Cell free supernatants prepared from Bacillus licheniformis JF-2 resulted in decrease in IFT for all the crude oils tested.

The results of the wettabiltiy research are summarized and the contributions to the permanant literature are listed. 


\section{SUMMARY}

This report covers research results for FY 1990 for the microbial enhanced oil recovery (MEOR) and wettability research program conducted by EG\&G Idaho, Inc. at the Idaho National Engineering Laboratory (INEL) for the U.S. Department of Energy (DOE). The research program is funded by the Office of Fossil Energy and managed by the Idaho Opeations Office and the Bartlesville Project Office.

The global objective of this multi-year project is to develop microbial enhanced oil recovery (MEOR) systems for application to reservoirs containing medium to heavy crude oils and the design and implementation of an industry cost-shared field demonstration project of the MEOR technology. An understanding of the controlling mechanisms will first be developed through the use of laboratory scale testing to determine the ability of microbially mediated processes to recover oil under reservoir conditions and to develop the design criteria for scale-up to the field. Concurrently with this work, the isolation and characterization of microbial species collected from various locations including target oil field environments is underway to develop more effective oil recovery systems for specific applications.

An understanding of the mechanisms by which microbial systems displace 011 under reservoir conditions is being developed through such avenues as core flooding, interfacial tension (IFT) measurements, and other laboratory techniques. The determination of the mechanisms of oil recovery by microbial systems, the range of applicability, and the economic viability of MEOR processes compared to other enhanced oil recovery (EOR) processes will be a significant contribution to EOR and specifically to MEOR technology. The mechanisms of MEOR are not fully understood or specifically known for a wide variety of reservoir conditions, crude oils, and microbial and nutrient systems. Bacteria that have characteristics such as the capability to emulsify crude oils and lower IFT are ideal candidates for improved oil recovery. Organisms that have the ability to produce acids or gases or both and organisms that are capable of asphaltic degradation are also significant 
to the technology and are presently being collected and isolated for application in EOR research activities.

Two fields in the Powder River Basin, Wyoming have been selected as targets for focus of the MEOR research. These reservoirs produce from the Minnelusa formation and provide an opportunity to study and evaluate reservoirs in two stages of depletion; primary and secondary. The crude $0 i 1$ produced from these reservoirs is about $20^{\circ} \mathrm{API}$ gravity at $60^{\circ} \mathrm{F}$. Assembly of existing field and reservoir data is underway for these candidates. Water analyses to determine the characteristics of the produced brine and injection water has been completed.

Companies that operate oil reservoirs of the target type will benefit through the geological, engineering, and microbial characterization of potential field test sites. Geoscience research will be expanded as required by characteristics of the target reservoir for a successful EOR field design and demonstration project. The industry will also benefit through technolingy transfer of data resulting from research and field demonstrations of the EOR technology.

Eight facultatively anaerobic surfactant producing isolates able to function in the reservoir conditions of the Minnelusa A Sands of the Powder River Basin in Wyoming have been isolated from naturally occurring oil-1aden environments. The isolates have been characterized according to morphology, thermostability, halotolerance, growth substrates, affinity to crude $0 \mathrm{il} / \mathrm{brine}$ interfaces, degradative effects on crude oils, and biochemical profiles.

A series of core flood experiments were performed to investigate parameters such as crude oil type, crude oil viscosity, aging and incubation time, IFT, and brine composition. The first set of cores were inoculated, incubated, and again waterflooded with varying degrees of success for the Bacillus licheniformis JF-2 (ATCC 39307) microbial system with the different oils. Six $0 i 1 s$ were used in the experimental core flood work ranging in API gravity from 17.5 to $50.5^{\circ} \mathrm{API}$ at $60^{\circ} \mathrm{F}$. The experimental program consisted of various core floods being performed with each oil. Non-fired Berea sandstone cores 
encapsulated in epoxy were used in all core floods. A 2.4\% NaCl brine solution was used to saturate the cores and for waterflooding the cores. All core floods were performed at room temperature, including the evacuation and saturation phase of the experimental work.

Viscosities of all oils have been measured and a characterization determined for each oil. The produced oil (postflood) samples were fractionated and analyzed with gas chromatography to determine any changes in the oil because of the conditions experienced in the core during the MEOR core flood. The oils remained basically unchanged after being subjected to the conditions of the MEOR core floods. Residual oil saturations are determined for both the waterflood and the microbial flood.

Base line (control) experiments have been performed for each oil. The control cores were injected with nutrient only (no microbes were injected), incubated at the same temperature and for the same period of time as the MEOR cores.

Numerous MEOR core floods were performed with varying degrees of success. The lower gravity oils tended to produce additional oil beyond waterflood more readily than the higher gravity oils. Microbial oil was produced from all MEOR cores with the exception of the core containing a refined oil (Soltrol 220). The Soltrol test was an early test and the microbes may have been poisoned by toluene used to clean the system. Subsequent testing has shown that Bacillus licheniformis will grow in the presence of and emulsify Soltrol 220. The 011 recovery test will be repeated in the future.

Spacial distribution of cells in a Berea sandstone core $(110 \mathrm{md})$ following a microbial flood was analyzed with scanning electron microscopy. The data indicate complete distribution of cells with a preduminance of organisms located near the outlet end of the core.

Dilution studies of supernatant solutions indicate the concentration of Bacillus licheniformis surfactant is about 2.5 times greater than the critical micelle concentration (CMC) of the surfactant. Interfacial tensions were measured for various dilutions of supernatant and plotted verses supernatant 
concentration. A break in the IFT-concentration curve occurs at a supernatant:water dilution of 2:5. Maximum $0 i 1$ recoveries with a given surfactant will be obtained if the surfactant concentration is at or above the CMC.

Thin layer chromatography (TLC) studies have been initiated to identify the compound(s) that give rise to the surfactant activity found. A search of the literature on microbial $0 i 1$ recovery indicates that the surfactant produced by Bacillus licheniformis is a glycolipid. TLC of an ethyl acetate extract of the supernatant (silica gel, 9:1 ethanol:water) shows one major and five minor spots.

The importance of microbial attachment at the $0 i 1$-water interface as compared to the isolated metabolites to increase oil mobility by way of change in interfacial properties is currently being determined. These experiments employ the BATH (Bacterial Adherence to Hydrocarbons) test to ascertain the hydrophobicity of cell surfaces and the direct measurement of interfacial tensions.

Results of the research with Bacillus licheniformis indicate that the oil recovery is surfactant mediated.

Research activities in the collaborative effort for wettability research at the New Mexico Petroleum Recovery Research Center (NMPRRC) are continuing. Work is progressing in several areas related to $0 i 1$ recovery studies and the effects of wettability on core flooding results. Interim results for the studies to determine the repeatability of the adhesion mapping technique have been completed. Initial results of research to evaluate the effects of drilling mud filtrates on the wettability of cores have been collected.

The effects of wettability changes on residual oil to waterflooding were significant in that they indicate that a highly water-wet state is not necessarily the best condition for achieving the lowest residual oil saturation. The effect of changing crude oil composition, either by dilution 
with solvents, fractionation, or evaporation of the lighter components has also been investigated.

A simple adhesion test, adapted from the contact angle measurements of a captive bubble, has been developed to characterize crude oils based on their surface interactions with smooth solids and varying brine composition. Adhesion tests have been performed for more than 20 different crude oils. Adhesion tests were performed using a West Texas crude, Moutray, diluted with a solvent to simulate the action of bacteria that may work to break down large molecules of crude to smaller ones. Results indicate the $\mathrm{pH}$ adhesion/nonadhesion cutoff was lowered from that of Moutray alone.

The ability to establish a range of intermediate wettabilities in Berea cores with crude oils has been developed. Extensive tests have been conducted on Berea sandstone cores to determine the effect of wettability on oil recovery. Wettability is measured by Amott tests, supplemented in some cases by measurements of imbibition rates. Weakly water-wet or mixed-wet cores have been observed to give much higher oil recoveries than reference cores of strongly water-wet conditions, even at breakthrough. Post-breakthrough recoveries also showed a wide variety of recovery rates.

Emulsions of several crude oils have been tested to determine mobilities of emulsion droplets. The isoelectric points (IEP) are estimated from the plotted zeta potential data by measurement fr.: graphs of $\mathrm{pH}$ value at which the line between the positive and negative zeta potentials closest to zero passes through zero. Reproducibility of the mobility measurements for a given emulsion batch for both a fresh emulsion and a 2 week old emulsion is very good. For most of the oils studied, some aging was observed. 


\section{ACKNOWLEDGEMENTS}

This research is performed under the Department of Energy (DOE), Idaho Operations Office (IDO) contract number DE-AC07-76ID01570. The Idaho Operations office project manager is Mr. Isamu Aoki. The technical program manager is Ms. Edith Allison of the DOE Bartlesville Project Office.

\section{INEL Contributors}

MEOR and Wettability Program Manager: C. P. Thomas

MEOR Task Principal Investigators: G. A. Bala and M. L. Duvall

MEOR Task Contributing Scientists/Engineers: W. A. Apel, G. A. Bala, K. B. Barrett, F. S. Colwe11, P. R. Dugan, M. L. Duval1, M. D. Herd, J. D. Jackson, M. E. McIlwain, R. L. Miller, E. P. Robertson, C. P. Thomas, A. D. Wells (Associated Western Universities summer fellow), and R. M. Pfister (Visiting Scientist, Department of Biotechnology and Geosciences)

Wettability Task Principal Investigator: C. P. Thomas Wettability Task Contributing Scientists: N. R. Morrow and J. S. Buckley, New Mexico Petroleum Recovery research Center, New Mexico Institute of Mining and Technology, Socorro, NM 


\section{CONTENTS}

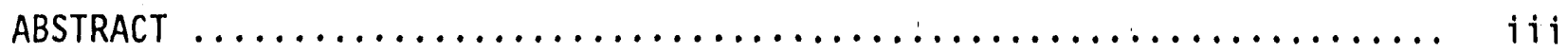

SUMMARY $\ldots \ldots \ldots \ldots \ldots \ldots \ldots \ldots \ldots \ldots \ldots \ldots \ldots \ldots \ldots \ldots \ldots \ldots \ldots$

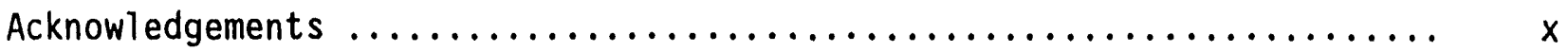

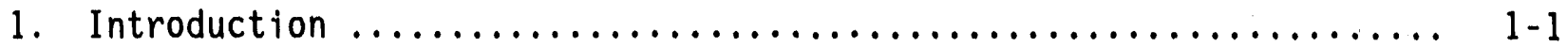

1.1 Program Purpose $\ldots \ldots \ldots \ldots \ldots \ldots \ldots \ldots \ldots \ldots \ldots \ldots \ldots \ldots \ldots \ldots 1$

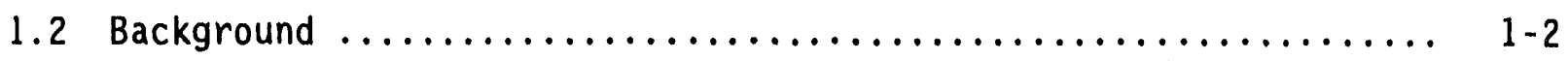

1.3 INEL Research $\ldots \ldots \ldots \ldots \ldots \ldots \ldots \ldots \ldots \ldots \ldots \ldots \ldots \ldots \ldots \ldots \ldots \ldots$

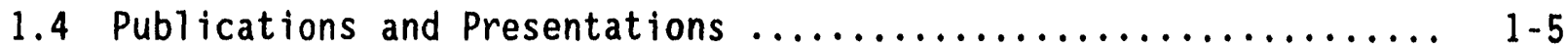

1.5 References $\ldots \ldots \ldots \ldots \ldots \ldots \ldots \ldots \ldots \ldots \ldots \ldots \ldots \ldots \ldots \ldots \ldots \ldots$

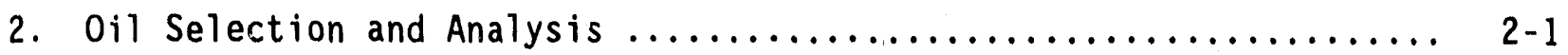

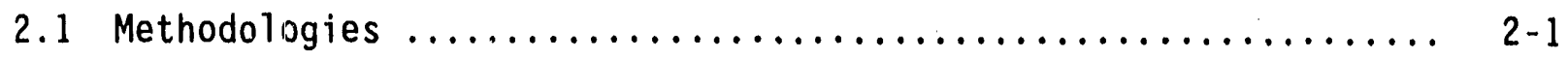

2.1.1 Fractionation (Liquid Chromatography) of Crude 0ils ....... 2-2

2.1.2 Gas Chromatography of Crude $0 i 1 s \ldots \ldots \ldots \ldots \ldots \ldots \ldots \ldots \ldots$

2.1.3 Gas Chromatograph/Mass Spectroscopy of Schuricht Crude .... 2-4

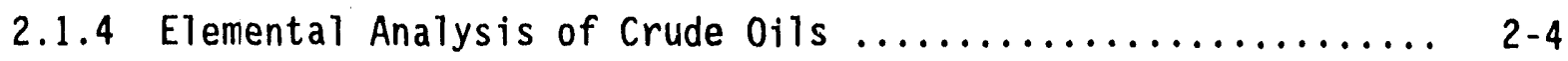

2.1.5 Viscosity Determination of Crude $0 i l s \ldots \ldots \ldots \ldots \ldots \ldots . . . \ldots$

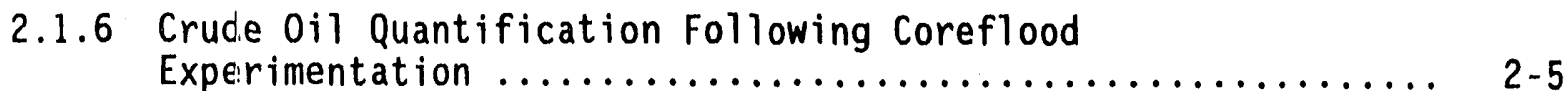

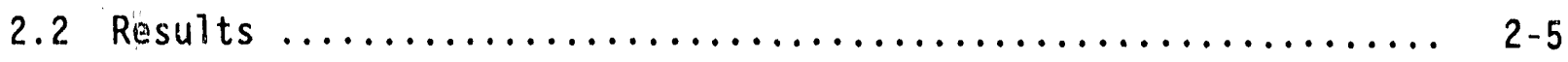

2.2.1 Friactionation (Liquid Chromatography) of Crude $0 i 1 s \ldots . . . .2-5$

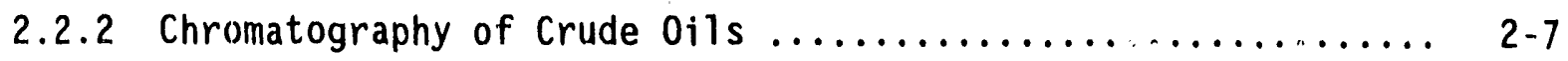

2.2.3 Gas Chromatography/Mass Spectroscopy of Schuricht Crude .... 2-7

2.2.4 Elemental Analysis of Crude $0 i 1 s \ldots \ldots \ldots \ldots \ldots \ldots \ldots \ldots \ldots \ldots$

2.2.5 Viscosity Determination of Crude $0 i 1 s \ldots \ldots \ldots \ldots \ldots \ldots$ 
2.2.6 Crude 0il Quantification Following Coreflood

Experimentation ............................... $2-9$

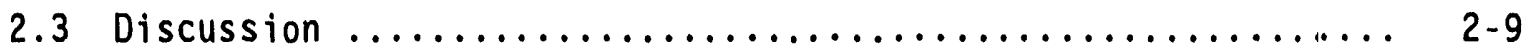

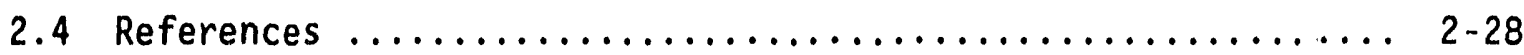

3. Microbial Analysis and Phenomena $\ldots \ldots \ldots \ldots \ldots \ldots \ldots \ldots \ldots . \ldots . \ldots . . .1$

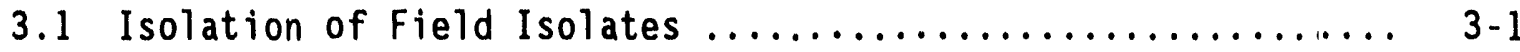

3.2 Biochemical Characterization of Bacillus Licheniformis JF. and Selected Field Isolates .......................... 3-3

3.3 Properties of Bacillus Licheniformis Strain JF-2 ......... 3-9

3.3.1 Culture Properties of Bacillus Licheniformis Strain... 3-9

3.3.2 Growth of Bacillus licheniformis JF-s for Coreflood Experimentation .............................. 3-11

3.3.3 Scanning Electron Microscopy (SEM) of Berea Sandstone Cores .................................... $3-12$

3.3.4 Surfactant Production by Bacillus licheniformis JF-2 $\ldots . .3-12$

3.3.5 Polymer Production by Bacillus licheniformis JF-2 ..... 3-13

3.4 Discussion $\ldots \ldots \ldots \ldots \ldots \ldots \ldots \ldots \ldots \ldots \ldots \ldots \ldots \ldots \ldots \ldots \ldots, 3-14$

3.5 References................................... 3-28

4. Measurement of Interfacial Tensions $\ldots \ldots \ldots \ldots \ldots \ldots \ldots \ldots . \ldots . \ldots .1$

4.1 Current INEL Interfacial Tension Measurement Technology .... 4-2

4.2 Interfacial Tension Measurements $\ldots \ldots \ldots \ldots \ldots \ldots \ldots \ldots . \ldots .6 . \ldots$

4.2.1 Calibration of Interfacial Tensiometer ............. 4-5

4.2.2 Determination of CMC for Bacillus licheniformis JF-2

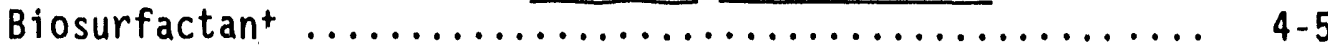

4.2.3 IFT Measurements of Bacillus licheniformis biosurfact using various crude $0 i 1 \mathrm{~s} \ldots \ldots \ldots \ldots \ldots \ldots \ldots \ldots \ldots . \ldots \ldots$ 4-7

4.3 Discussion $\ldots \ldots \ldots \ldots \ldots \ldots \ldots \ldots \ldots \ldots \ldots \ldots \ldots \ldots \ldots, 4,7$

4.4 References $\ldots \ldots \ldots \ldots \ldots \ldots \ldots \ldots \ldots \ldots \ldots \ldots \ldots \ldots \ldots \ldots, 4-15$ 
5. Laboratory Core Floods with Microbial Systems $. . . \ldots \ldots . . . \ldots . . .6$. $5-1$

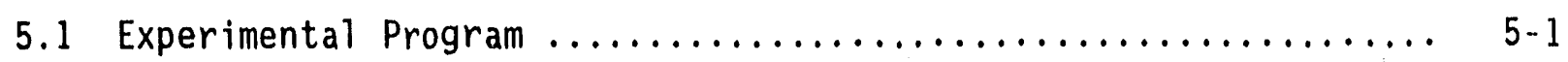

5.2 Core Flood Apparatus $\ldots \ldots \ldots \ldots \ldots \ldots \ldots \ldots \ldots \ldots \ldots \ldots \ldots, 5-2$

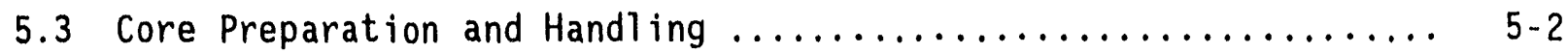

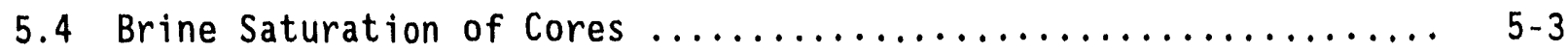

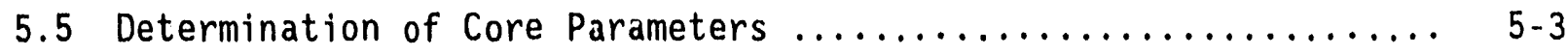

5.6 Initial Core Saturation Conditions $\ldots \ldots \ldots \ldots \ldots \ldots \ldots \ldots . \ldots .4$

5.7 Waterflood Residual 0il Saturation ..................... 5-4

5.8 Microbial Flood Residual 0il Saturation .................... 5-5

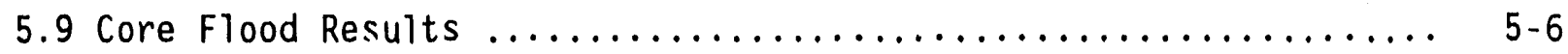

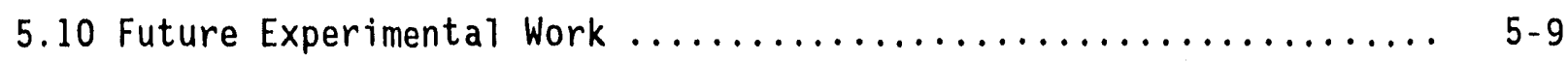

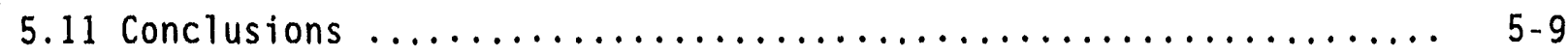

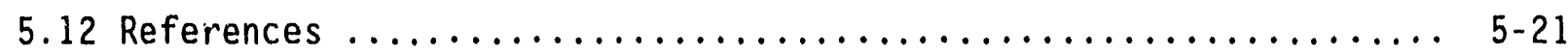

6. Target Reservoir Selection ............................. 6-1

6.1 Candidate Reservoir Selection for Focus of MEOR Research ...... 6-2

6.2 Analysis of Schuricht and Moorcroft West Crude 0ils .......... 6-4

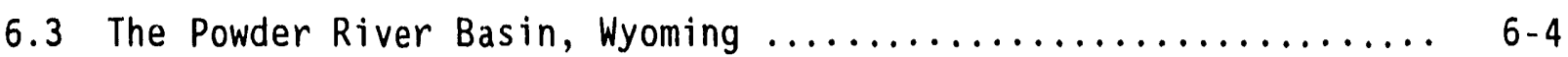

6.4 The Minnelusa Formation $\ldots \ldots \ldots \ldots \ldots \ldots \ldots \ldots \ldots \ldots . \ldots \ldots, 6-5$

6.5 Minnelusa Reservoir Characteristics ................... $6-7$

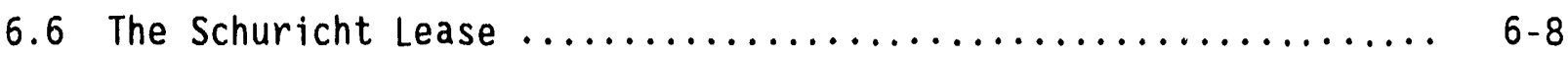

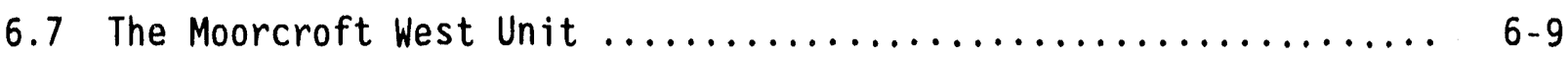

6.8 Future Work $\ldots \ldots \ldots \ldots \ldots \ldots \ldots \ldots \ldots \ldots \ldots \ldots \ldots \ldots \ldots \ldots \ldots \ldots, 6-10$

6.9 Summary and Conclusions $\ldots \ldots \ldots \ldots \ldots \ldots \ldots \ldots \ldots \ldots \ldots, 6-11$

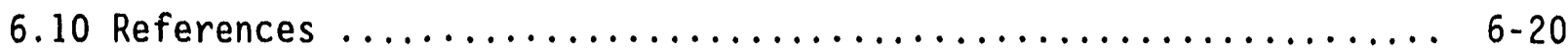

7. Reservoir Wettability and its Effect on $0 i 1$ Recovery ........... 7-1

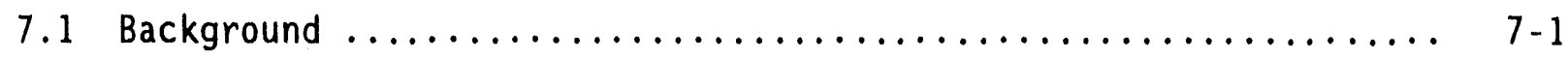




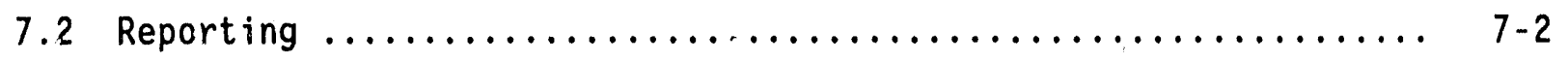

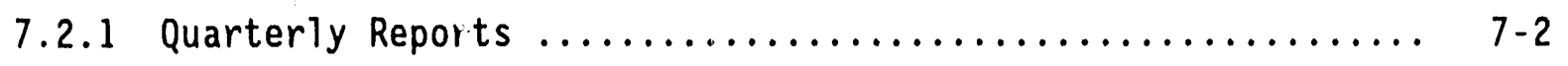

7.2.2 General Communication of Project Results in the Public Domain ...................................... $7-3$

7.2.3 First International Symposium on the Effect of

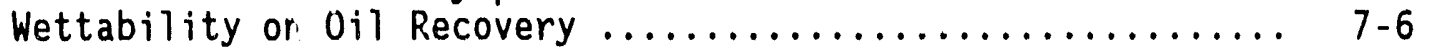

TABLES

2-1. 0ils selected for MEOR research $\ldots \ldots \ldots \ldots \ldots \ldots \ldots \ldots \ldots, 2-2$

2-2. Liquid Chromatography Fractionation of Selected Crudes ........ 2-6

2-3. Elemental Analysis of Selected Crude 0ils (Data presented

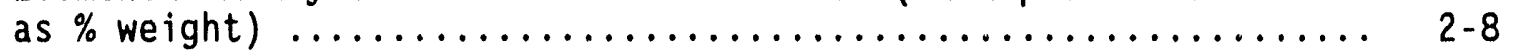

3-1. Origin, morphology and desirable MEOR phenotype of selected

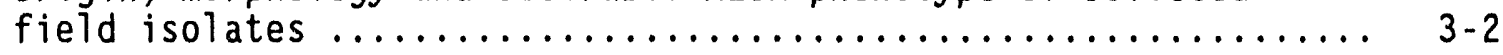

3-2. Pristane $/ C_{17}$ and phytane $/ C_{18}$ ratios obtained followilg aerobic emulsification of Schuricht crude oil ..................... 3-5

3-3. Pristane $/ C_{17}$ and phytane $/ C_{18}$ ratios obtained following anaerobic emulsification of Schuricht crude oil ...................... $3-6$

3-4. Biochemical characterization of MEOR field isolates .......... 3-10

4-1. IFT measurements for $\mathrm{n}$-butanol/water $\left(1.8 \mathrm{mN} / \mathrm{m} \odot 20^{\circ} \mathrm{C}\right)$ systems

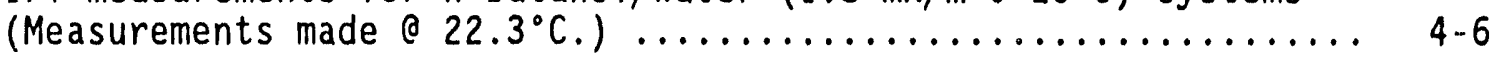

4-2. IFT measurements for $n$-hexane/water $\left(51.1 \mathrm{mN} / \mathrm{m}\right.$ ○ $\left.20^{\circ} \mathrm{C}\right)$ system

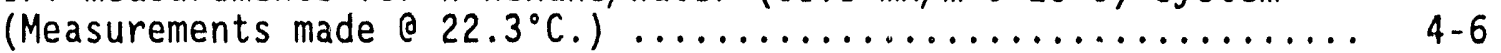

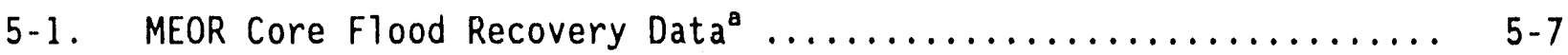

6-1. Criteria for reservoir selection for MEOR processes ${ }^{\circledR} \ldots \ldots \ldots .66$ 6-1

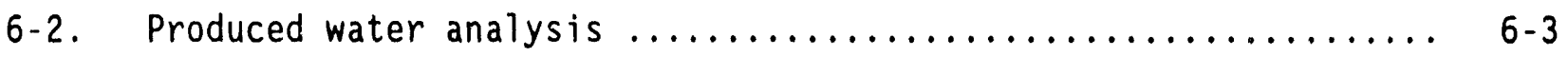

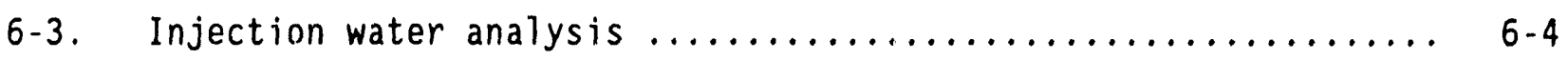

6-4. Average reservoir characteristics of Minnelusa reservoirs ${ }^{a} \ldots .66-8$

7-1. Presentation program for the First International Symposium on the Effect of Wettability on 0il Recovery held September 18-21, 1990 in Socorro, New Mexico ............. 7-6 


\section{FIGURES}

2-1a. GC spectra of standard hydrocarbon mixture $\ldots \ldots \ldots \ldots \ldots \ldots, 2-11$

2-1b. GC spectra of standard hydrocarbon mixture $\ldots \ldots \ldots \ldots \ldots \ldots . \ldots . \ldots . \ldots .11$

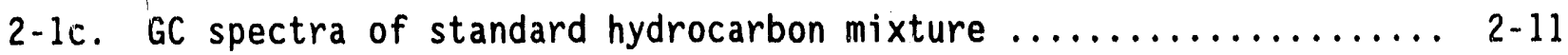

2-2a. GC spectra of Soltrol 220 aliphatic eluent $\ldots \ldots \ldots \ldots \ldots \ldots \ldots$ 2-12

2-2b. GC spectra of Soltrol 220 total oil (deasphalnated sample) ..... 2-12

2-3a. GC spectra of Burbank crude aliphatic eluent $\ldots \ldots \ldots \ldots \ldots \ldots$ 2-13

2-3b. GC spectra of Burbank crude aromatic eluent $\ldots \ldots \ldots \ldots \ldots \ldots . \ldots 2-13$

2-3c. GC spectra of Burbank crude total oil (deasphalnated sample) ... 2-13

2-4a. GC spectra of Schuricht crude aliphatic eluent $\ldots \ldots \ldots \ldots \ldots, 2-14$

2-4b. GC spectra of Schuricht crude aromatic eluent $\ldots \ldots \ldots \ldots \ldots \ldots . \ldots 2-14$

2-4c. GC spectra of Schuricht total oil (deasphalnated sample) ....... 2-14

2-5a. GC spectra of Moorcroft West crude aliphatic eluent $\ldots \ldots \ldots \ldots .2-15$

2-5b. GC spectra of Moorcroft West crude aromatic eluent $\ldots \ldots \ldots \ldots .2-15$

2-5c. GC spectra of Moorcroft West crude total oil (deasphalnated

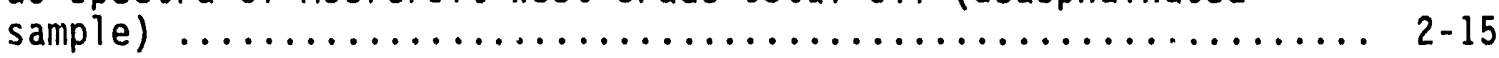

2-6a. GC spectra of Alworth crude aliphatic eluent $\ldots \ldots \ldots \ldots \ldots \ldots .2$ 2-16

2-6b. GC spectra of Alworth crude aromatic eluent $\ldots \ldots \ldots \ldots \ldots \ldots .2-16$

2-6c. GC spectra of Alworth crude total oil (deasphalnated sample) .... 2-16

2-7a. GC spectra of Lick Creek crude aliphatic eluent ............. 2-17

2-7b. GC spectra of Lick Creek crude aromatic eluent $\ldots \ldots \ldots \ldots \ldots .2-17$

2-7c. GC spectra of Lick Creek crude total oil (deasphalnated

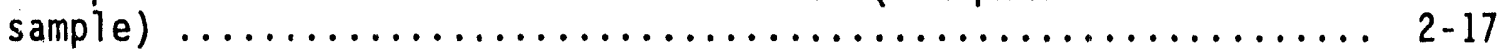

2-8. GC/MS spectra (total ion current) $\ldots \ldots \ldots \ldots \ldots \ldots \ldots \ldots \ldots \ldots \ldots \ldots \ldots \ldots .18$

2-9. Temperature dependence of viscosity of Soltrol $220 \ldots \ldots \ldots \ldots .2-19$

2-10. Temperature dependence of viscosity of Burbank Crud $\ldots \ldots \ldots \ldots$ 2-20

2-11. Temperature dependence of viscosity of Schuricht Crude $\ldots \ldots \ldots$ 2-21 
2-12. Temperature dependence of viscosity of Moorcroft West Crude .... 2-22

2-13. Temperature dependence of viscosity of Alworth Crude ....... 2-23

2-14. Temperature dependence of viscosity of Lick Creek Crude ....... 2-24

2-15. Temperature dependence of viscosity of Media $E \ldots \ldots \ldots \ldots .25$

2-16. Comparison of true and calculated $0 i 1$ volumes $\ldots \ldots \ldots \ldots \ldots . \ldots 26$

2-17. Comparison of true and measured water volumes $\ldots \ldots \ldots \ldots \ldots . \ldots 27$

3-1a. Comparison of pre- and post-flood (microbial) chromatography fractions, Schuricht crude ............... 3-15

3-1b. Comparison of pre- and post-flood (microbial) chromatography fractions, Moorcroft West crude ............ 3-16

3-1c. Comparison pre- and post-flood (microbial) chromatography fractions, Alworth crude ............................... 3-.

3-1d. Comparison pre- and post-flood (microbial) chromatography fractions, Lick Creek crude ........................ 3-18

3-2. Growth response of Bacillus licheniformis JF-2 as a function of temperature ................................... $3-19$

3-3. Growth response of Bacillus licheniformis JF-2 as a function

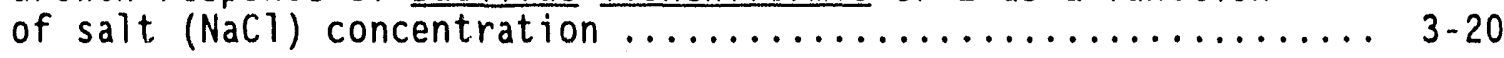

3-4. Growth response of Bacillus licheniformis JF-2 as a function

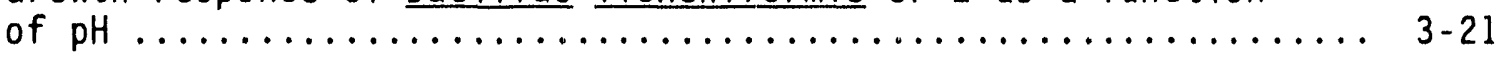

3-5. Scanning electron micrograph of virgin coarse $(300$ to $500 \mathrm{md}$ permeability) Berea sandstone ........................... 3-22

3-6. Scanning electron micrograph of virgin coarse (100 to $300 \mathrm{md}$ permeability) Berea sandstone ............................. 3-23

3-7. Scanning electron micrograph of oil coated (Schuricht) fine

(100 to 300 md permeability) Berea sandstone

3-8. Scanning electron micrograph (inlet region) of a Berea

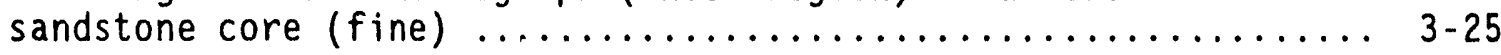

3-9. Scanning electron micrograph (mid region) of a Berea

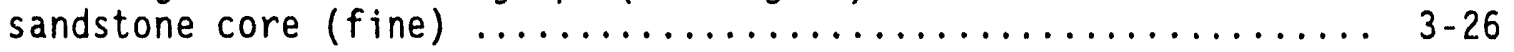

3-10. Scanning electron micrograph (outlet region) of a Berea sandstone core (fine) 
4-1. Critical dimensions used in calculating interfacial tensions ... 4-9

4-2. Drop forming cell for interfacial tensiometer ............. 4-10

4-3. Video camera, lenses, magnification system setup for interfacial

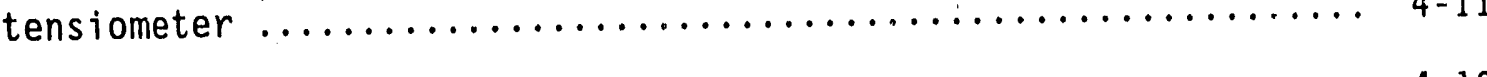

4-4. Calibration of interfacial tensiometer ................. 4-12

4-5. Video image of drop for interfacial tension measurement ....... 4-13

4-6. Determination of critical micelle concentration for cell
free supernatants of Bacillus licheniformis JF $-2 \ldots \ldots \ldots \ldots \ldots$

5-1. Core Flood Apparatus ......................... 5-11

5-2. Microbial flood oil recovery - Burbanli oil - core \#22 ........ 5-11

5-3. Microbial flocd oil recovery - Schuricht oil - core \#25 ..... 5-12

5-4. Microbial flood oil recovery - Schuricht oil - core \#10 ..... 5-12

5-5. Microbial flood oil recovery - Alworth oil - core \#23 ........ 5-13

5-6. Microbial flood oil recovery - Alworth $0 i 1$ - core \#12 ........ 5-13

5-7. Microbial flood oil recovery - Moorcroft West 0il - core \#13 ... 5-14

5-8. Microbial flood oil recovery 0 Moorcroft West oil - core \#24 .... 5-14

5-9. Microbial flood oil recovery - Lick Creek oil - core \#11 ...... 5-15

5-10. Microbial flood oil recovery - Lick Creek oil - core \#26 ...... 5-15

5-11. Core flood total oil recovery for all oils ............... 5-16

5-12. Recovery efficiency - Burbank oil - core \#22 ............ 5-16

5-13. Recovery efficiency - Schuricht oil - core \#25 ............ 5-17

5-14. Recovery efficiency - Schuricht oil - core \#10 ........... 5-17

5-15. Recovery efficiency - Alworth oil - core $\# 23 \ldots \ldots \ldots \ldots \ldots \ldots$ 5-18

5-16. Recovery efficiency - Ailworth $0 i 1$ - core $\# 12 \ldots \ldots \ldots \ldots \ldots \ldots \ldots$ 5-18

5-17. Recovery efficiency - Moorcroft West $0 i 1$ - core \#13 ......... 5-19

5-18. Recovery efficiency - Moorcroft West oil - core \#24 ......... 5-19

5-19. Recovery efficiency - Lick Creek oil - core \#11 ........... 5-20 
5-20. Recovery efficiency - Lick Creek oil - core $\$ 26 \ldots \ldots \ldots \ldots \ldots$ 5-20

6-1. Produced brine viscosity - Moorcroft West Unit ............ 6-13

6-2. Produced brine viscosity - South Rozet Unit ............. 6-14

6-3. Crude oil viscosity - South Rozet Unit, $22.1^{\circ}$ API @ $60^{\circ} \mathrm{F} \ldots \ldots 6-15$

6-4. Structure contour map - Powder River Basin, from Strickland,

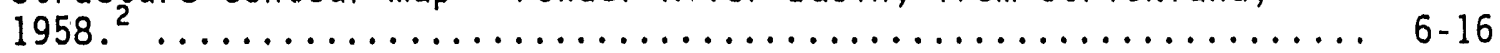

6-5. Generalized stratigraphic column - NE Powder River Basin ...... 6-17

6-6. Minnelusa type logs, from $\operatorname{Van}$ West, $1972 .{ }^{4} \ldots \ldots \ldots \ldots \ldots \ldots \ldots$

6-7. SE-NE cross section - east flank Powder River Basin ........ 6-19 


\section{INTRODUCTION}

\subsection{Program Purpose}

The global objective of this multi-year project is to develcp microbial enhanced oil recovery (MEOR) systems for application to reservoirs containing medium to heavy crude oils, and the design and implementation of an industry cost-shared field demonstration project of the MEOR technology. An understanding of the controlling mechanisms must first be developed through the use of laboratory scale testing to determine the ability of microbial processes to recover oil under reservoir conditions. A multi-disciplinary geological, biological, chemical, and engineering characterization of the target reservoir will be conducted to ensure a successful design and application of the process. The technical and economic potential of enhanced oil recovery in the target reservoir type will be determined to provide an evaluation of the ultimate technology potential. The feasibility of combining microbial systems with other EOR methods such as gas and chemical flooding will be addressed. The effects of following other EOR processes such as polymer flooding with an MEOR application also needs to be determined. The applicability and oil recovery potential of MEOR processes in actual reservoir environments will be evaluated by single well injectivity testing and backflow production before initiation of an MEOR flood.

This report is organized into seven sections; Introduction, 0il Selection and Analysis, Microbial Analysis and Phenomena, Measurement of Interfacial Tensions, Laboratory Core Floods with Microbial Systems, Target Reservoir Selection, and Reservoir Wettability and its Effect on 0 il Recovery. It is a progress report of on-going research and is not intended as a final report. Whenever possible, definitive conclusions have been drawn based on the experimental data. However, due to the dynamic nature of this research, final conclusions are not possible at this time. 


\subsection{BACKGROUND}

Revie'ss of MEOR from an historical perspective have appeared in the literature and will not be discussed here.' MEOR is a process that allows for the introduction of miscible and chemical fluids in the form of metabolic endprcducts by way of either injection of microorganisms into the reservoir or stimulation of naturally occurring populations. These microorganisms represent a replenishaile in situ source of acid, gas, biopolymer, solvent, or surfactant or combinations of these microbially mediated products that $c$ an be supported anci manipulated by the addition of simple and inexpensive nutrients. The potential appl sation of MEOR techno?ogies inay be realized in microbial product ability to overcome common recovery problems. MEOR (while representing a valuable tool for increased $0 i 1$ recovery and available world energy) is the least understood EOR meinod, and thus offers $z$ broad forum of investigation.

It is extremely important that the mechanisms of oil recovery for the many possible variations of MEOR processes be understood and the recovery Dotentials quantified. Only afier an adequate uriderstanding is developed can MEOR processes be engineered to address specific recovery problems for a broad range of reservoir types and crude oil characteristics. More field tests that are designed, implemented, and conducted in a manner that allows a clear determination of the mechanisms and effectiveness of the process are needed. Most of the fielc tests to date have failed to establish baseline data or have not been conducted under reservoir or operational situations that allow unequivocal determination of the effectiveness of the MEOR process. Poor or incomplete characterization of the reservoir before implementation has been a frequent cause of failure of the test. Thus, a mu?ti-disciplinary approach involving geology, petroleum enginearing, microbiology, and chemistry is essential for an effective, environmentally-safe, research, and demonstration project.

Field research has and is being conducted to prove the ffectiveness of microbes to enhance the recovery of $0 i 1 .^{2,3}$ Microbes responsible for $0 i 1$ 
recovery are reasonably well characterized but their activities, kinetics of bio-product production, and nutrient requirements in reservoirs are not well understood. The mechanisms of increased production are unknown and could be caused by several metabolic functions attributed to the introduced or indigenous bacteria. Results from field tests are encouraging, but it is important to understand and control microbial phenomena so that it can be optimized for specific reservoir problems. Microbial processes may fail vecause of a lack of understanding of environmental conditions under which the process is occurring or because oi a lack of understanding of the microbes being used. This is especially true for microbial pricesses conducted in heterogentous, remote environments such as oil reservoirs, which are implicitly difficult to understand and control.

\subsection{INEL RESEARCH}

The use of microbes for EOR is a difficult process to understand and predict. Therefore, basic experiments are being conducted in simulated reservoir environments with known collections of microbes that show promise for enhancing oil recovery. These microbes have been obtained from enrichment of environmental samples, culture collections, and other investigators. Specific activities of the microbes (the ability to alter wettability, change interfacial properties, and produce acids, gases, solvents, surfactants, and polymers) are monitored based on conditions in the test medium and produced fluids.

Development of an understanding of the mechanisms by which specific microbial systems displace oil under reservoir conditions through such avenues as core flooding, measurement of IFT and viscosities, and other laboratory techniques will be a significant contribution to EOR technology and specifically MEOR technology. The mechanisms of MEOR are not specifically known or well understood for a wide variety of reservoir conditions, crude oils, and microbial/nutrient systems. 
The first objective of the current research is to determine the important biologically induced factors that increase oil recovery by analys is and experimentation with the microbes, $0 i 1$, and production waters. Research will proceed from determination of displacement mechanisms to development of process design variables for target field conditions. The determination of oil field project design variables will allow comparisons of MEOR process economics with those of chemical EOR systems. The objective is to place MEOR in the mainstream of EOR technology by removing the uncertainty that currently discourages acceptance of MEOR as a viable EOR process by the mainstream of the petroleum industry. It is imperative to bring MEOR to the same scientific and engineering level as other EOR processes that have benefitted from detailed research, which has been openly reported and discussed in the petroleum literature. An integrated research program is necessary for the development of MEOR as a viable EOR process for use by the $0 i 1$ industry.

Field process designs for testing of microbial systems in target reservoirs are being developed and evaluated. Crude oil samples and reservoir cores need to be obtained from target reservoirs for testing of microbial processes under the most realistic conditions possible in the laboratory.

Research at the INEL is focusing on the underlying fundamental mechanisms of MEOR and is not limited to understanding the microbial mechanisms that facilitate the displacement of oil. Instead, a more comprehensive understanding of the microbial mechanisms and the chem:ral and physical attributes of the rock/fluid interactions controlling microbial processes and mechanisms in reservoirs are being studied. The intention of this research is to gain a better understanding of how and why MEOR works. Efforts have been made to perform realistic and definitive laboratory testing, to collect and preserve oil samples that will best represent reservoir composition, and to carefully conduct all experimental protocols to answer the appropriate questions. The amount of $0 i 1$ that may be recovered under optimum laboratory conditions is of les's value at this stage of development of MEOR processes than the developnient of a fundamental understanding of MEOR gained through realistic laboratory simulation. A better fundamental understanding is 
necessary before MEOR processes can be tailored for specific recovery probl ms in specific reservoirs.

The wettability research program is a collaborative effort between EG\&G Idaho, Inc. and the New Mexico Petroleum Recovery Research Center at the New Mexico Institute of Mining and Technology. The research program is directed by $D r$. N. R. Morrow and co-funded by industry and the State of New Mexico. The results of the research program have been presented at several industry symposia and through contributions to the permanent literature and are not repeated in this report.

\subsection{Publications and Presentations}

The following publications and presentations have resulted from the MEOR and Wettability research program.

1. G. A. Bala and M. L. Duval1, "Microbial Enhanced 0il Recovery: Current Status and Future Direction, "A Group of Independent $0 i 1$ Operators and Industry Consultants, Denver, Colorado, July 24, 1990.

2. K. B. Barrett and F. S. Colwel1, "Microbial Attachment at the 0i1-water Interface Versus Soluble Microbial Products to Increase Emulsification," American Society of Microbiology (ASM) Annual Meeting, Anaheim, California, May 13-18, 1990.

3. J. S. Buckley, "Control of Core Wettability with Crude 0i1, " First International Symposium on Evaluation of Reservoir Wettability and Its Effect on 0il Recovery, Socorro, New Mexico, September 18-21, 1990.

4. J. S. Buckley, "Multiphase Displacements in Micromodels, "Interfacial Phenomena in 0 il Recovery, Ed. N. R. Morrow, Marcel Dekker, 1990, pp. 157-189. 
5. J. S. Buckley, "Prediction of Crude $011 /$ Rock Wettability, "Society of Core Analysts Fourth Annual Technical Conference, Dallas, Texas, August 14-16, 1990.

6. J. S. Buckley, "Wettability Effects of Crude 0ils," American Geophysical Union Spring Meeting, Baltimore, Maryland, May 29-June 1, 1990.

7. J. S. Buckley, "Wetting Behavior of Crude 0il/Brine/Solid Surfaces from Adhesion Tests and Electrophoretic Mobilities, "First International Symposium on Evaluation of Reservoir Wettability and Its Effect on 011 Recovery, Socorro, New Mexico, September 18-21, 1990.

8. J. S. Buckley and N. R. Morrow, "Characterization of Crude $0 i 1$ Wetting Behavior by Adhesion Tests," Society of Petroleum Engineers/Department of Energy Seventh Symposium on Enhanced $0 i 1$ Recovery. Tulsa, Oklahoma, April 21-25, 1990, SPE/DOE 20263, to be published, Society of Petroleum Engineers Formation Evaluation.

9. J. S. Buckley and N. R. Morrow, "Crude $0 i 1$ Wetting, "poster, International Symposium on Contact Angles and Wetting Phenomena, Society of Chemical Industry, Toronto, Canada, June 21-23, 1990.

10. M. E. Cather, "Diagenesis, Pore Structure, and Surface Properties of Res srvoir Rocks," First International Symposium on Evaluation of Reservoir Wettability and Its Effect on $0 i 1$ Recovery, Socorro, New Mexico, September 18-21, 1990.

11. M. E. Cather, N. R. Morrow, and I. Klich, "Characterization of Porosity and Pore Quality in Sedimentary Rocks, " Second IUPAC Symposium on Characterization of Porous Solids, Alicante, May, 1990.

12. V. A. Deason, R. L. Miller, A. D. Watkins, M. B. Ward, and K. B. Barrett, "Measurements of Interfacial Tension by Automated Video Techniques," Society of Photo-optical Instrumentation Engineers Conference, San Diego, Cal ifornia, July 8-13, 1990. 
13. J. Duo, "Effect of Drilling Mud Filtrates on Mixed Wettability Rock," First International Symposium on Evaluation of Reservoir Wettability and Its Effect on 011 Recovery, Socorro, New Mexico, September 18-21, 1990.

14. M. L. Duva11, G. A. Ba1a, K. B. Barrett and M. D. Herd, "MEOR: Current Research at the INEL," Society of Petroleum Engineers Forum Series, Crested Butte, Colorado, Auqust 5-10, 1990.

15. M. L. Duvall and C. P. Thomas, "Microbial Enhanced 0il Recovery: EOR Process of the Future?," Society of Petroleum Engineers Forum Series, Crested Butte, Colorado, August 5-10, 1990.

16. P. Jadhunandan, "Effect of Brine Composition, Crude 0i1, and Aging Conditions on Wettability and 011 Recovery, "First International Symposium on Evaluation of Reservoir Wettability and Its Effect on 0 il Recovery, Socorro, New Mexico, September 18-21, 1990.

17. P. Jadhunandan and N. R. Morrow, "Crude 011 Recovery in Laboratory Water Floods, "Fifth IFP Research Conference on Exploration and Production. Fundamentals of Fluid Transport in Porous Media, Arles, May 14-18, 1990.

18. D. Jia, J. S. Buckley, and N. R. Morrow, "Control of Core Wettability with Crude 0i1," Society of Petroleum Engineers International Symposium on 0ilfield Chemistry, Anaheim, California, February 20-22, 1991, SPE 21041.

19. S. Ma and N. R. Morrow, "Effect of Firing on Fluid Flow Properties in Berea Sandstone," Society of Petroleum Engineers International Symposium on Oilfield Chemistry, Anaheim, California, February 20-22, 1991, SPE 21045.

20. G. Mason and N. R. Morrow, "Capillary Behavior of a Wetting Liquid in Irregular Triangular Tubes," to be published, Journal of Colloid and Interface Science. 
21. N. R. Morrow, "Capillary Properties of Single Pores, " First International Symposium on Evaluation of Reservoir Wettability and Its Effect on 0il Recovery, Socorro, New Mexico, September 18-21, 1990.

22. N. R. Morrow, "Introduction to Interfacial Phenomena in 011 Recovery," Interfacial Phenomena in 0 il Recovery, Ed. N. R. Morrow, Marcel Dekker, 1990, pp. 1-21.

23. N. R. Morrow, "Measurement of Wettability and Its Effect on $0 i 1$ Recovery, "First International Symposium on Evaluation of Reservoir Wettability and Its Effect on Oil Recovery, Socorro, New Mexico, September $18-21,1990$.

24. N. R. Morrow, "Surfaces and Interfaces," keynote address, Fifth IFP Research Conference on Exploration and Production. Fundamentals of Fluid Transport in Porous Media, Arles, May 14-18, 1990.

25. N. R. Morrow, "Wettability and Its Effect on 0il Recovery," Society of Petroleum Engineers Distinguished Author Series, Journal of Petroleum Technology, 42, 12, 1990, pp. 1476-1484.

26. N. R. Morrow and J. C. Melrose, "Application of Capillary Pressure Data to the Determination of Connate Water Saturation, "Interfacial Phenomena in 0il Recovery, Ed. N. R. Morrow, Marcel Dekkar, 1990, pp. 257-287.

27. N. R. Morrow and J. C. Melrose, "Application of Capillary Pressure Data to the Determination of Connate Water Saturation, " keynote address, European Core Analysis Symposium, London, May, 1990.

28. A. Ouenes, "Numerical Simulation of Core Floods," First International Symposium on Evaluation of Reservoir Wettability and Its Effect on 0 il Recovery, Socorro, New Mexico, September 18-21, 1990.

29. C. P. Thomas, "MEOR: An Overview, " Society of Petroleum Engineers Forum Series, Crested Butte, Colorado, August 5-10, 1990. 
30. C. P. Thomas, G. A. Bala, K. B. Barrett and M. L. Duva11, "MEOR Research on Heavy 0ils, "Microbial Enhanced 0il Recovery International Conference, Norman, Oklahoma, May 27-June 1, 1990.

31. C. P. Thomas, W. A. Ape1, G. A. Bala, K. B. Barrett, F. S. Colwe11, P. ?. Dugan, M. L. Duva11, M. E. McIlwain and R. L. Miller, "MEOR Research Program: Idaho National Engineering Laboratory, "First Technical Meeting of the United States Department of Energr/Venezuela Ministry of Energy and Mines Energy Research and Development Agreement, Annex XIII, Cooperation in the Area of Microbial Enhanced 011 Recovery, Norman, Oklahoma, May 27, 1990 .

32. A. D. We11s, "Microbial Enhanced 011 Recovery: A Novel Approach," Associated Western Universities Summer Research Fellows Conference, Idaho Falls, Idaho, August 1, 1990.

\subsection{References}

1. D. M. Updegraff, "Early Research on Microbial Enhanced 0il Recovery," Developments in Industrial Microbiology, 31, 1990, pp. 135-148.

2. R. S. Bryant, T. E. Burchfield, D. M. Dennis, and D. O. Hitzman, "Microbial-Enhanced Waterflooding: Mink Unit Project," Society of Petroleum Engineers/Department of Energy Enhanced 0il Recovery Symposium, Tulsa, OKTahoma, 1988, SPE/DOE 17341.

3. R. M. Knapp, M. J. McInerney, D. E. Menzie, and R. A. Raiders, "MEOR Field Pilot Study, " Contracts for Field Projects and Supporting Research on Enhünced 0il Recovery, Progress Review No. 53, 1987, DOE/BC-88/1 (DE88001233). 


\section{OIL SELECTION AND ANALYSIS}

Data obtained from the analysis of crude oil provides valuable information on the physical and chemical characteristics of the $0 i 1$. These characteristics may influence microbial recovery and the mechanisms by which microbial recoveries are facilitated. Monitoring these characteristics is an integral part of the INEL MEOR research program. Although microbial enhanced oil recovery under economically favorable conditions may be advantageous, the advantage could be quickly lost if the value of the oil or the reservoir are not maintained. This could occur through microbial degradation of the oil, microbial souring of the oil, or microbially mediated plugging of the reservoir.

0ils were selected for use in the MEOR program primarily on gravimetric characteristics. Mecium to heavy oils ( 17.5 to $\left.38.1^{\circ} \mathrm{API}\right)$ were selected. A refined mineral oil, Soltro ${ }^{\mathrm{a}} 220\left(50.5^{\circ} \mathrm{API}\right)$ was also chosen for control purposes. Suitable oils were found that originated in a variety of geographical lorations. 0ils selected are presented in Table 2-1.

\subsection{Methodologies}

The methodologies used to analyze and characterize the oils include fractionation of the oils, gas chromatography (GC), gas chromatography/mass spectroscopy (GC/MS), elemental analysis, and viscosity determination (temperature variant). Gravimetric analysis of phase separated effluents was the method used to determine the volume of oil produced from core floods.

a. Soltrol - Registered Trademark, Phillips 66 Company, Bartlesville, OK 74004 . 
Table 2-1. 0ils selected for MEOR research

\begin{tabular}{|c|c|c|c|c|c|}
\hline $0 i 1$ & Source Sand & County & State & $\begin{array}{c}\text { Gravity } \\
\text { API }^{\circ}\end{array}$ & $\begin{array}{l}\text { Viscosity } \\
\text { at } 23^{\circ} \mathrm{C} \\
(\mathrm{Pa} \cdot \mathrm{s})^{\mathrm{a}} \\
\end{array}$ \\
\hline Soltrol 220 & Commercialb & - & - & 50.5 & 0.003 \\
\hline Burbank & Burbank & Osage & OK & 38.1 & 0.006 \\
\hline Schuricht & Minnelusa & Crook & WY & 25.4 & 0.054 \\
\hline Moorcroft & Minnelusa & Crook & WY & 22.3 & 0.142 \\
\hline Alworth & Cole & Jim Hogg & $T X$ & 19.1 & 0.134 \\
\hline Lick Creek & Meakin & Union & $A R$ & 17.5 & 0.288 \\
\hline
\end{tabular}

a. $\mathrm{Pa} \cdot \mathrm{s}=$ centipoise $\times\left(1.0 \times 10^{-3}\right)$

b. Phillips 66 Company, Specialty Chemicals, Bartlesville, OK

\subsubsection{Fractionation (Liquid Chromatography) of Crude 0ils}

Paraffinic, aromatic, and asphaltic components of the selected crude oils were fractionated utilizing modified procedures of R.M. Atlas, ${ }^{1}$ and D.W. Later. ${ }^{2}$ $500 \mathrm{mg}$ of crude was weighed directly into a $50 \mathrm{~mL}$ glass tube and washed with $40 \mathrm{~mL}$ of $n$-pentane. This was allowed to stand at room temperature for 30 min following complete mixing. The sample was centrifuged at 1800 rpm (International TableTop centrifuge) to facilitate precipitation of the pentane insoluble asphaltics. The supernatant was removed from the tube and the precipitate was taken up in $1 \mathrm{~mL}$ toluene and the tube was washed $5 \times 1 \mathrm{~mL}$ with the same. The toluene elueits were combined into a pre-tared $10 \mathrm{~mL}$ crimp top vial (teflon lined septa) and the solvent was removed under nitrogen at room temperature and the vial was weighed and capped. The supernatant fraction was placed in a glass Kontes reflux tube and evaporated to critical volume (ascertained by a constant weight) at room temperature and taken up in $3 \mathrm{~mL}$ of 
chloroform. The $3 \mathrm{~mL}$ of chloroform/oil was mixed with $3 \mathrm{~g}$ of Brockman neutral alumina and the chloroform was allowed to evaporate. The oil loaded alumina was then placed in an $11 \mathrm{~mm}$ ID column stopped with a modular flow valve topped with a piece of glass wol filter paper held in place with $10 \mu$ m-mesh teflon cloth. The column contained $6 \mathrm{~g}$ of dry packed neutral alumina. The paraffinic, aromatic, and non-pentane precipitable (ppt) asphaltic resins were eluted sequentially with $20 \mathrm{~mL}$ hexane, $50 \mathrm{~mL}$ benzene, and $70 \mathrm{~mL}$ chloroform/methanol at $2: 1$ ratio. Individual component fractions were collected into $250 \mathrm{~mL}$ Erlenmeyer flasks and solvents were allowed to evaporate at room temperature. All components were taken up in $4 \times 1 \mathrm{~mL}$ of elution solvent and placed in individual pre-tared vials, taken to critical volume, weighed, and sealed under nitrogen for further analysis.

\subsubsection{Gas Chromatography of Crude $0 \mathrm{ils}$}

Samples (deasphalnated "total oil" or liquid chromatography eluents) were brought to $60 \mathrm{mg} / \mathrm{mL}$ in hexane and injected in either 1,2 , or $5 \mu \mathrm{L}$ aliquots for peak visualization of hydrocarbons $C_{6}$ to $C_{34}$.

A $30 \mathrm{~m} \times 0.244 \mathrm{~mm}$ J\&W scientific DB-5 column with a film thickness of $0.25 \mu \mathrm{m}$ was used on a Hewlett Packard 5890A GC equipped with a 7673A autosampler and a 3396A integrator. Conditions were as follows: Column head pressure was 16 psi yielding a gas velocity of $1.1 \mathrm{~mL} / \mathrm{min}$. Make-up gas was added at detection such that total flow was $30 \mathrm{~mL} / \mathrm{min}$. A purge of $1.5 \mathrm{~mL} / \mathrm{min}$ was maintained at the inlet except during injection at which time there was no purge. Split vent flow was at $20 \mathrm{~mL} / \mathrm{min}$. An initial oven temperature of $80^{\circ} \mathrm{C}$ was held for 4 min after injection and then increased to $300^{\circ} \mathrm{C}$ at a rate of $8{ }^{\circ} \mathrm{C} / \mathrm{min}$ and held at $300^{\circ} \mathrm{C}$ for $16 \mathrm{~min}$. Detection was with flame ionization at $325^{\circ} \mathrm{C}$. A reasonable baseline was obtained at an attenuation of 3 .

A known hydrocarbon mixture used for methods development (constituents from PolyScience Corporation) was mixed to contain $n$-Dodecane, $n$-Tridecane, $n$ Tetradecane, $n$-Hexadecane, $n$-Octadecane, $n$-Nonadecane, $n$-Heneicosane, and $n$ Docosane. 


\subsubsection{Gas Chromatography/Mass Spectroscopy of Schuricht Crude}

Pyrolysis GC/MS analysis of Schuricht crude was performed at the University of Utah Center for Micro-Analys is and Reaction Chemistry. Samples were prepared by liquid chromatography fractionation of the $0 i 1$ into aliphatic, aromatic, pentane precipitable asphaltics, and non-pentane precipitable asphaltics.

\subsubsection{Elemental Analysis of Crude 0ils}

Elemental analysis was performed with a Carlo Erba CHNOS EA1108 elemental analyzer equipped with an AS200 autosampler. Separation was with a PoraPak QS (80 to 100) mesh $2 \mathrm{~m} \times 4 \mathrm{~mm}$ column operated at $65^{\circ} \mathrm{C}$ with a flow rate of 100 $\mathrm{mL} / \mathrm{min}$. Combustion of the sample was at $1000^{\circ} \mathrm{C}$ in a combustion chamber packed with $50 \mathrm{~g}$ reduced copper proximal and $40 \mathrm{~g}$ tungstic anhydride distal, separated, and capped on both ends with $10 \mathrm{~mm}$ of quartz wool. Detection was with a thermal conductivity detector operated at a filament temperature of $190^{\circ} \mathrm{C}$.

Analysis was performed on samples of deasphalnated crude (pentane ppt asphaltics removed). Each sample (4 to $5 \mathrm{mg}$ ) was placed into a pre-tared tin cup filled with Brockman neutral alumina, weighed, and placed in the autosampler. An isotiourea standard was used for instrument calibration.

\subsubsection{Viscosity Determination of Crude $0 i 1 \mathrm{~s}$}

Viscosity measurements were performed on the selected crudes at temperatures from $22^{\circ} \mathrm{C}$ to reservoir temperature (dependant on the origin of the 0i1). All viscosity measurements were made using a Wells-Brookfield Cone and Plate Digital Viscometer, model LTVDV II with a CP-40 spindle.

The viscometer was zeroed according to the manufacturers protocol. ${ }^{3}$ This procedure was performed each time the spindle was removed from the viscometer and replaced or when the temperature at which viscosity measurements were to be taken was changed. Calibration was checked using Brookfield Viscosity standards under controlled temperature conditions. 
A sample volume of $0.5 \mathrm{~mL}$ was used to accommodate the CP-40 spindle. This was sufficient to wet the entire face of the spindle and about $1.0 \mathrm{~mm}$ up the outside edge of the spindle. The sample was placed in the cup taking care that it was bubble-free and spread evenly over the surface of the cup.

\subsubsection{Crude $0 i 1$ Quantification Following Coreflood Experimentation}

Crude oil volume in fluid effluents from water and microbial floods was analyzed gravimetrically following separation of the aqueous and organic phases. Tubes to be used in coreflood experimentation were pre-weighed using a Fisher XD400 analytical balance interfaced directly (RS232) to an IBM AT computer formatted for data acquisition and reduction (Lotus 123). Following aliquoted effluent collection ( 2 to $3 \mathrm{~mL}$ ), tubes containing no visual oil were reweighed and emptied. The volume of brine was calculated by density corrected gravimetric analysis. Tubes containing oil and brine were also weighed and then subjected to phase separation. Separation was facilitated by the addition of hexane $(3 \times 2 \mathrm{~mL})$. The aqueous brine phase was collected into pre-tared tubes and volume was calculated as above. $0 i 1$ volume was calculated by difference. The hexane/oil phase from all tubes of one experiment are collected in bulk, the solvent is removed and the $0 i 1$ is stored for later analysis. Data were reduced using Lotus 123.

\subsection{Results}

Results for analysis of oils with respect for fractionation, gas chromatography, coupled gas chromatography/mass spectroscopy, elemental analysis, viscosity, and quantification of oils following coreflood experimentation are presented.

\subsubsection{Fractionation (Liquid Chromatography) of Crude $0 i 1 s$}

Five crude oils and one rofined mineral oil (see Subsection 2.1), were analyzed for aliphatic, aromatic pentane $\left(C_{5}\right)$ soluble asphaltics, and $C_{5}$ insoluble asphaltics with fractionation techniques. Data are presented 
collectively in Table 2-2. It should be noted that it is unlikely that Soltrol 220 contains $C_{5}$ insoluble asphaltics and this is assumed to be experimental error for samples containing little or no $C_{5}$ insoluble asphaltics. This consideration effects Soltrol 220, Burbani crude, and Alworth crude.

Table 2-2. Liquid Chromatography Fractionation of Selected Crudes

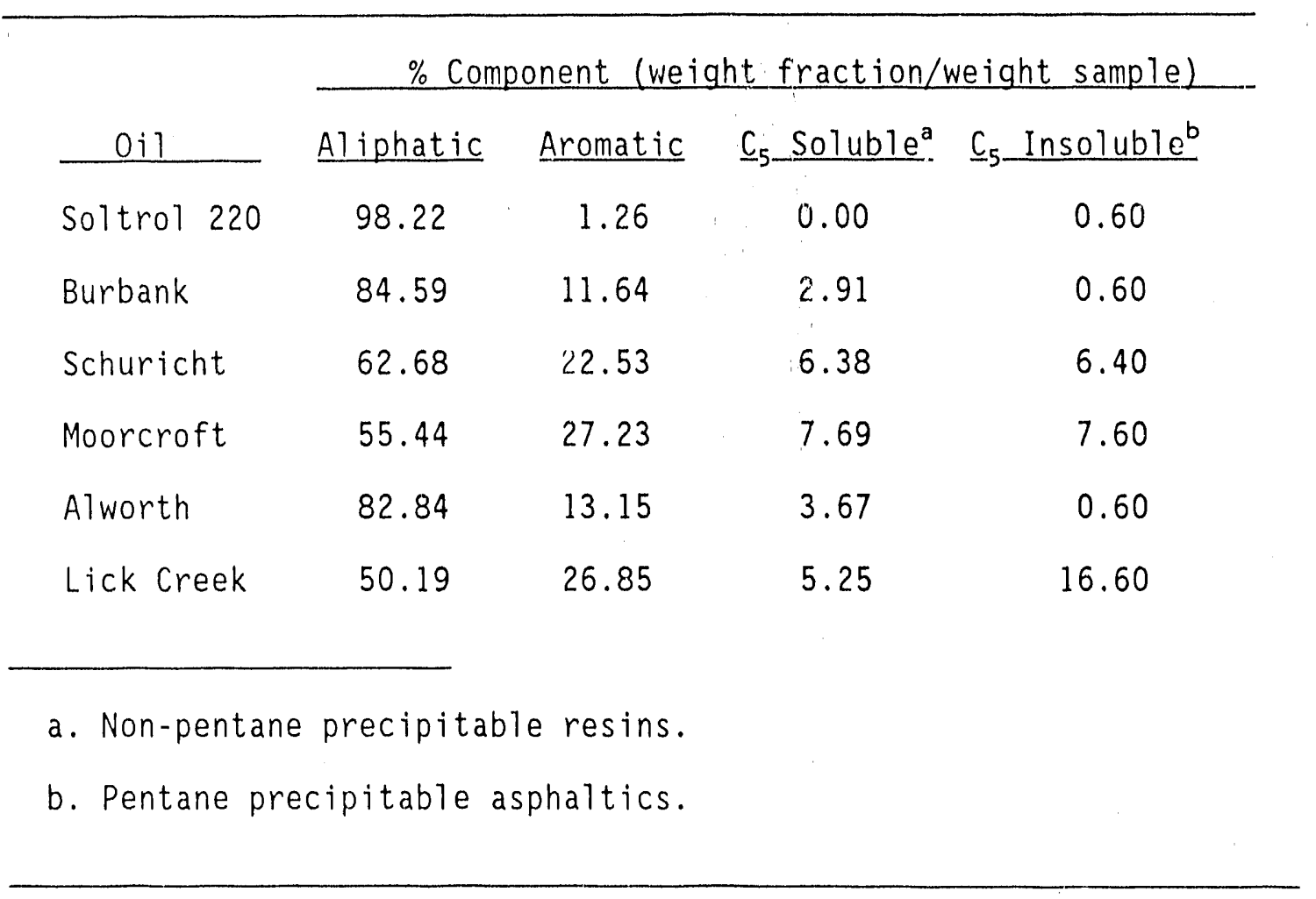

Recoveries of oil from this process vary from $60.54 \%$ (Soltrol) and $93.72 \%$ (Lick Creek). There is a positive correlation between $0 i 1$ gravity and recovery. This is caused by loss of the light-end hydrocarbons in the fractionation procedure. 


\subsubsection{Chromatography of crude $0 i 1 \mathrm{~s}$}

GC analysis was performed with known hydrocarbon standards, and the six $011 \mathrm{~s}$ shown in Table 2.1. Samples analyzed for each sample vere "total oil" (deasphalnated sample), aliphatic, and aromatic constituents. Chromatographs are presented in Figures 2-1 to 2-7.

As noted in the fractionation of $0 i 1 s$ and as evidenced by the aliphatic chromatographs (Figures 2-3a, 2-4a, 2-5a, 2-6a, and 2-7a) componerits from $C_{6}$ to $C_{15}$ are lost in the sample fractionation process. Loss is assumed to occur during solvent removal processes. It is clear in the GC analys is of the "total 0i1" (deasphainated) samples that the light ends are present (Figures $2-3 c, 2-4 c, 2-5 c, 2-6 c$, and 2-7c). Soltrol (60.54\% recovery), for example, shows 1 :ttle difference between the fractionated chromatogram (Figure 2-2a) and the "total oil" chromatogram (Figure 2-2b). This indicates an equivaient loss (expected because Soltrol is $98 \%$ aliphatic) of all components (manifested by the similarity of the chromatograms). Schuricht $(76.16 \%$ recovery, $62 \%$ aliphatic) however, shows a clear difference between the aliphatic (Figure 24a) and "total 0i1" (Figure 2-4c) chromatograms, in the light end region. Lick Creek, like Schuricht, shows differences in the chromatogram (Figure 2-7a and $2-7 \mathrm{c}$ ) but unlike schuricht had a $93 \%$ recovery. This is attributed to the relative heavy composition of the Lick Creek crude.

\subsubsection{Gas Chromatography/Mass Spectroscopy of Schuricht Crude}

A total ion chromatograph of Schuricht crude is presented as Figure 2-8. GC/MS analysis indicates an $0 i 1$ of phytoplankton origin as evidenced by a predominance of $\mathrm{C}_{17} \cdot{ }^{4}$ Even though the Moorcroft West lease is in close proximity to the Schuricht lease and both are produced from Minnelusa A Sands, similar conclusions should not be drawn about the origin of the Moorcroft West oil based on Schuricht results. 


\subsubsection{Elemental Analys is of Crude 0ils}

Elemental analysis was performed on deasphalnated samples. Data are presented collectively in Table 2-3. It is unknown if sulfur reported is in the form of sulfur heterocycles or present as elemental sulfur. The sample exhibiting the highest sulfur content (Moorcroft West) is, interestingly, the only sour oil of those selected. Schuricht, an oil from the same sands and in close geographical proximity to Moorcroft West, is not sour and has a lower sulfur content.

Table 2-3. Elemental Analys is of Selected Crude 0ils (Data presented as wt\%)

\begin{tabular}{llllll}
\hline & \multicolumn{5}{c}{ Element } \\
\cline { 4 - 6 } Oil & Carbon & Hydrogen & Nitrogen & Sulfur \\
Soltrol 220 & 83.68 & 15.01 & 0.10 & 0.00 \\
Burbank & 79.36 & 12.24 & 0.13 & 0.00 \\
Schuricht & 82.37 & 11.60 & 0.35 & 3.24 \\
Moorcroft & 81.99 & 11.28 & 0.38 & 4.21 \\
Aiworth & 88.36 & 12.23 & 0.12 & 0.00 \\
Lick Creek & 85.47 & 11.46 & 0.29 & 3.31 \\
\hline
\end{tabular}

\subsubsection{Viscosity Determination of Crude $0 i 1 \mathrm{~s}$}

Data from viscosity determination of Soltrol 220 and the five crudes are presented graphically in Figures 2-9 through 2-14. Viscosity determination of Media E (microbiological growth media) is presented in Figure 2-16. 
Viscosities measured at $23^{\circ} \mathrm{C}$ correlated well with API gravities. In general, as API gravity decreased, viscosity increased. However, Moorcroft West and Alworth were inverted when viscosity is compared to API gravity. Moorcroft West $\left(22.3^{\circ} \mathrm{API}\right)$ has a viscosity of $142 \mathrm{cp}$ and Alworth $\left(19.1^{\circ} \mathrm{API}\right.$ ) has a viscosity of $134 \mathrm{cp}$. The apparent inversion of data is easily understood when the compositions of the oils are taken into account. Alworth is a "heavier" 011 than Moorcroft West but is comprised of only $3.67 \%$ asphaltic residues while Moorcroft West is comprised of $15.29 \%$ asphaltic residues. The majority of the class constituents of Alworth are aliphatic $(82.8 \%$ versus $55.4 \%$ for Moorcroft West). Because viscosity is strongly influenced by the heavier constituents, this inversion is not unusual.

\subsubsection{Crude 0il Quantification Following Coreflood Experimentation}

Values obtained with this methodology compare very favorably to the direct core weight technique (previously used but not included in this report values correlate within $1 \%$ or less) but have the added advantage of obtaining not only beginning and end point data but dynamic interim data as well.

Comparison of true oil volumes and calculated oil volumes from methodology development experiments indicate close agreement between the measured and expected values. A Tinear curve between 13 and $250 \mu \mathrm{L}$ crude $0 i 1$ is achieved (see Figure 2-16). Brine volumes of 2 to $3 \mathrm{~mL}$ are typically collected during coreflood experimentation and volume measurement is also very good (see Figure 2-17).

\subsection{Discussion}

Collective oil analysis data provide useful information on the preflood (water or microbial) conditions and composition of the $0 i 1 \mathrm{~s}$. It is clear that the oils contain quantifiable differences. Data will be used for comparison purposes to monitor changes occurring during coreflood experimentation and to ascertain microbial alterations to the oils. Data will also be used to 
monitor changes in oil composition (if any) over time as samples are collected from the field. 


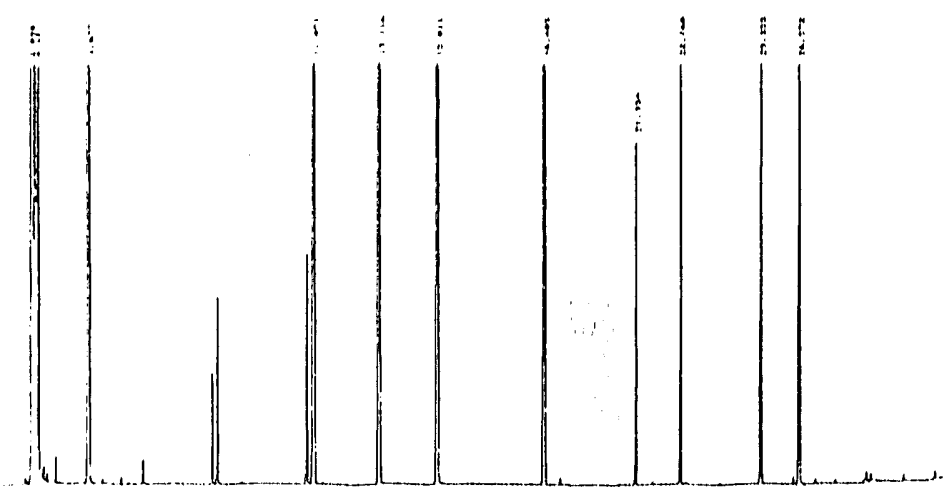

Figure 2-1a. GC spectra of standard hydrocarbon mixture. Injection volume $=$ $1 \mu \mathrm{L}$. Respective peaks from right: $C_{22}, C_{21}, C_{19}, C_{18}, C_{16}, C_{14}, C_{13}, C_{12}$, ethylbenzene (carrier solvent), and hexane (carrier solvent).

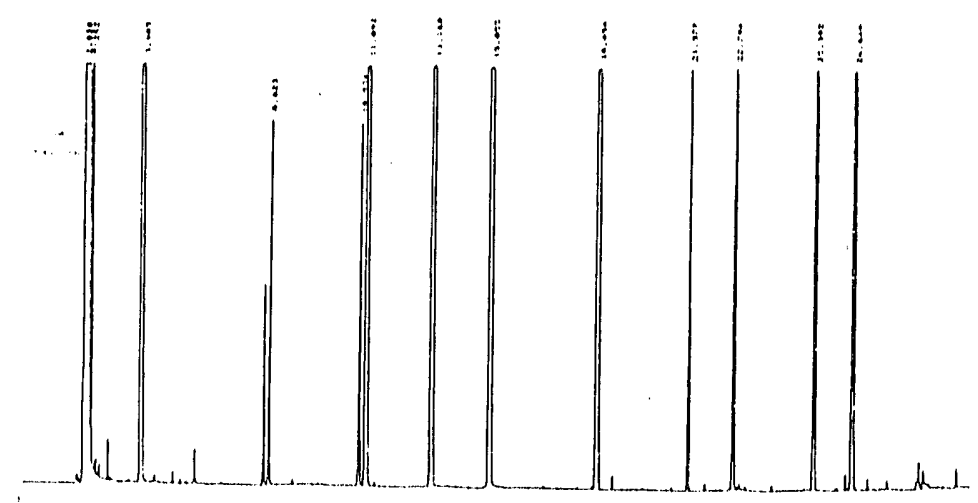

Figure 2-1b. GC spectra of standard hydrocarbon mixture. Injection volume $=$ $2 \mu \mathrm{L}$. Respective peaks from right: $C_{22}, C_{21}, C_{19}, C_{18}, C_{16}, C_{14}, C_{13}, C_{12}$, ethyibenzene (carrier solvent), and hexane (carrier solvent).

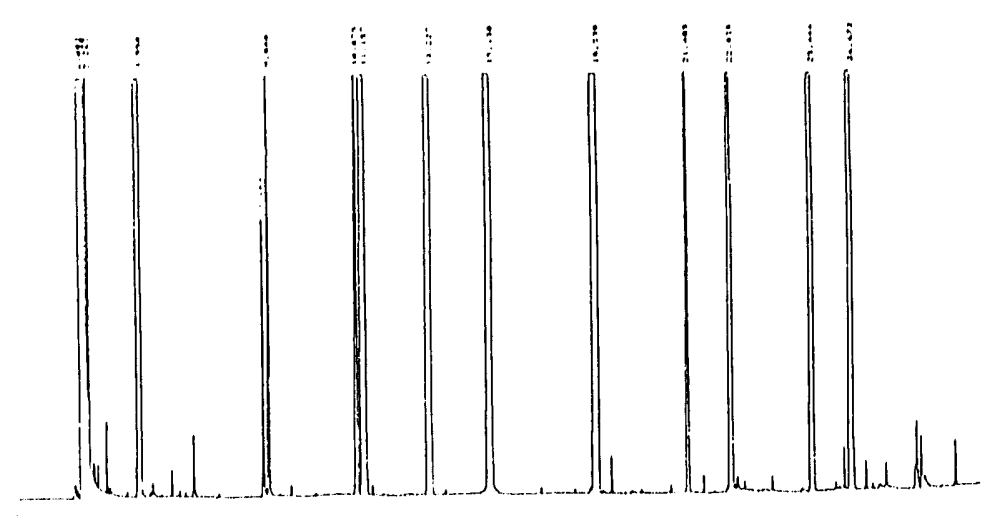

Figure 2-1c. GC spectra of standard hydrocarbon mixture. Injection volume = $5 \mu \mathrm{L}$. Respective peaks from right: $C_{22}, C_{21}, C_{19}, C_{18}, C_{16}, C_{14}, C_{13}, C_{12}$, ethyibenzene (carrier solvent), and hexane (carrier solvent). 


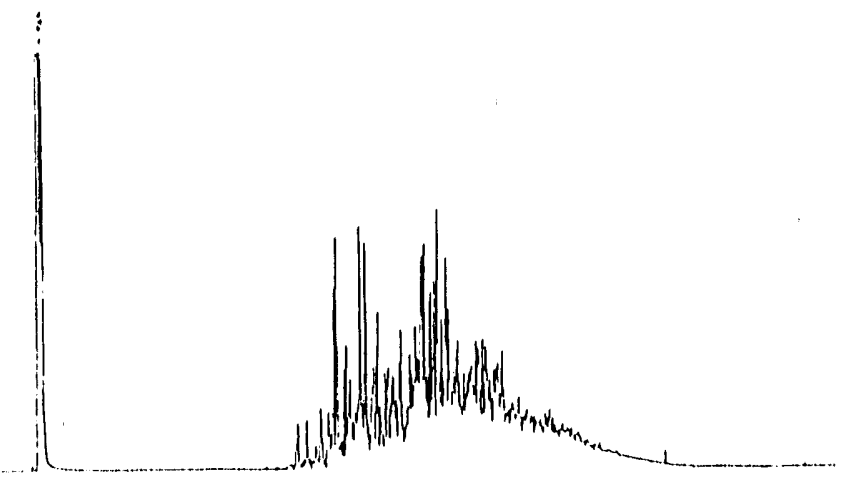

Figure 2-2a. GC spectra of Soltrol 220 aliphatic eluent. Injection volume = $1 \mu \mathrm{L}$.

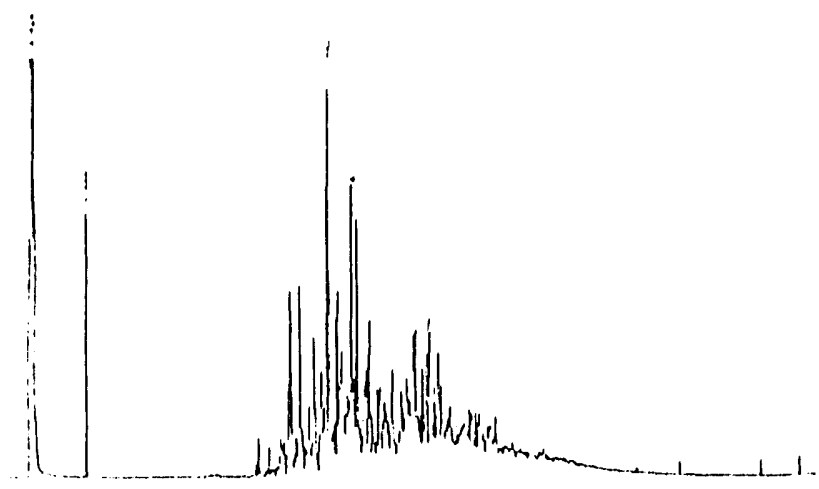

Figure 2-2b. GC spectra of Soltrol 220 total oil (deasphalnated sample). Injection volume $=1 \mu \mathrm{L}$. 


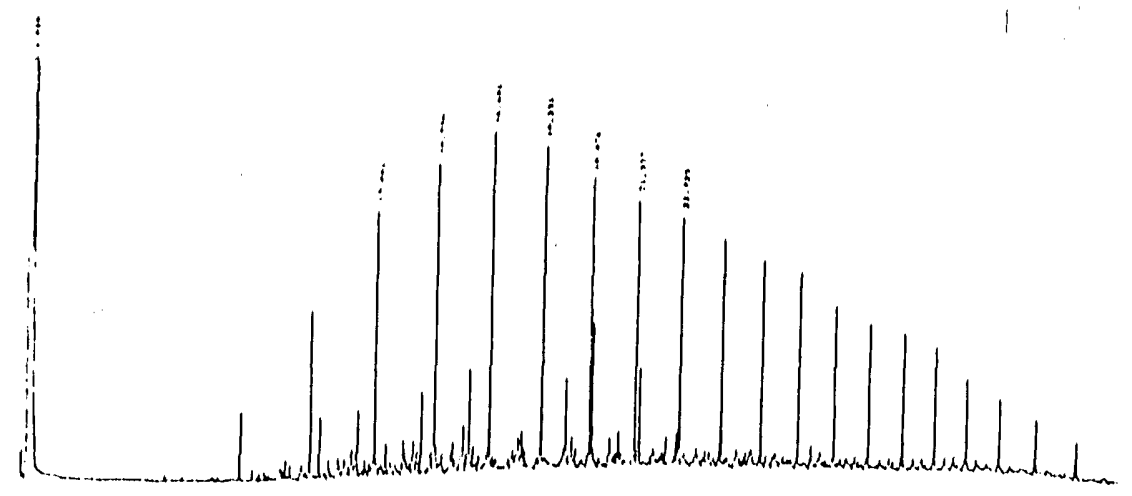

Figure 2-3a. GC spectra of Burbank crude aliphatic eluent. Injection volume $=1 \mu \mathrm{L}$.

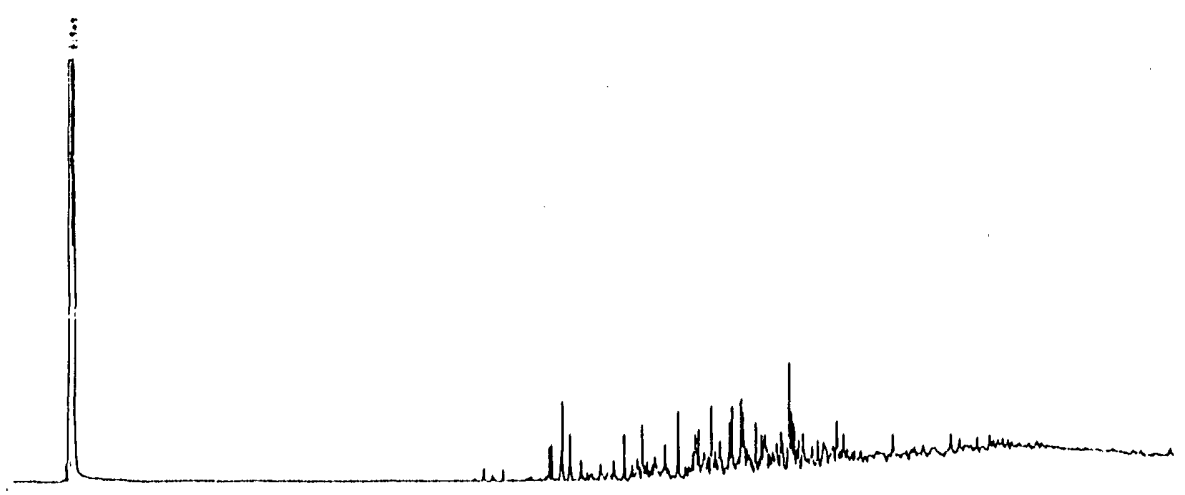

Figure 2-3b. GC spectra of Burbank crude aromatic eluent. Injection volume $=$ $1 \mu \mathrm{L}$.

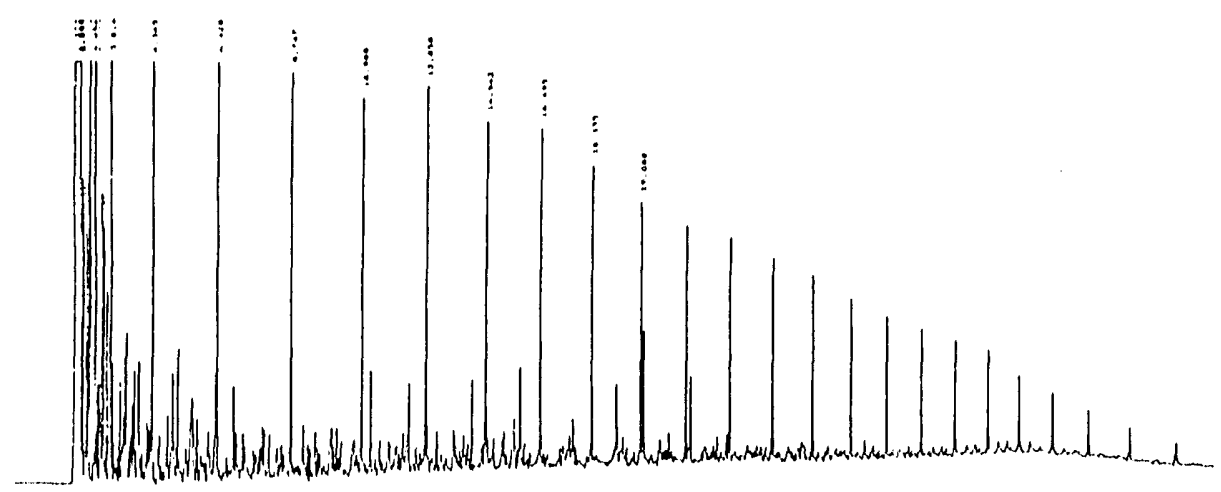

Figure 2-3c. GC spectra of Burbank crude total oil (deasphalnated sample). Injection volume $=1 \mu \mathrm{L}$. 


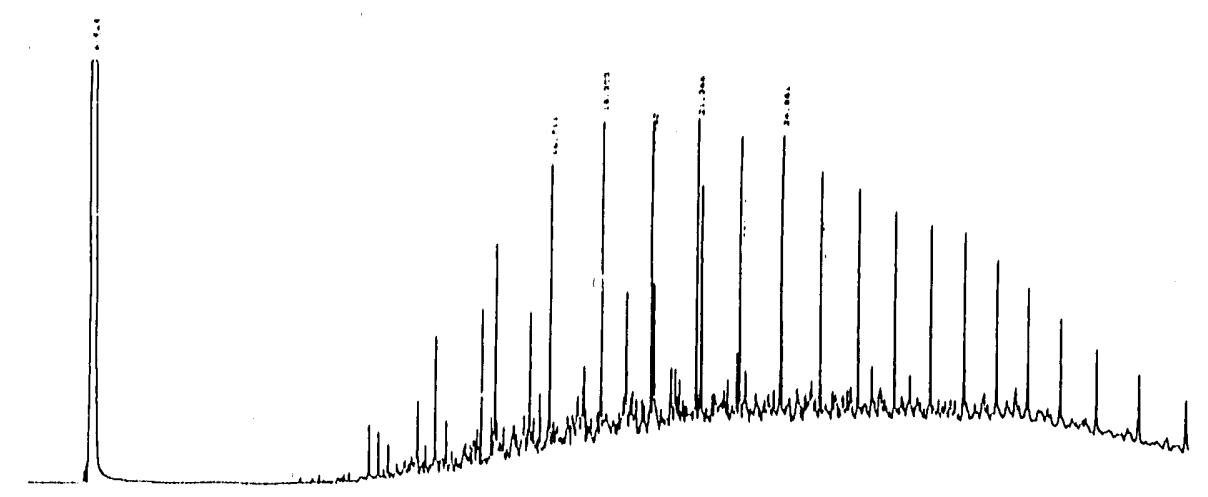

Figure 2-4a. GC spectra of Schuricht crude aliphatic eluent. Injection volume $=2 \mu \mathrm{L}$.

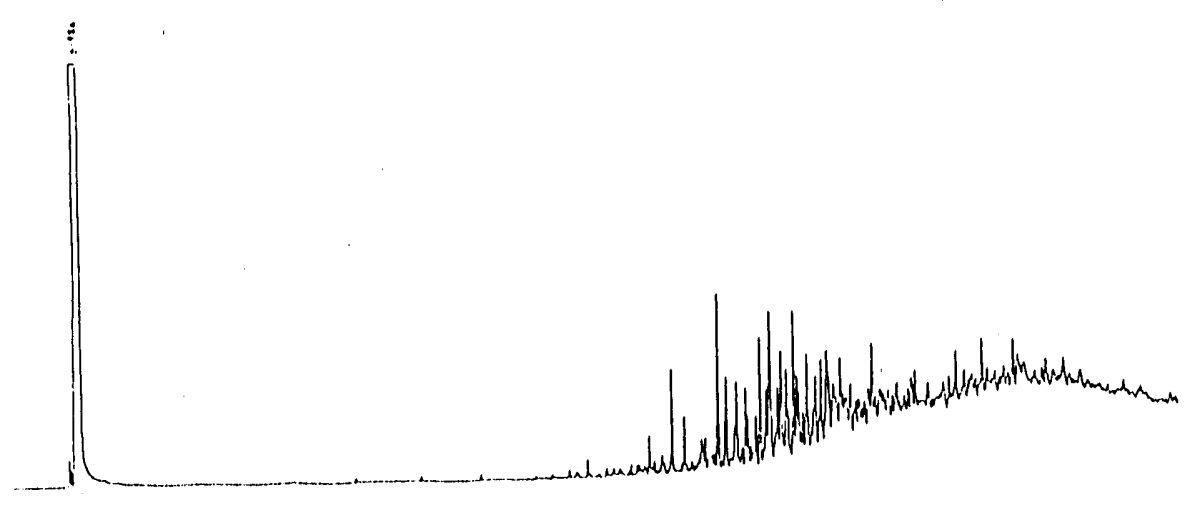

Figure 2-4b. GC spectra of Schuricht crude aromatic eluent. Injection volume $=5 \mu \mathrm{L}$.

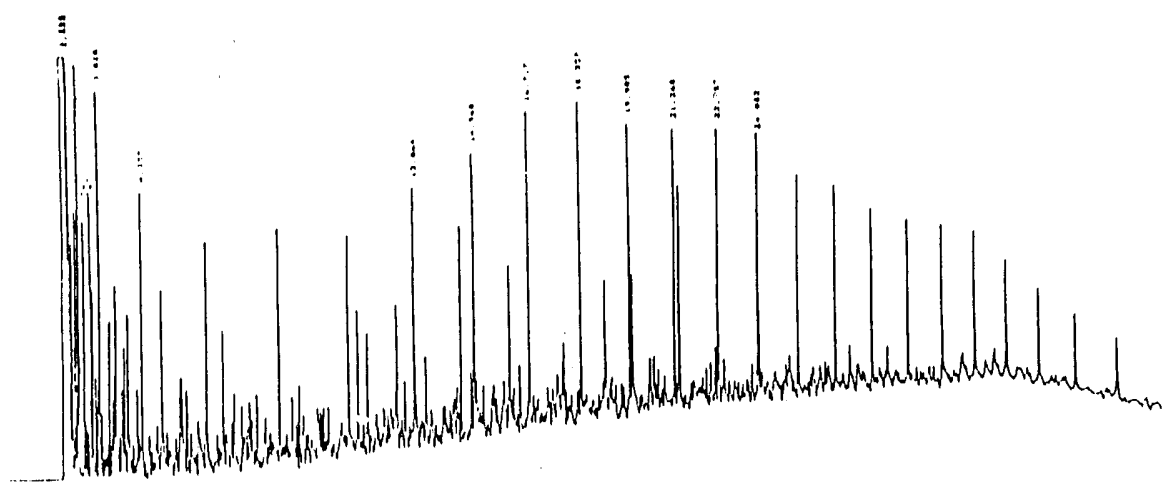

Figure 2-4c. GC spectra of Schuricht total oil (deasphalnated sample). Injection volume $=2 \mu \mathrm{L}$. 


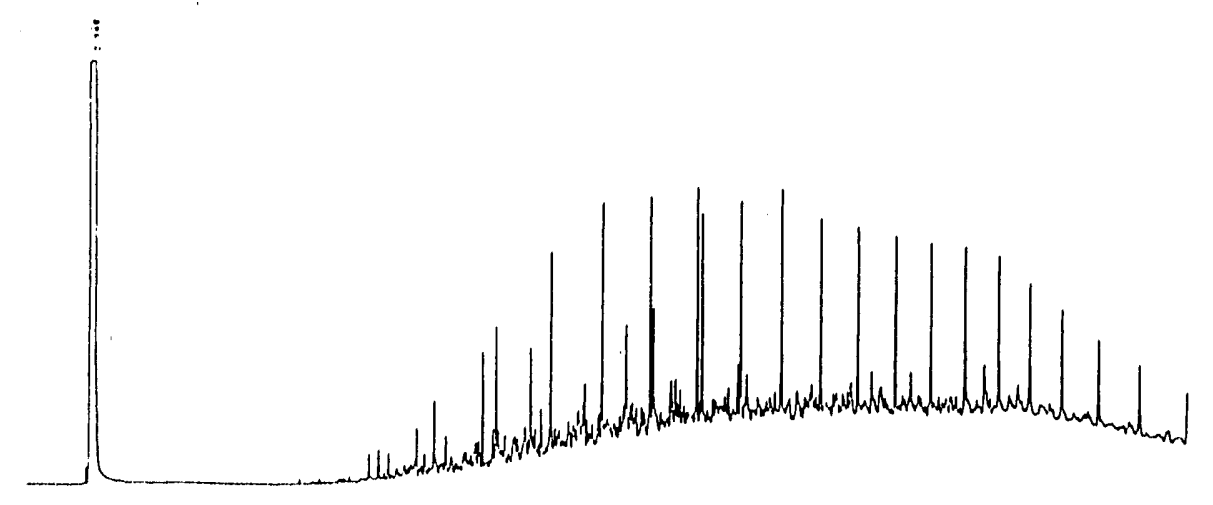

Figure 2-5a. GC spectra of Moorcroft West crude aliphatic eluent. Injection volume $=2 \mu \mathrm{L}$.

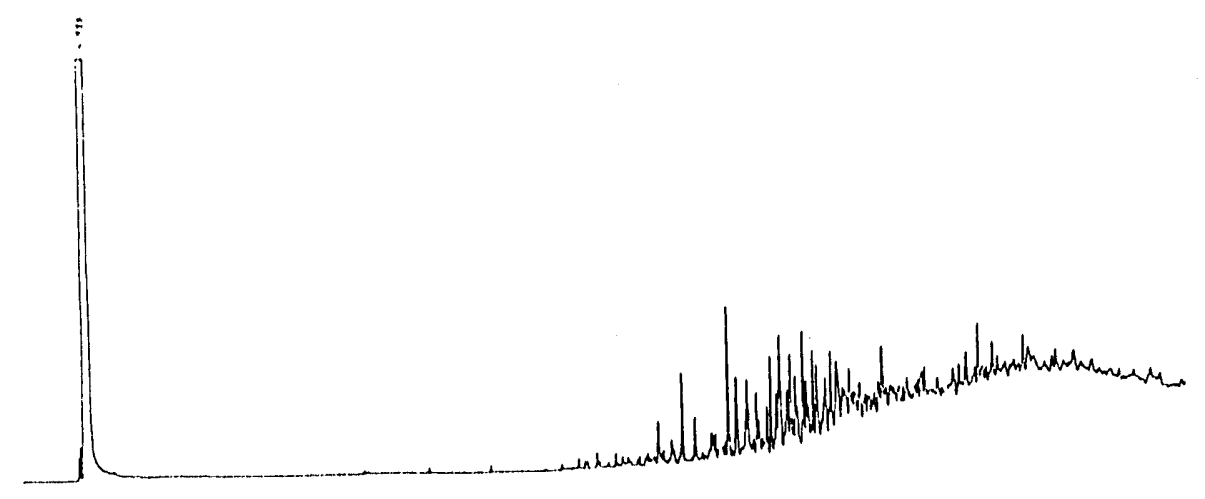

Figure 2-5b. GC spectra of Moorcroft West crude aromatic eluent. Injection volume $=5 \mu \mathrm{L}$.

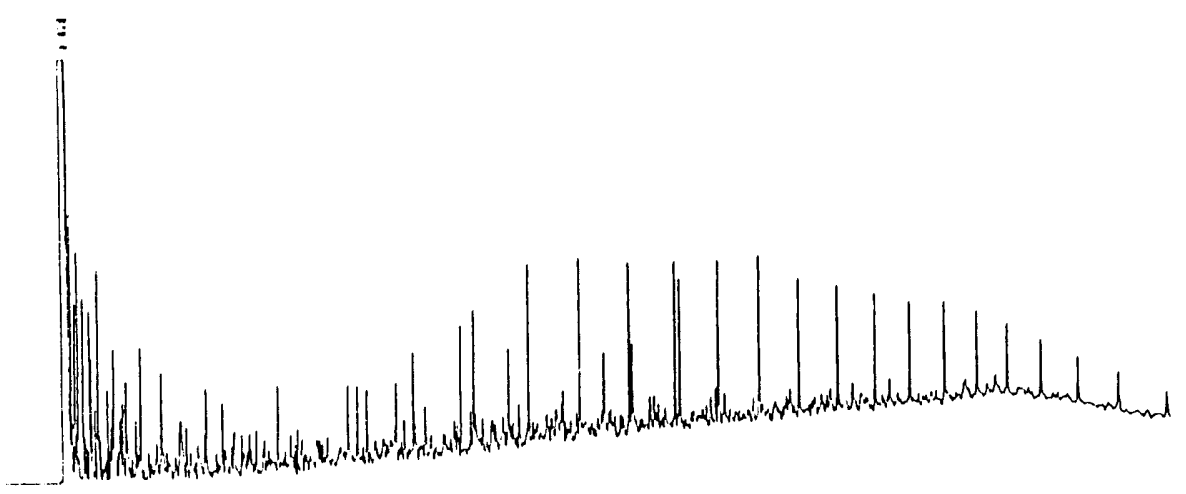

Figure 2-5c. GC spectra of Moorcroft West crude total oil (deasphalnated sample). Injection volume $=2 \mu \mathrm{L}$. 


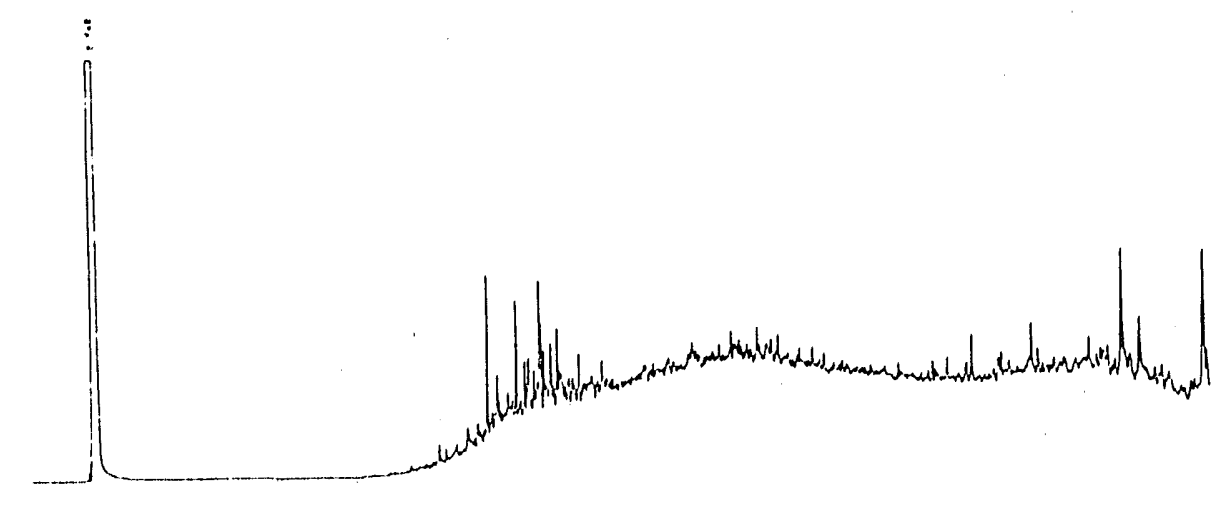

Figure 2-6a. GC spectra of Alworth crude aliphatic eluent. Injection volume $=2 \mu \mathrm{L}$.

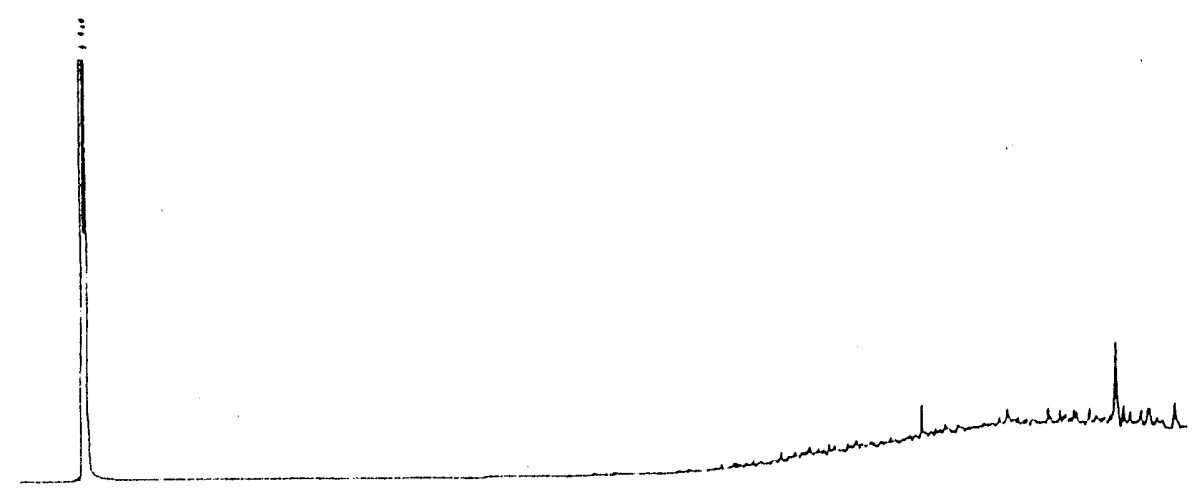

Figure 2-6b. GC spectra of Alworth crude aromatic eluent. Injection volume = $1 \mu \mathrm{L}$.

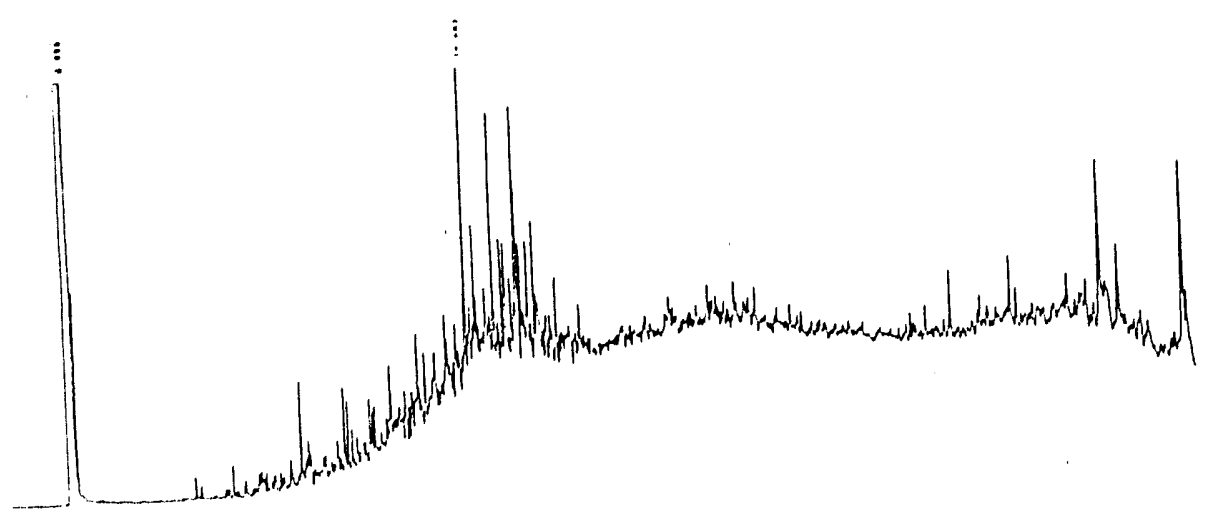

Figure a-Ge. GC spectra of Alworth crude tota? oil (deaspha?nated sample). Injection volume $=2 \mu \mathrm{L}$. 


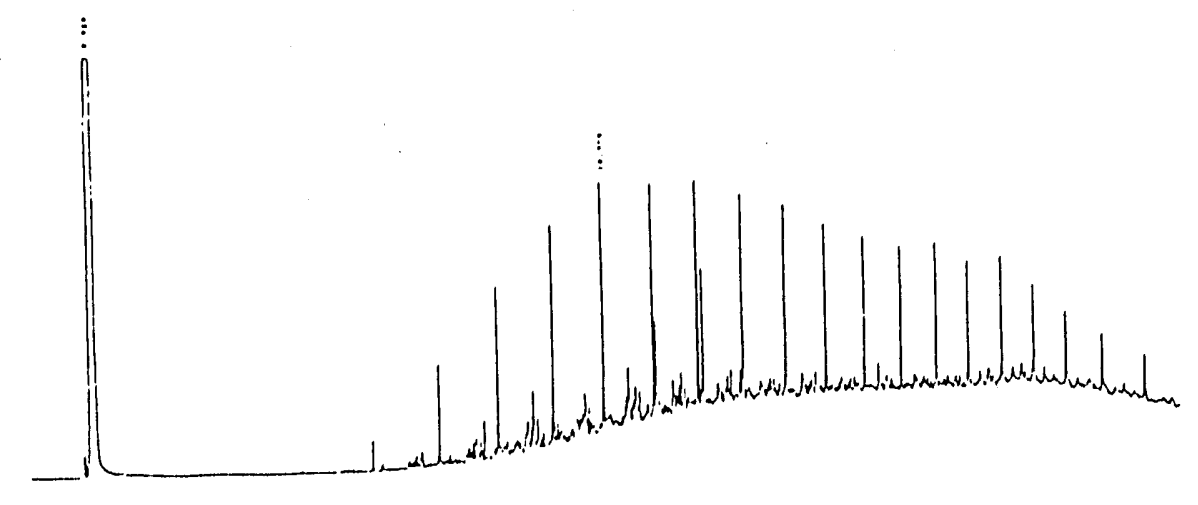

Figure 2-7a. GC spectra of Lick Creek crude aliphatic eluent. Injection volume $=2 \mu \mathrm{L}$.

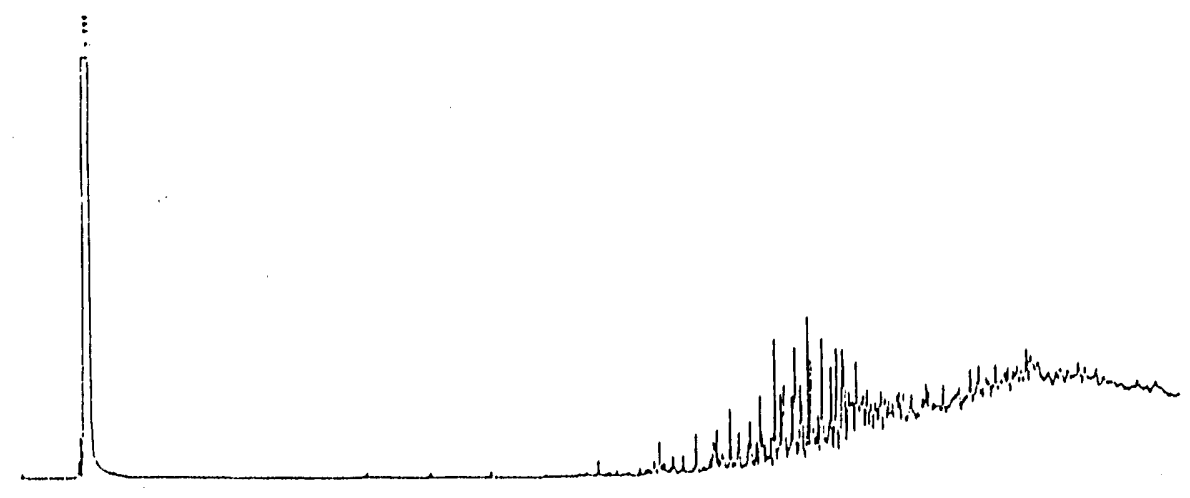

Figure 2-7b. GC spectra of Lick Creek crude aromatic eluent. Injection volume $=5 \mu \mathrm{L}$.

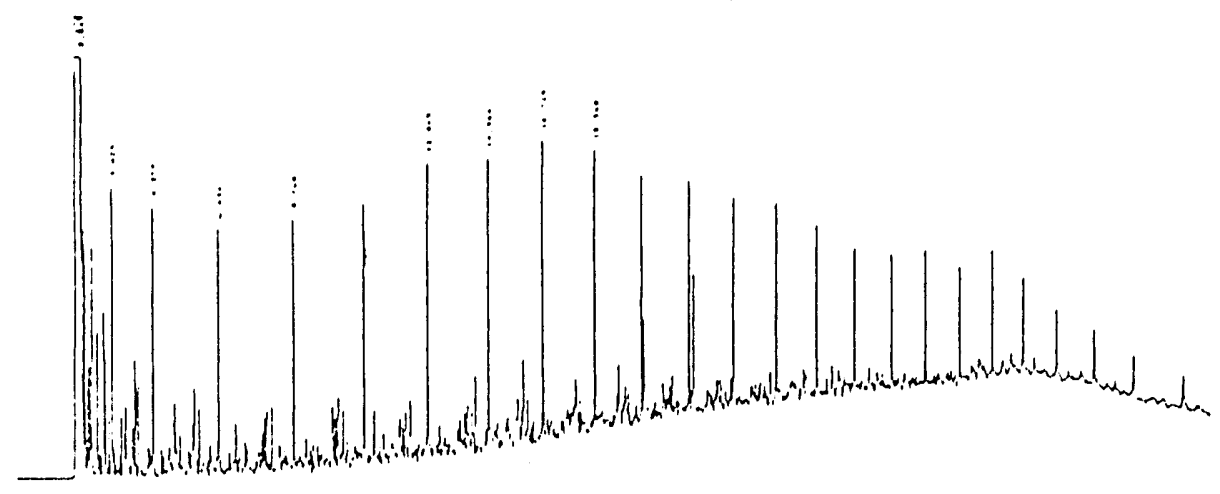

Fịgure 2-7c. GC spectra of Lick Creek crude total oil (deasphalnated sample). Injection volume $=2 \mu \mathrm{L}$. 

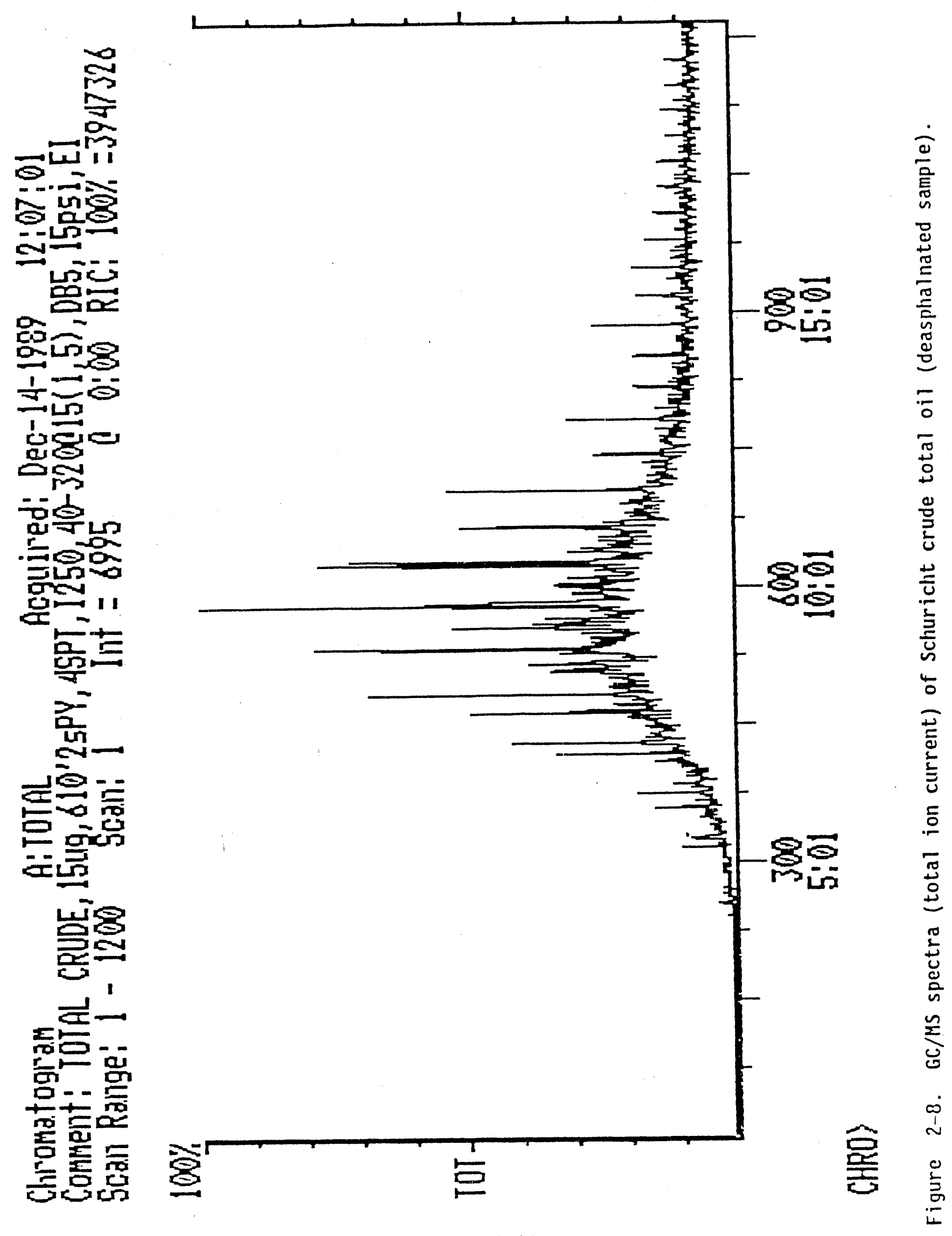


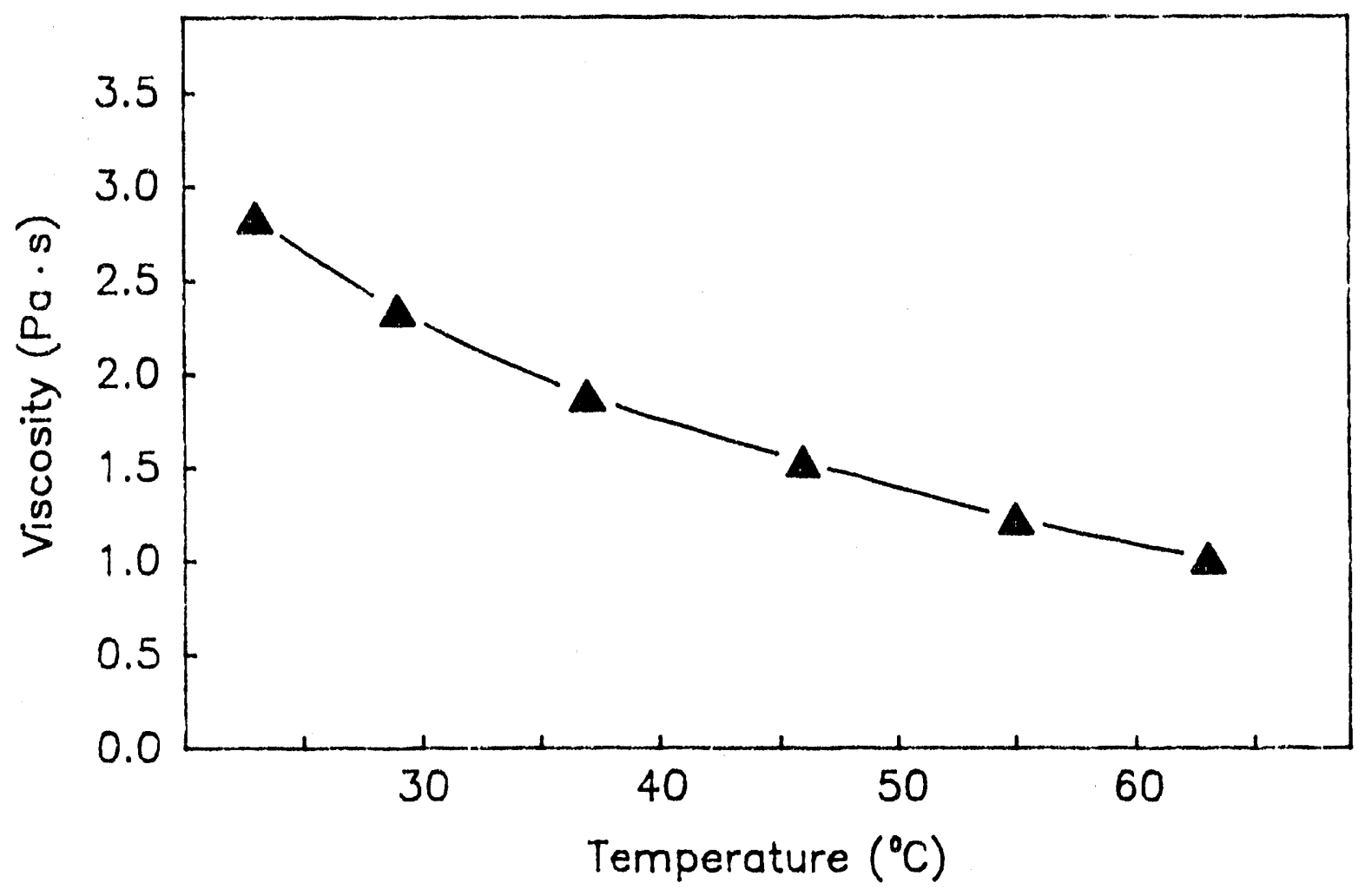

Figure 2-9. Temperature dependence of viscosity of Soltrol $220,50.5^{\circ} \mathrm{API}$ $60^{\circ} \mathrm{F}$. 


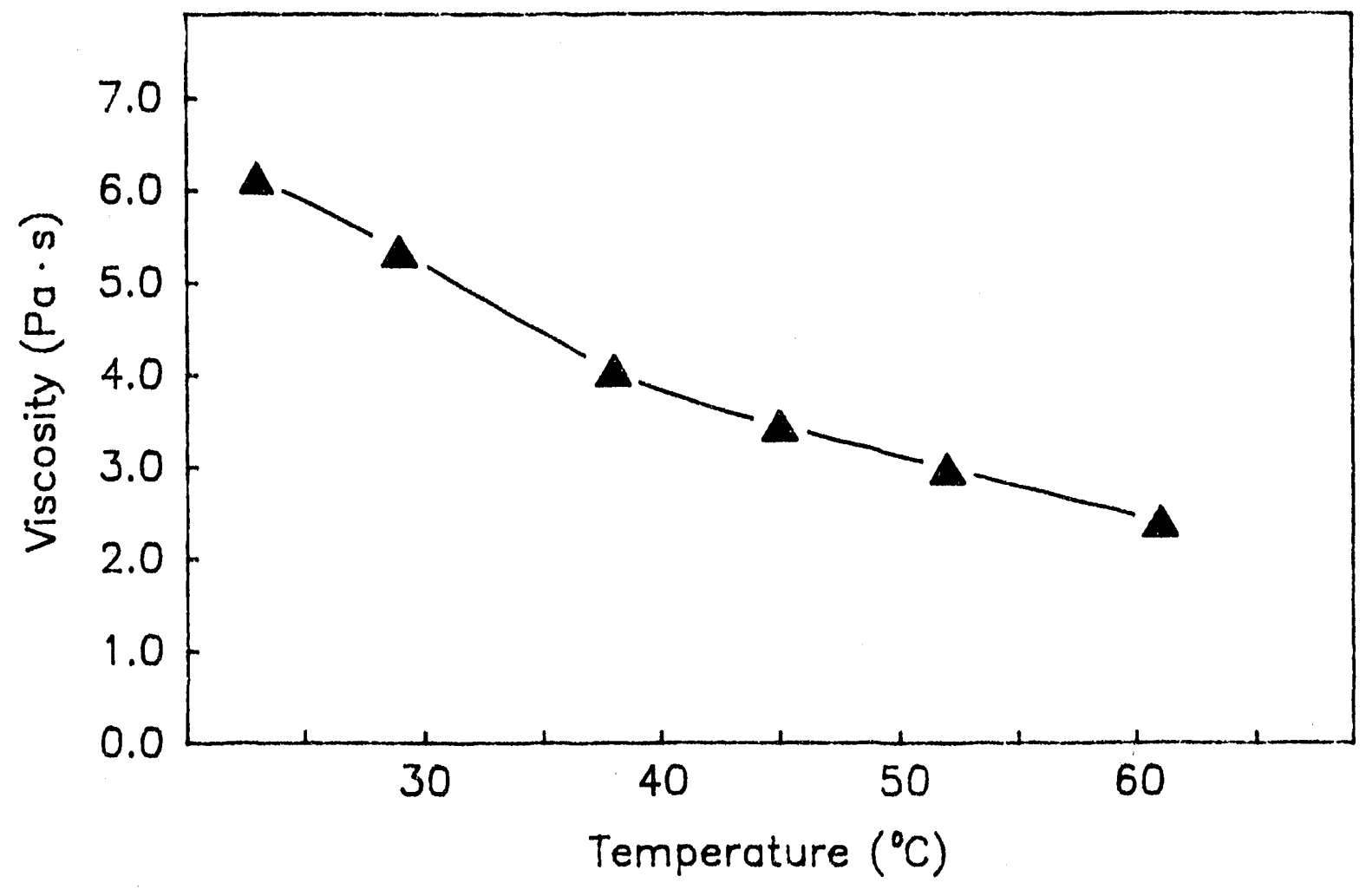

Figure 2-10. Temperature dependence of viscosity for Burbank Crude. Burbank Field, Osage County, OK, $38.1^{\circ} \mathrm{API} @ 60^{\circ} \mathrm{F}$. 


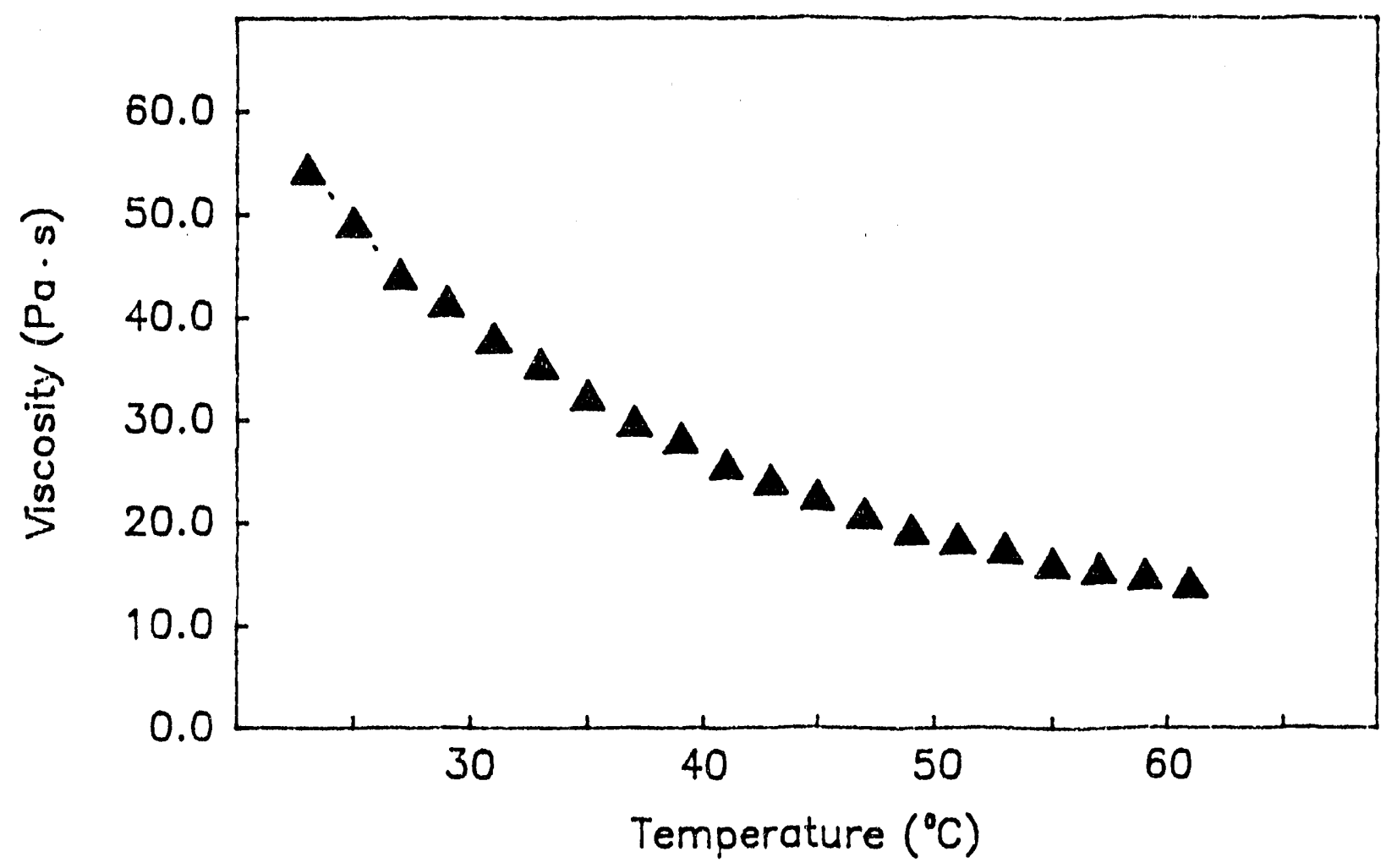

Figure 2-11. Temperature dependence of viscosity of Schuricht Crude. Schuricht Lease, Crook County, WY, $25.4^{\circ}$ @ $60^{\circ} \mathrm{F}$. 


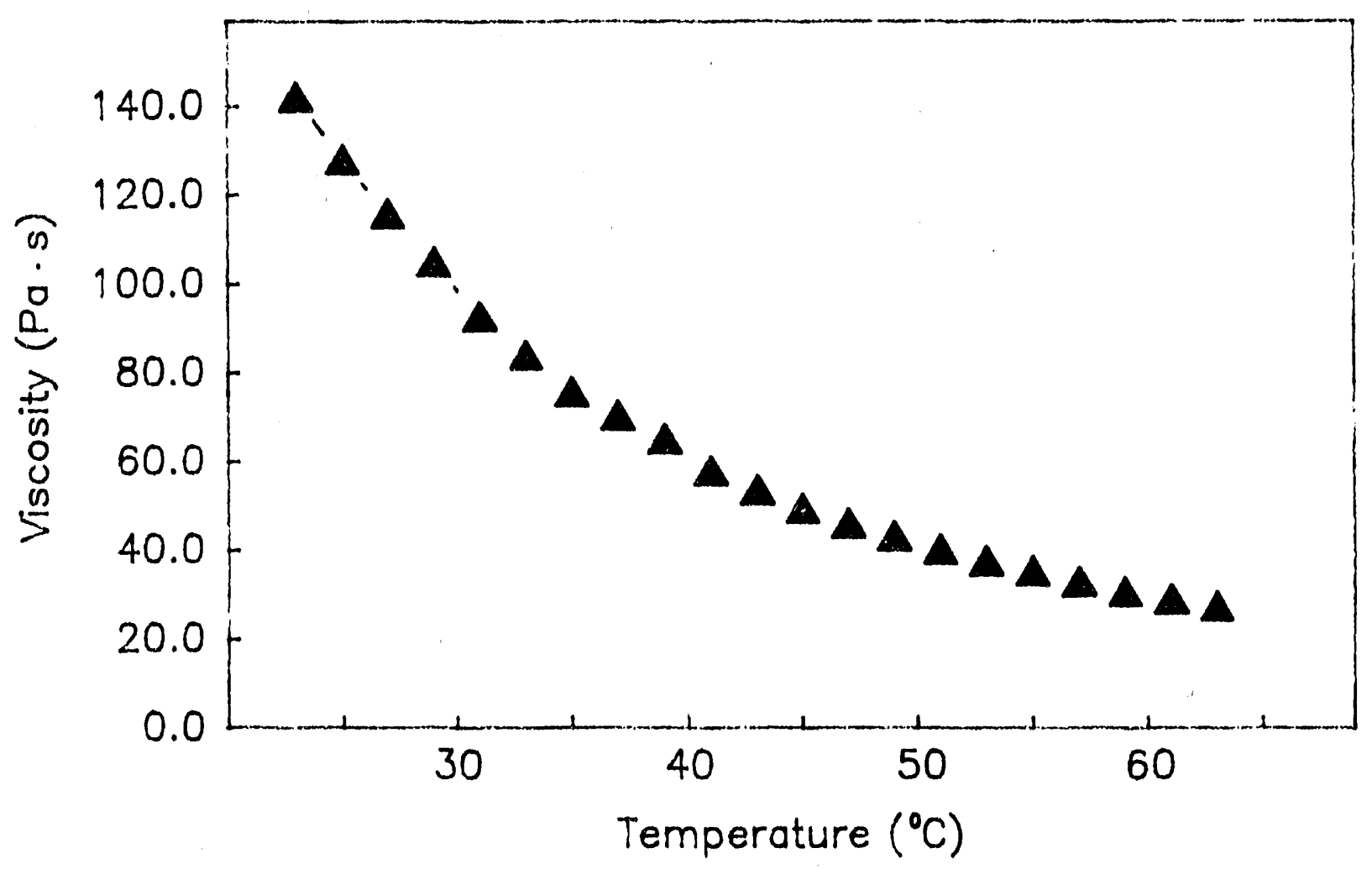

Figure 2-12. Temperature dependence of viscosity of Moorcroft West Crude. Texas Trails \#l Lease, Crook County, WY, $22.3^{\circ} \mathrm{API}$ (c) $60^{\circ} \mathrm{F}$. 


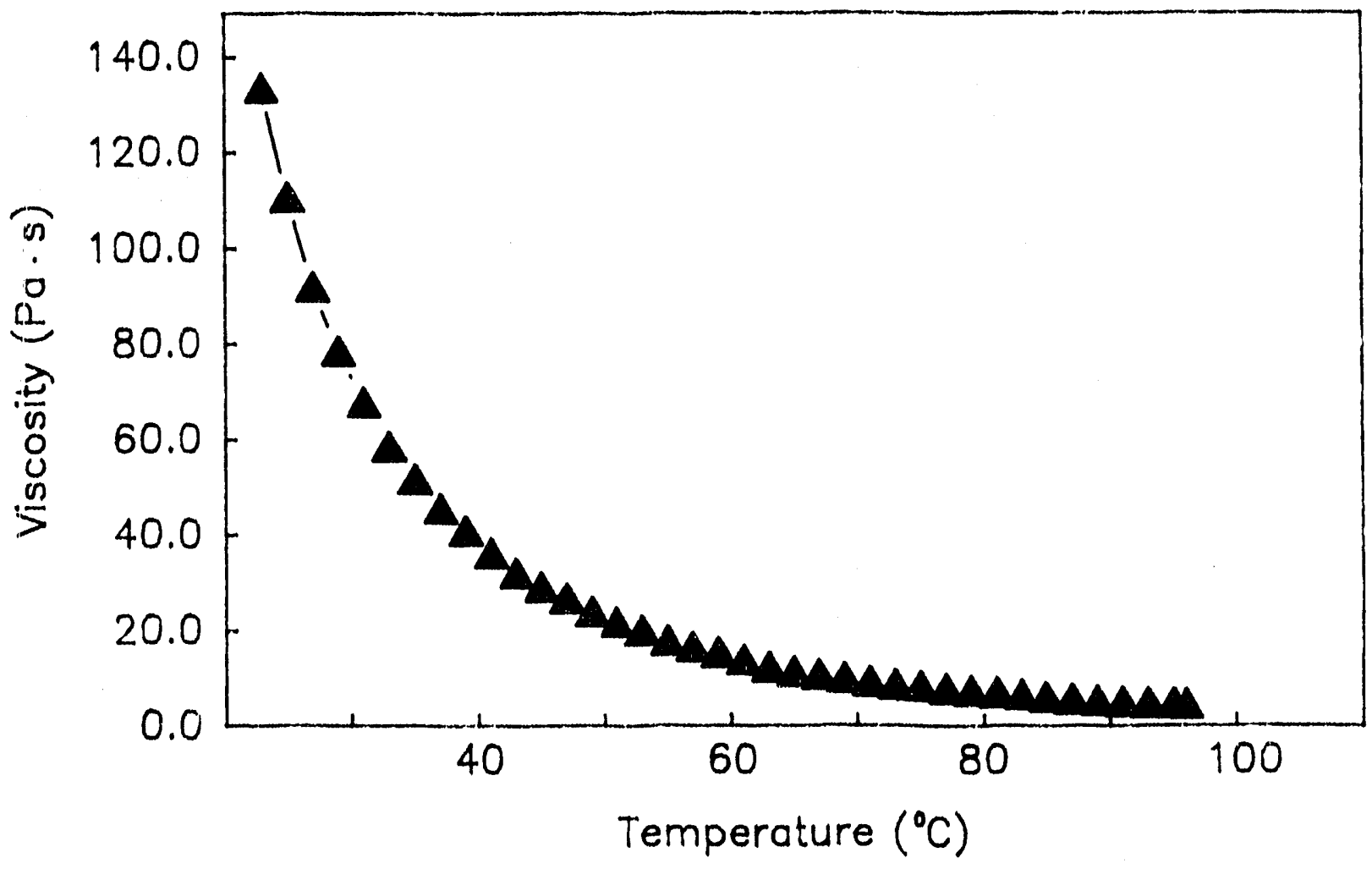

Figure 2-13. Temperature dependence of viscosity of Alworth Crude. Alworth Field, Jim Hogg County, TX, $19.1^{\circ} \mathrm{API}$ @ $60^{\circ} \mathrm{F}$. 


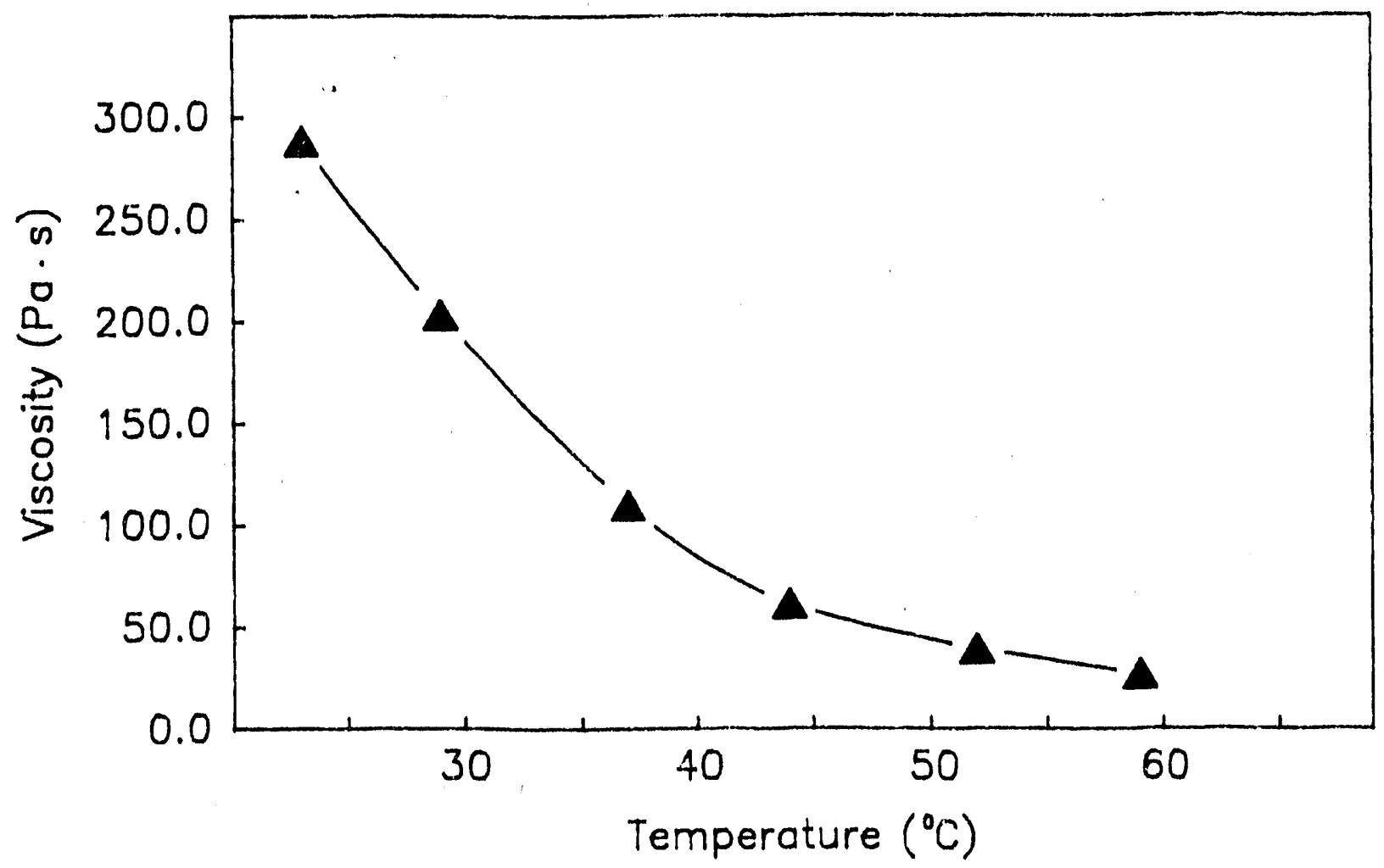

Figure 2-14. Temperature dependence of viscosity of Lick Creed Crude. Lick Creek Meakin Sand Unit, Union County, AR, $17.5^{\circ} \mathrm{API} \odot 60^{\circ} \mathrm{F}$. 


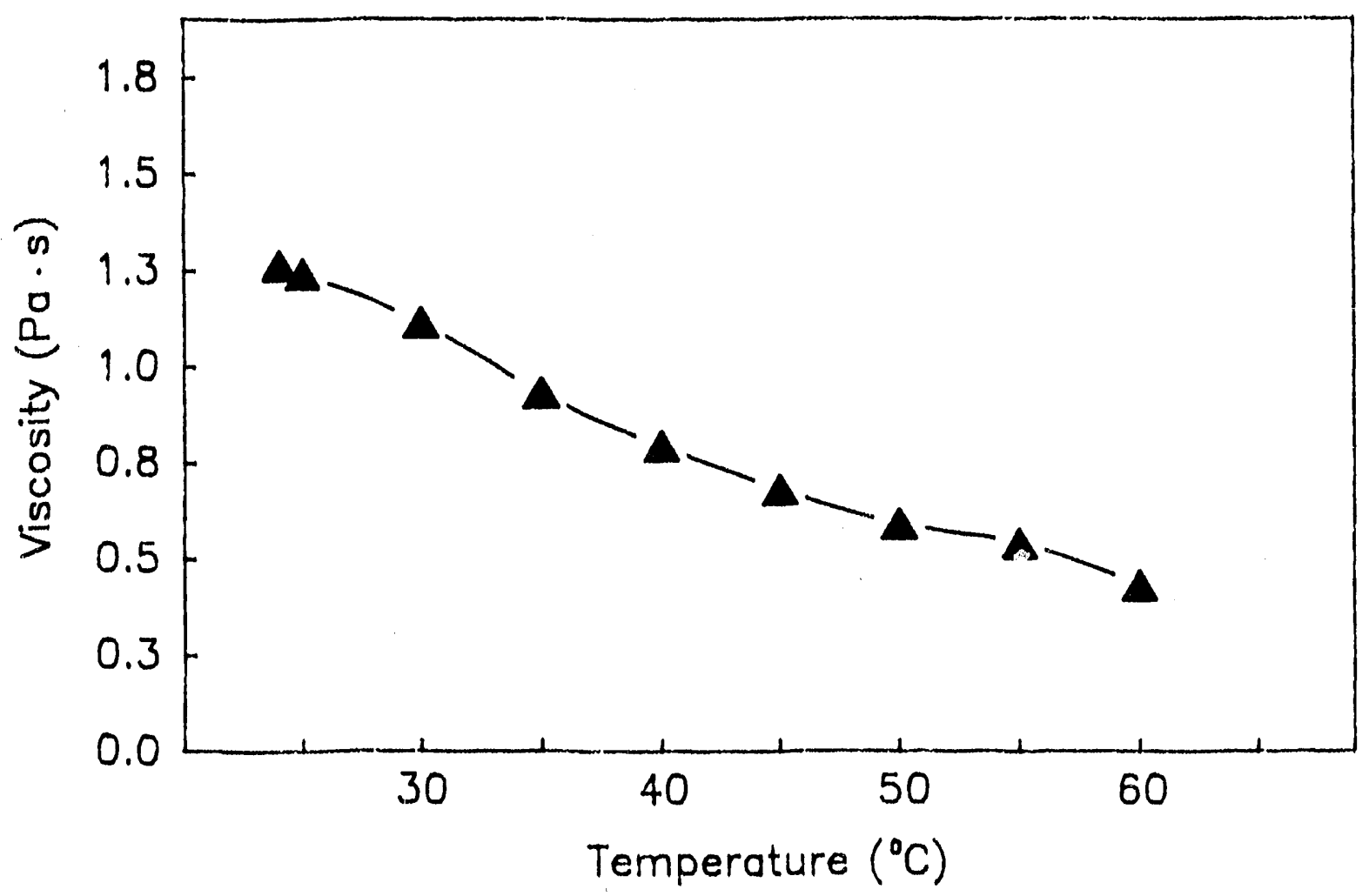

Figure 2-15. Temperature dependence of viscosity of Media E (bacteriological media). 


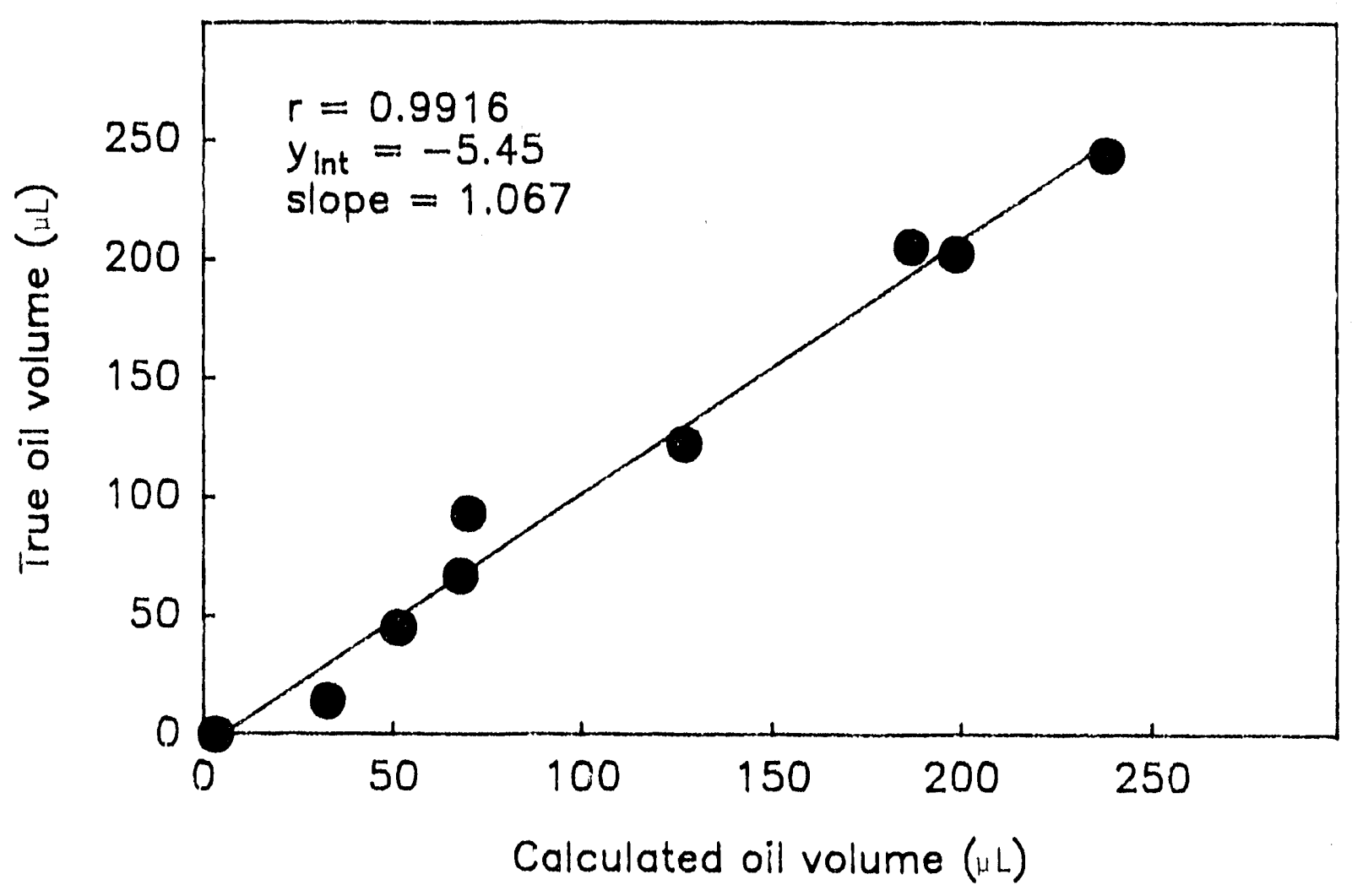

Figure 2-16. Comparison of true and calculated oil volumes resulting from separation and subsequent gravimetric analys is of mixed oil/water systems. Experiment performed according to method outlined in Section 2.3.6. 


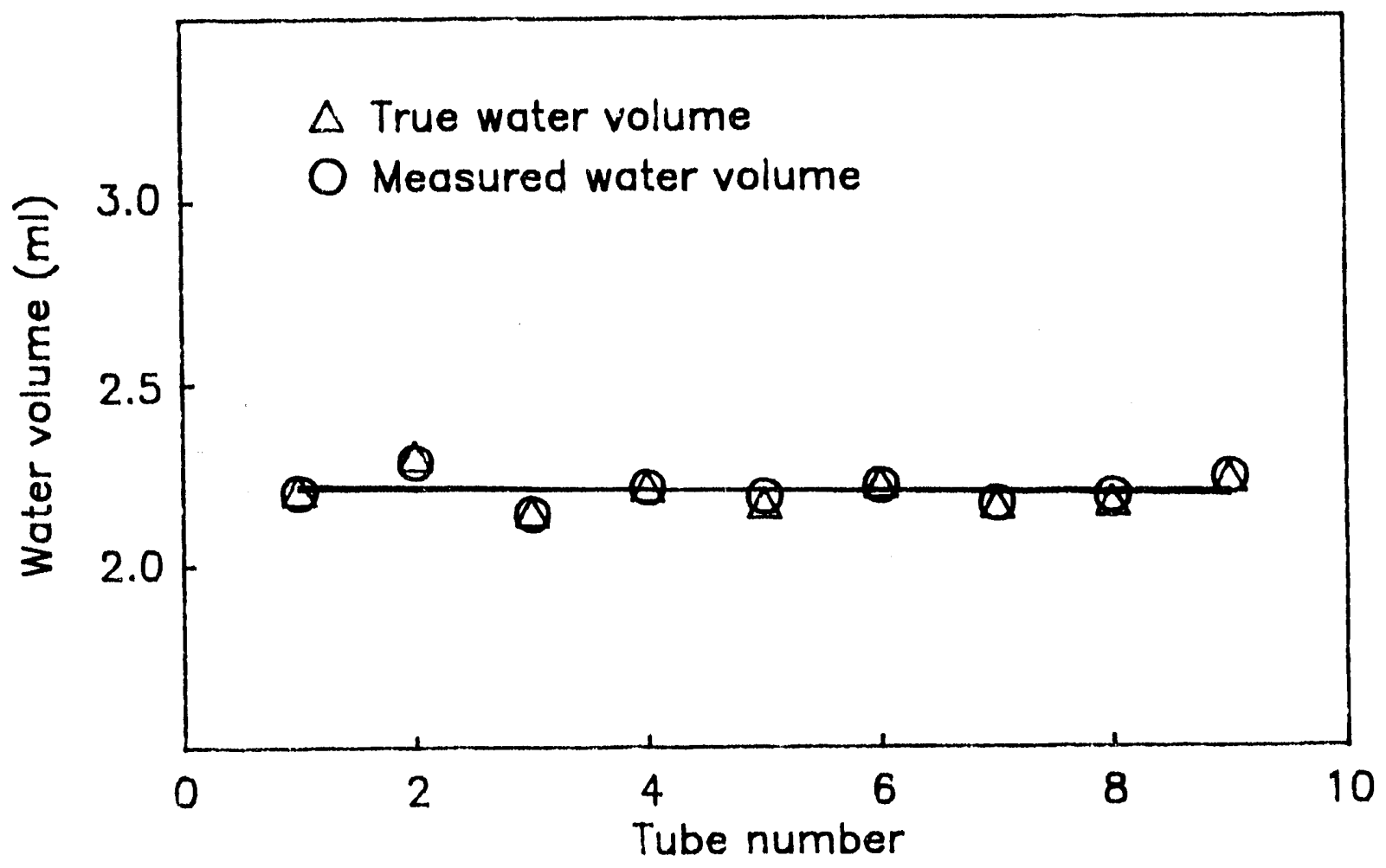

Figure 2-17. Comparison of true and measured water volumes resulting from separation and subsequent gravimetric analysis of mixed oil/water system. 


\subsection{References}

1. R.M. Atlas, "Effects of Temperature and Crude 011 Composition on Petroleum Biodegradation," Applied Microbiology, 30, 3, 1975, pp. 396-403.

2. D.W. Later, M.L. Lee, K.D. Bartle, R.C. Kong, and D.L Vassilaros, "Chemical Class Separation and Characterization of Organic Compounds in Synthetic Fuels," Analytical Chemistrv, 53, 11, 1981, pp. 1612-1620.

3. Manual No. M/85-106-F, "The Brookfield Digital Viscometer Model DV-II, Operating Instructions."

4. R.P. Philip, "Biological Markers in Fossil Fuel Production," Mass Spectrometry Reviews, 4, 1985, pp. 1-54. 


\section{MIECROBIAL ANALYSIS AND PHENOMENA}

Microbial isolates selected for analysis in the MEOR program were screened for phenotypic and genotypic properties that allow them to function in 011 reservoir environments such as those found in the Minnelusa sands of the Powder River Basin, WY. These properties are facultative anaerobicity, thermotolerance to $45^{\circ} \mathrm{C}$, halotolerance to $2.5 \%$ (in the form of $\mathrm{NaCl}$ ), and a desirable MEOR phenotype. Desirable phenotypes for MEOR include organisms capable of producing acids, gases, solvents, polymers, surfactants, or any combination of these. Also desirable would be the ability to degrade asphaltic oil components or significantly perturb the oil water interface through direct physical interactions. For application of MEOR technologies, the organisms should have no significant detrimental effect on the economically valuable constituents of crude oil.

To facilitate the selection and comparison of collected isolates and strains, a benchmark organism, Bacillus licheniformis strain JF-2 (ATCC 39307) ${ }^{1}$ was chosen. Bacillus licheniformis JF-2 was chosen because it produces a surfactant that has been isolated and characterized by other laboratories ${ }^{2,3}$ and because it has been previously used in a field test of MEOR. ${ }^{4}$

Other organisms selected for study were collected from the Powder River Bas in in Wyoming, Yellowstone National Park in Wyoming, Tinker Air Force Base in Norman, OK, and the Idaho Falls sewage treatment plant in Idaho Falls, ID. See Table 3-1 for a summary of selected isolates, morphology, geographical origin, and MEOR phenotype.

\subsection{IsOlation OF Field IsOlates}

Samples were collected aseptically in screw cap containers from the noted locations. A11 isolates were screened for thermotolerance to $45^{\circ} \mathrm{C}$, halotolerance to $2.5 \% \mathrm{NaCl}$, and growth on minimal 1502 Medium $\mathrm{E}$ for Bacillus ${ }^{5}$ 
Table 3-1. Origin, morphology and desirable MEOR phenotype of selected field isolates

\begin{tabular}{|c|c|c|c|}
\hline Isolate & Origin & Gram Rxn./Morph. & MEOR Phenotype \\
\hline B. Iicheniformis & a & + Rod, Linear & Acid, Surfactant, Polymer \\
\hline SEW BL & $b$ & $+\operatorname{Rod}$ & Acid, Surfactant \\
\hline COW BL & c & + Rod, Linear & Acid, Surfactant \\
\hline SPCDW & $d$ & $+\operatorname{Rod}$ & Acid \\
\hline SPCDY & e & $+\operatorname{Rod}$ & Acid, Surfactant \\
\hline COWPY1 & c & + Cocci, Linear & Acid, Surfactant \\
\hline FSC6DW & e & + Lrg. Rod, Linear & Acid \\
\hline YELDY & e & $+\operatorname{Rod}$ & Acid, Surfactant \\
\hline TNK3PY & f & - Small Rod & Gas, Surfactant \\
\hline MWWH & g & - Small Rod & Gas, Surfactant \\
\hline
\end{tabular}

a. American Type Culture Collection (ATCC 39307).

b. Activated sewage from the Idaho Falls sewage treatment plant.

c. $0 i 1$ soaked cow dung outside the Moorcroft West heater treater.

d. External spill of produced brines and $0 i 1$ at the Moorcroft West heater treater.

e. Natural hydrocarbon seeps in the Rainbow Springs area, Yellowstone National Park.

f. Mixed waste stream (industrial metal plating/stripping, air/land vehicle maintenance, and human sewage) at Tinker Air Force Base, Norman OK.

g. Oil sample from the wellhead at the Moorcroft West Unit. 
(all constituents per liter: $1 \mathrm{~g}\left(\mathrm{NH}_{4}\right)_{2} \mathrm{SO}_{4}, 0.51 \mathrm{~g} \mathrm{MgSO}_{4}, 2.5 \mathrm{~g} \mathrm{NaCl}, 5.3 \mathrm{~g}$ $\mathrm{KH}_{2} \mathrm{PO}_{4}, 10.6 \mathrm{~g} \mathrm{~K}_{2} \mathrm{PO}_{4}, 0.01 \mathrm{~g} \mathrm{Na}_{2}$ EDTA, $0.03 \mathrm{~g} \mathrm{MnSO}_{4}, 0.001 \mathrm{~g} \mathrm{CaCl}_{2}, 0.001 \mathrm{~g}$ $\mathrm{FeSO}_{4}, 0.001 \mathrm{~g} \mathrm{ZnSO}_{4}, 0.001 \mathrm{~g} \mathrm{CoCL}_{2}, 0.0001 \mathrm{~g} \mathrm{CuSO}_{4}, 0.0001 \mathrm{~g} \mathrm{Na}_{2} \mathrm{MoO}_{4}, 0.0001 \mathrm{~g}$ $\left.\operatorname{AlK}\left(\mathrm{SO}_{4}\right)_{2}\right)$ with $1 \%$ sucrose as the sole carbon source. All selections were conducted under aerobic conditions. Halotolerance and minimal media experiments were conducted at $30^{\circ} \mathrm{C}$. Sucrose was chosen as the carbon source because it represents the major carbohydrate constituent of beet molasses (molasses has historically been the feedstock of choice for MEOR applications in the field). ${ }^{6}$ Sucrose represents $63.5 \%$ of total solids in beet molasses and $95.4 \%$ of all carbohydrate present. ${ }^{7}$

Samples were streaked onto Trypticase Soy Agar (TSA) containing 2.5\% $\mathrm{NaCl}$ and incubated under anaerobic conditions at room temperature. Colonies were picked and re-streaked for secondary anaerobic incubation. Isolated colonies were picked and streaked again onto TSA for primary aerobic incubation at $30^{\circ} \mathrm{C}$. Facultative anaerobes (organisms growing under anaerobic and aerobic conditions) were picked from the aerobic plates and re-streaked. We11 isolated colonies were picked and inoculated into $3 \mathrm{~mL}$ of Trypticase Soy Broth (TSB) with $2.5 \% \mathrm{NaCl}$ and grown at $30^{\circ} \mathrm{C}$ overnight, gram stained to check homology and gram reaction and held at $4^{\circ} \mathrm{C}$ as stock cultures.

\subsection{Brochemical Characterization of BACILLUS LICHENIFORMIS JF-2 and Selected field Isolates}

Characteristics common to all organisms are thermo and halo-tolerance, aerobic growth on Media E (1502) with sucrose as the sole carbon source (1\%), no production of $\mathrm{H}_{2} \mathrm{~S}$ on Triple Sugar Iron Agar (TSI), no affinity for hydrocarbon/water interfaces as assayed by the Bacterial Adherence To Hydrocarbon (BATH) assay, ${ }^{8}$ and no degradative capacity for Schuricht crude $0 i 1$ (see Section 2 for characteristics) in the presence of $1 \%$ sucrose. Schuricht crude oil was chosen to determine the effects of MEOR isolates and Bacillus licheniformis JF-2 on the composition of crude oil because it comes from a reiativeiy pristane fieiú linat is under primary proúucion, has nut been 
perturbed with a waterflood, and has had no chemical intervention. It also represents a median of those oils selected for MEOR research at the INEL.

Isolates with the ability to aerobically emulsify oil were found by inoculating $30 \mathrm{~mL}$ Trypticase Soy Broth containing $2.5 \% \mathrm{NaCl}$ and $1 \%$ Schuricht crude oil with $100 \mu \mathrm{L}$ of the $4^{\circ} \mathrm{C}$ stocks. Isolates emulsifying oil after $10 \mathrm{~d}$ were taken as surfactant producers. Emulsification was judged based on a positive control (Bacillus licheniformis JF-2). Isolates producing acids were found by monitoring $\mathrm{pH}$ changes in liquid culture using phenol red as the $\mathrm{pH}$ indicator. Gas producers were found using Durham tube culture techniques.

Degradative effects of Bacillus licheniformis JF-2 on Schuricht crude $0 i 1$ composition was determined by comparing volume (as percent) of crude oil constituents (1iquid chromatography) of oil extracted from aerobic emulsifications with oil extracted from abiotic culture flasks incubated under identical conditions (see Figure 3-1a to 3-1d). Extraction was facilitated with $2 \times 5 \mathrm{~mL}$ aliquots of hexane (culture volume $=50 \mathrm{~mL}$, crude $=500 \mu \mathrm{L}$ ). Gas chromatographs of the aliphatic and aromatic fractions of Schuricht crude were also obtained for aerobic and anaerobic emulsification studies extracted as above. Comparisons of gas chromatography (GC) data was made by comparing pristane $/ C_{17}$ and phytane/ $C_{18}$ ratios of biotic and abiotic culture flasks and GC profiles. Data for pristane $/ C_{17}$ and phytane $/ C_{18}$ ratios obtained during aerobic emulsification experiments are presented in Table 3-2, data obtained from anaerobic emulsification experiments are presented in Table 3-3. Chromatography profiles from both anaerobic and aerobic experiments concur with the pristane $/ C_{17}$ and phytane/ $C_{18}$ ratios and indicate no degradation. Anaerobic experiments were monitored for anaerobicity with head space analysis of all samples (GC analysis performed on a Gow Mac series 550P GC fitted with a $6 \mathrm{ft}$ Alltech CTR 1 concentric column). Degradative effects of MEOR isolates on Schuricht crude were determined by comparative gas chromatography. No fractionation data were obtained.

Bacillus licheniformis JF-2 (ATCC 39307) has a highly varigated white surface morphology and was observed to have positive reactions for oxidase and catalase and also observed to possess arginine dihydrolase, gelatinase, alpha 
Table 3-2. Pristane $/ \mathrm{C}_{17}$ and phytane/ $\mathrm{C}_{18}$ ratios obtained following aerobic emulsification of Schuricht crude 0 il

$\begin{array}{lcc}\frac{1}{\text { Isolate }} & \text { Pristane } / C_{17} & \text { Phytane } / C_{18} \\ \text { Aseptic control } & 0.66 & 0.98 \\ \text { B. Iicheniformis } & 0.65 & 0.94 \\ \text { SEW BL } & 0.66 & 1.00 \\ \text { COW BL } & 0.67 & 0.89 \\ \text { SPCDW } & 0.67 & 1.01 \\ \text { SPCDY } & 0.65 & 0.93 \\ \text { COWPY1 } & 0.54 & 0.94 \\ \text { FSC6DW } & 0.74 & 0.96 \\ \text { YELDY } & 0.68 & 1.00 \\ \text { TNK3PY } & 0.68 & 0.96 \\ \text { MWWH } & 0.69 & 0.94\end{array}$

amylase, and beta galactosidase. The organism was able to use acetate, pyruvate citrate, and malate as growth substrates. Nitrate was reduced to nitrite but not to nitrogen gas. Acid, but not acid and gas, was formed during growth on glucose. Bacillus licheniformis JF-2 was found to produce a polymer (levan) as well as a surfactant.

SEW $B L$ is a gram positive rod having a creamy white variegated surface morphology on agar plates. SEW BL originated from activated sewage from the Idaho Falls, ID sewage treatment plant. SEW BL was observed to have positive reactions for oxidase and catalase, and also observed to possess gelatinase, and beta galactosidase. The organism was able to use arabinose, D-mannose, Dmannitol, acetyl-D-glucosamine, maltose, D-gluconate, acetate, pyruvate, 
Table 3.3. Pristane $/ C_{17}$ and phytane $/ C_{18}$ ratios obtained following anaerobic emulsification of Schuricht crude oil

\begin{tabular}{lcc}
\hline \multicolumn{1}{c}{ Isolate } & Pristane $/ C_{17}$ & ${\text { Phytane } / C_{18}}_{18}$ \\
Aseptic control & 0.497 & 0.853 \\
B. Iicheniformis & 0.558 & 0.912 \\
SEW BL & 0.695 & 0.988 \\
COW BL & 0.787 & 0.980 \\
SPCDW & 0.808 & 1.021 \\
SPCDY & 0.699 & 0.932 \\
COWPY1 & 0.676 & 0.959 \\
FSC6DW & 0.686 & 0.959 \\
YELDY & 0.718 & 0.996 \\
TNK3PY & 0.728 & 0.982 \\
MWWH & 0.649 & 0.957 \\
\hline
\end{tabular}

malate, and citrate as growth substrates. Nitrate was reduced to nitrite but not to nitrogen gas. Acid (but not acid and gas) was formed during growth on glucose. SEW BL was found to produce a surfactant in aerobic and anaerobic shake flasks.

COW $\mathrm{BL}$ is a gram positive rod having a mucoid white variegated surface morphology on agar plates. COW BL originated from oil laden cow dung positioned just outside the Moorcroft West heater treater. COW BL was observed to have positive reactions for oxidase and catalase and was also observed to possess gelatinase, and beta galactosidase. The organism was able to use arabinose, D-mannose, D-mannitol, acetyl-D-glucosamine, maltose, D- 
gluconate, acetate, pyruvate, malate, and citrate as growth substrates. Nitrate was reduced to nitrite but not to nitrogen gas. Acid (but not acid and gas) was formed during growth on glucose. COW BL was found to produce a surfactant in aerobic and anaerobic shake flasks.

SPCDW is a gram positive rod having a dense, pinpoint white surface morphology on agar plates. SPCDW originated from a spill of produced brines and $0 i 1$ just outside the Moorcroft West heater treater. SPCDW was negative for oxidase and catalase but was observed to possess gelatinase, and beta galactosidase. The organism was able to use arabinose, D-mannose, D-mannitol, acetyl-Dglucosamine, maltose, D-gluconate, malate, and citrate as growth substrates. Acid (but not acid and gas) was formed during growth on glucose. SPCDW was found to produce a surfactant in anaerobic shake flasks but not in aerobic shake flasks.

SPCDY is a gram positive rod having a dense, pinpoint yellow surface morphology on agar plates. SPCDY originated from a spill of produced brines and $0 i 1$ just outside the Moorcroft West heater treater. SPCDY was negative for oxidase and catalase but was observed to possess gelatinase, and beta galactosidase. The organism was able to use arabinose, D-mannose, D-mannitol, acetyl-D-glucosamine, maltose, D-gluconate, pyruvate, malate, and citrate as growth substrates. Acid (but not acid and gas) was formed during growth on glucose. SPCDY was found to produce a surfactant in aerobic and anaerobic shake flasks.

COWPY 1 is a gram positive cocci or small rod having a dense, pinpoint yellow surface morphology on agar plates. COWPYl originated from oil laden cow dung positioned just outside the Moorcroft West heater treater. COWPY1 was negative for oxidase and catalase but was observed to possess beta galactosidase. Acid (but not acid and gas) was formed during growth on glucose. COWPY 1 was found to produce a surfactant in aerobic and anaerobic shake flasks.

FSCEDW is a large gram positive rod having a creamy white diffuse surface morphology on agar plates. FSC6DW originated from an active algal matt in the 
Rainbow Springs area in Yellowstone National Park, an area known for natural hydrocarbon seeps. FSC6DW was observed to have a positive reaction for oxidase and a negative reaction for catalase and also observed to possess gelatinase, and beta galactosidase. The organism was able to use arabinose, D-mannose, D-mannitol, acetyl-D-glucosamine, maltose, D-gluconate, adipate, phenylacetate, acetate, malate, and citrate as growth substrates. Acid (but not acid and gas) was formed during growth on glucose. FSC6DW was found to produce a surfactant in anaerobic but not aerobic shake flasks.

YELDY is a gram positive rod having a dense yellow surface morphology on agar plates. YELDY originated from an oil laden soil sample from the Rainbow Springs area in Yellowstone National Park. YELDY was negative for oxidase and catalase but was observed to possess gelatinase, and beta galactosidase. The organism was able to use arabinose, D-mannose, D-mannitol, acetyl-Dglucosamine, maltose, D-gluconate, adipate, phenylacetate, acetate, and citrate as growth substrates. Acid (but not acid and gas) was formed during growth on glucose. YELDY was found to produce a surfactant in aerobic and anaerobic shake flasks.

TNK3PY is a gram negative rod having a dense yellow surface morphology on agar plates. TNK3PY originated from a mixed waste stream comprised of human sewage effluent, effluent from a metals plating/stripping facility, and effluent from a vehicle maintenance shop all located on Tinker Air Force Base Norman, OKlahoma. TNK3PY was observed to have a positive reaction for oxidase and a negative reaction for catalase. The organism was able to use D-gluconate, caprate, acetate, pyruvate, and citrate as growth substrates. Nitrate was reduced to nitrite. Gas (weak production) was formed during growth on glucose. TNK3PY was found to produce a surfactant in aerobic and anaerobic shake flasks.

MWWH is a small gram negative rod having a glossy yellow surface morphology on agar plates. MWWH originated from a sample of gravel taken from the Moorcroft West wellhead. MWWH was observed to have a positive reaction for oxidase and catalase. The organism was able to use D-gluconate, caprate, acetate, pyruvate, and citrate as growth substrates. Nitrate was reduced to nitrite. 
Gas (weak production) was formed during growth on glucose. MWWH was found to produce a surfactant in aerobic and anaerobic shake flasks.

Collective properties of all strains are 1isted in Table 3-4.

\subsection{Properties of Bactllus Lichentformis Strain JF-2}

Properties of Bacillus licheniformis strain JF-2 with respect to culture characteristics, transport through and spacial distribution in Berea sandstone, surfactant production, and polymer production were elucidated. Culture characteristics, surfactant production, and polymer production were investigated using Media E (1502) with sucrose as the sole carbon source.

Growth protocols for coreflood experimentation in Media E (1502) with sucrose are also delineated.

\subsubsection{Culture Properties of Bacillus licheniformis Strain JF-2}

Experiments were conducted aerobically in media $E$ (1502) with sucrose as the carbon source. These experiments indicate a temperature optimum at $37^{\circ} \mathrm{C}$ with a tolerance to at 1 east $50^{\circ} \mathrm{C}$ (Figure $3-2$ ), a salinity tolerance of 1 to 6 w\%/v (as $\mathrm{NaCl}$, Figure 3-3), and a pH tolerance of 6 to at least 8.5 (Figure 34).

Temperature data indicate a sharp response at $37^{\circ} \mathrm{C}$ that peaks by $72 \mathrm{~h}$. After $72 \mathrm{~h}$ the cells most likely begin to sporulate and therefore the optical density decreases. At $45^{\circ} \mathrm{C}$ growth continues at $144 \mathrm{~h}$ and has not began to subside. This is indicative of slower metabolism at this temperature. Temperatures of $55^{\circ} \mathrm{C}$ were found to be lethal for the organism.

Salinity data indicate pronounced sensitivity to salt only during the first few days of growth. By $90 \mathrm{~h}(3.75 \mathrm{~d}$ ) a broad tolerance to salt (as $\mathrm{NaCl}$ ) is observed. Optical densities of 1.0 and greater were obtained after $1 \mathrm{~d}$ because of an increased inoculum size in this experiment. 


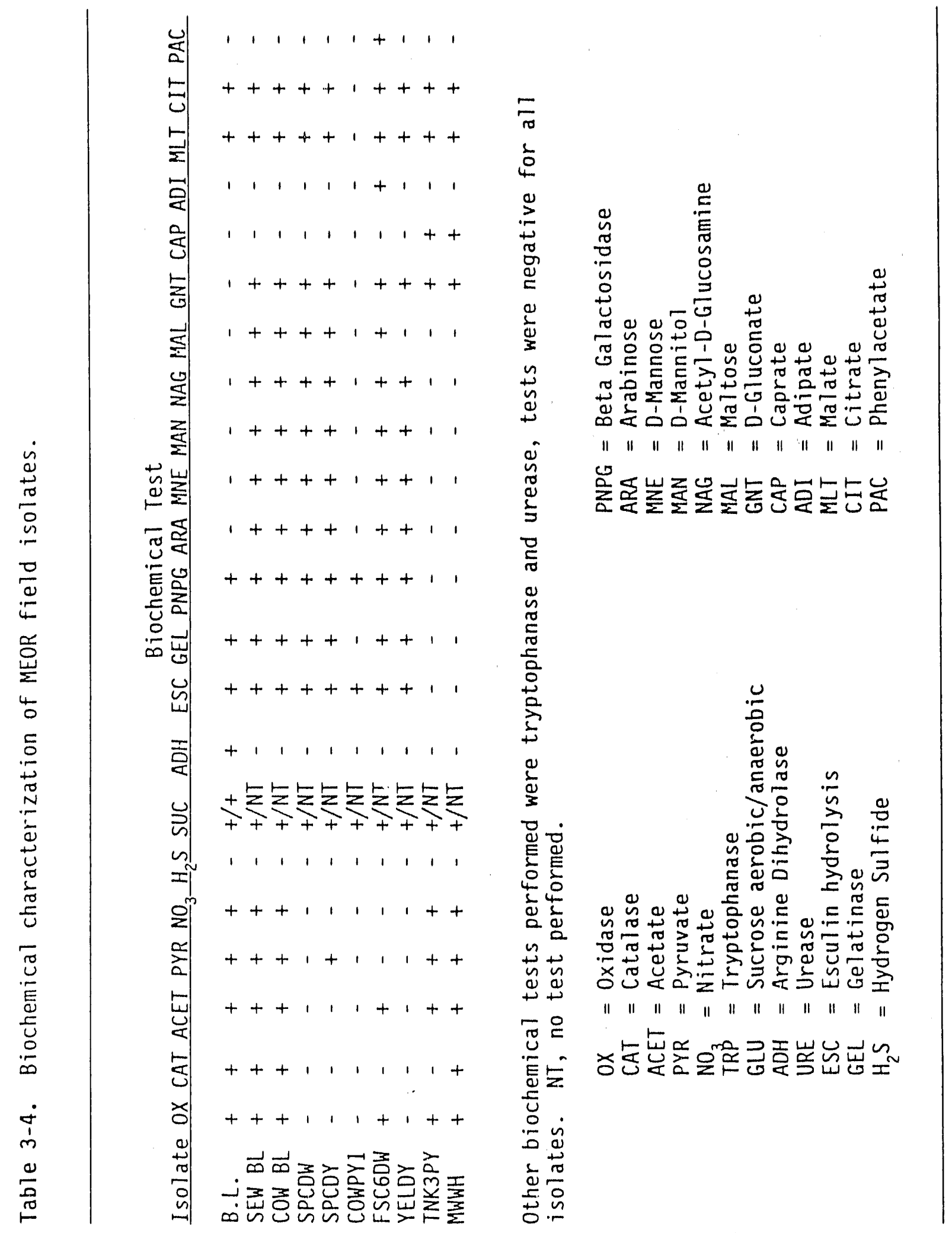


Experiments conducted to ascertain response to $\mathrm{pH}$ indicate Bacillus

licheniformis JF-2 will grow in a pH range from 6 to at least 8.5. Growth may occur at a $\mathrm{pH}>8.5$ but precipitation of media constituents at $\mathrm{pH} 9.0$ precluded data collection beyond this point.

The temperature, salinity, and $\mathrm{pH}$ data for Bacillus Iichentformis JF-2 when grown in Media E (1502) indicate the organism will most 11kely be adaptable to the reservoir environment of the Minnelusa Sands in the Powder River Basin, WY. The primary MEOR metabolite of the organism, a surfactant, has been discussed in the literature ${ }^{2}$ and reported to function well at the reservoir conditions of the Powder River Basin, WY. Optimal surfactant activity was reported to occur at salinities $>4 \%$ and temperatures of $50^{\circ} \mathrm{C}$. The salinity of the Moorcroft West Unit is about 2.8\% and appears to be increasing. Concentrations of $\mathrm{Ca}^{++}$at $7 \mathrm{w \%} / \mathrm{v}$ are reported to decrease surfactant activity compared to concentrations of 2 and $10 \%$. The $\mathrm{Ca}^{++}$concentrations in the Moorcroft West Unit in the Minnelusa Sands in the Powder River Basin are in the range of $0.10 \pm 0.006 \%$ (personal communication, Julie Smith TIORCO Inc.).

\subsubsection{Growth of Bacillus licheniformis JF-2 for Coreflood Experimentation}

Organisms used in core flood experimentation (Bacillus licheniformis JF-2) were routinely grown by inoculating $50 \mathrm{~mL}$ Media $\mathrm{E}$ (1502, supplemented with $1 \%$ sucrose and $2.4 \% \mathrm{NaCl}$, see Subsection 3.2) with $100 \mu \mathrm{L}$ of a fresh overnight culture (trypticase soy broth). Incubation was conducted aerobically at $30^{\circ} \mathrm{C}$ until the cultures reached an optical density of $1.0 \pm 0.15$. The cells were harvested by centrifugation $(3000 \mathrm{rpm} \times 10 \mathrm{~min}$ at room temperature, Sorval1 rotor SS34) and resuspended in fresh Media $E$ (1502) with sucrose $(1.0 \%)$ and $\mathrm{NaCl}(2.5 \%)$ added. This procedure was followed to allow differentiation between metabolic products produced outside of the core and those metabolites produced in the core. Under this regiment, only the cells themselves were used for inoculum and therefore oil displacement that occurred was caused by either in situ production of metabolic products or the physical presence of bactcinial cells. Cells were injected into epoxy coated Berea sandstone cores using a $6 \mathrm{~mL}$ accumulator operated at $1.5 \mathrm{~mL} / \mathrm{h}$. 
Where noted, unwashed cells (cells plus metabolites liberated in culture) were used for comparitave experimentation.

\subsubsection{Scanning Electron Microscopy (SEM) of Berea Sandstone Cores}

Spactal distribution of Bacillus Itcheniformis JF-2 in Berea sandstone cores following microbial flood experiments was analyzed with SEM. Controls for SEM experiments were coarse (permeability 300 to $500 \mathrm{md}$, Figure 3-5) and fine (permeability 100 to $300 \mathrm{md}$, Figure 3-6) virgin Berea sandstone and 011 coated Berea sandstone cores (Figure 3-7) that had been previously waterflooded to residual oil (Schuricht crude). The SEM of microbial coreflood experiments was performed after the core had been waterflooded for production following a microbial flood. The core was broken into three distinct regions, the inlet (Figure 3-8), mid section (Figure 3-9) and the outlet (Figure 3-10).

The SEM was performed with an AMRAY scanning electron microscope. All samples (biotic and abiotic) were treated the same. Small pieces (5 to $10 \mathrm{~mm}$ ) of material were broken from larger core elements and placed in $4 \%$ glutaraldehyde in Sorensens buffer (phosphate buffer, pH 7) and allowed to fix for $4 \mathrm{~h}$. The samples were then washed $5 x$ in the buffer and transferred to a $1 \%$ osmium tetroxide (in Sorensens buffer) and allowed to stand for $2 \mathrm{~h}$. Each sample was placed on a standara SEM aluminum stub and glued in place using silver paint. The samples were then coated with a thin layer of gold (75 $A$ ) to ensure conductivity.

Although organisms were found to be distributed completely through the core (Figures 3-8, 3-9,3-10), a predominance of organisms were found in the region distal to injection (Figure 3-10). Based on the size of the cells, it is hypothesized that spores and germinative cells are present. It is not known if the cells were committed to sporulation before they were injected or if the cells sporulated once inside the core. 


\subsubsection{Surfactant Production by Bacillus licheniformis JF-2}

Bactllus lichentformis JF-2 was proven to produce a surfactant when grown on minimal Media $E$ (1502) in the presence of sucrose. Interfactal tensions were measured on cell free supernatants using various crude olls as the organtc phase. The production, characterization, and IFT measurements of Bactllus licheniformis JF-2 surfactant is presented and discussed in Section 4.

\subsubsection{Polymer Production by Bactllus lichentformis uF-2}

Levan production by Bacillus Iicheniformis strain NRC 9012 has been previously reported in the literature. ${ }^{10}$ Levan, B-D-fructofuranose 1inked primarily 2,6 with branched chains 1inked 2,1, ${ }^{11}$ produced by Bacillus licheniformis strain $\mathrm{JF}-2$ has been demonstrated. Initial experiments were conducted aerobically at $30^{\circ} \mathrm{C}$ in Media $\mathrm{E}$ (1502) supplemented with $0.5 \%$ sucrose. Cultures, abiotic controls, and abiotic media + levan were incubated for $7 \mathrm{~d}$.

Levan was isolated with modifications based on the procedure of Leeper. ${ }^{12}$ Ice cold methanol was added to the cultures as a three fold excess $(\mathrm{V} / \mathrm{V})$ and allowed to stand ai $4^{\circ} \mathrm{C}$ overnight. The insoluble material was harvested by centrifugation at 2,000 rpm (International table top centrifuge) for $10 \mathrm{~min}$ at room temperature. The supernatant was discarded and the pellet was overlaid with pyridine and agitated to mix. The insol ible material was harvested as above and brought up in distilled water. Levan concentrations were ascertained by a spectrophotometric assay based on the ability of hydrolyzed levan (fructose) to reduce 3,5-dinitrosalicylic acid to a colored product. ${ }^{13}$ $500 \mu \mathrm{L}$ of the isolated material was added to $1.0 \mathrm{~mL}$ of $1.0 \mathrm{M}$ oxalic acid and incubated at $100^{\circ} \mathrm{C}$ for $30 \mathrm{~min}$ to facilitate hydrolysis. Following hydrolysis, $100 \mu \mathrm{L}$ of the sample was reacted with $1.0 \mathrm{~mL}$ of 3,5-dinitrosalicylic acid for $10 \mathrm{~min}$ at $100^{\circ} \mathrm{C}$. Samples were analyzed spectrophotometrically at $590 \mathrm{~nm}$. Net levan production was calculated based on the difference between hydrolyzed and unhydrolyzed samples. Previous experiments indicate no difference between glucose and fructose with respect to reduction of 3,5-dinitrosalicylic acid to its colored product under nonhydrolyzing or hydrolyzing conditions (data not shown). 
Although polymer production was nominal, research will continue to elucidate the importance of production under field conditions in conjunction with surfactant.

\subsection{Drscussron}

Development of an understanding on the mechanisms by which microbial systems displace 011 under reservoir conditions through such avenues as core flooding and other laboratory techniques will be a significant contribution to EOR technology and specifically MEOR technology. The mechanisms of MEOR are not fully understood or specifically known for a wide variety of reservoir conditions, crude 0ils, microbial, and nutrient systems. Bacteria that have characteristics such as the capability to emulsify crude oils and lower IFT are ideal candidates for improved oil recovery. Organisms that have the ability to produce acids or gas or both and organisms that are capable of asphaltic degradation are also significant to the techrology and are presentiy being collected, isolated, and characterized for application in EOR research activities.

The utilization of Bacillus licheniformis JF-2 as a benchmark organism has allowed the selection of promising microbial isolates with selected phenotypic and genotypic properties to facilitate MEOR as well as providing for a systematic comparison of the effects of different $0 i 1$ characteristics. 


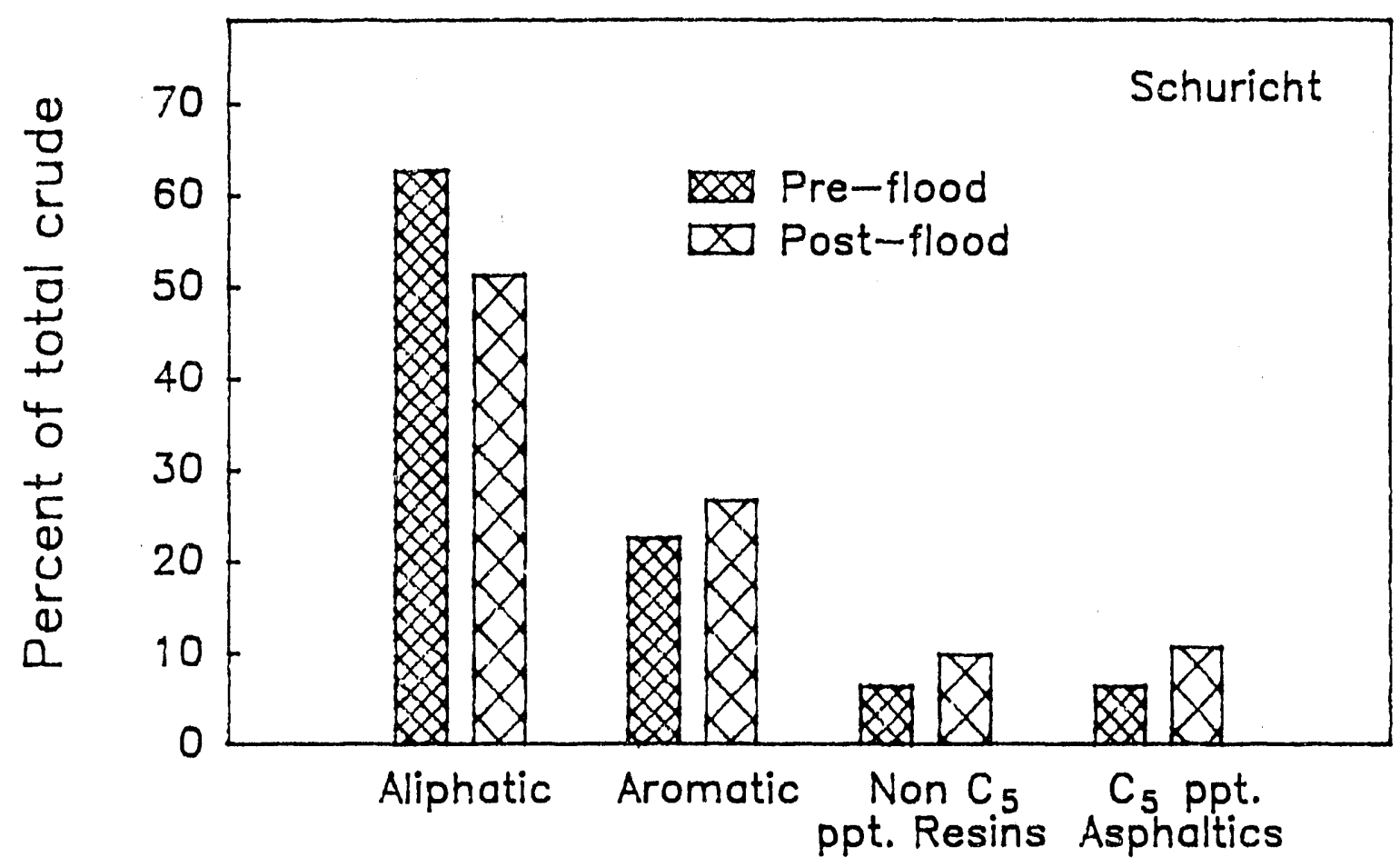

Figure 3-1a. Comparison of pre- and post-flood (microbial) chromatoaraphy fractions, Schuricht crude. 


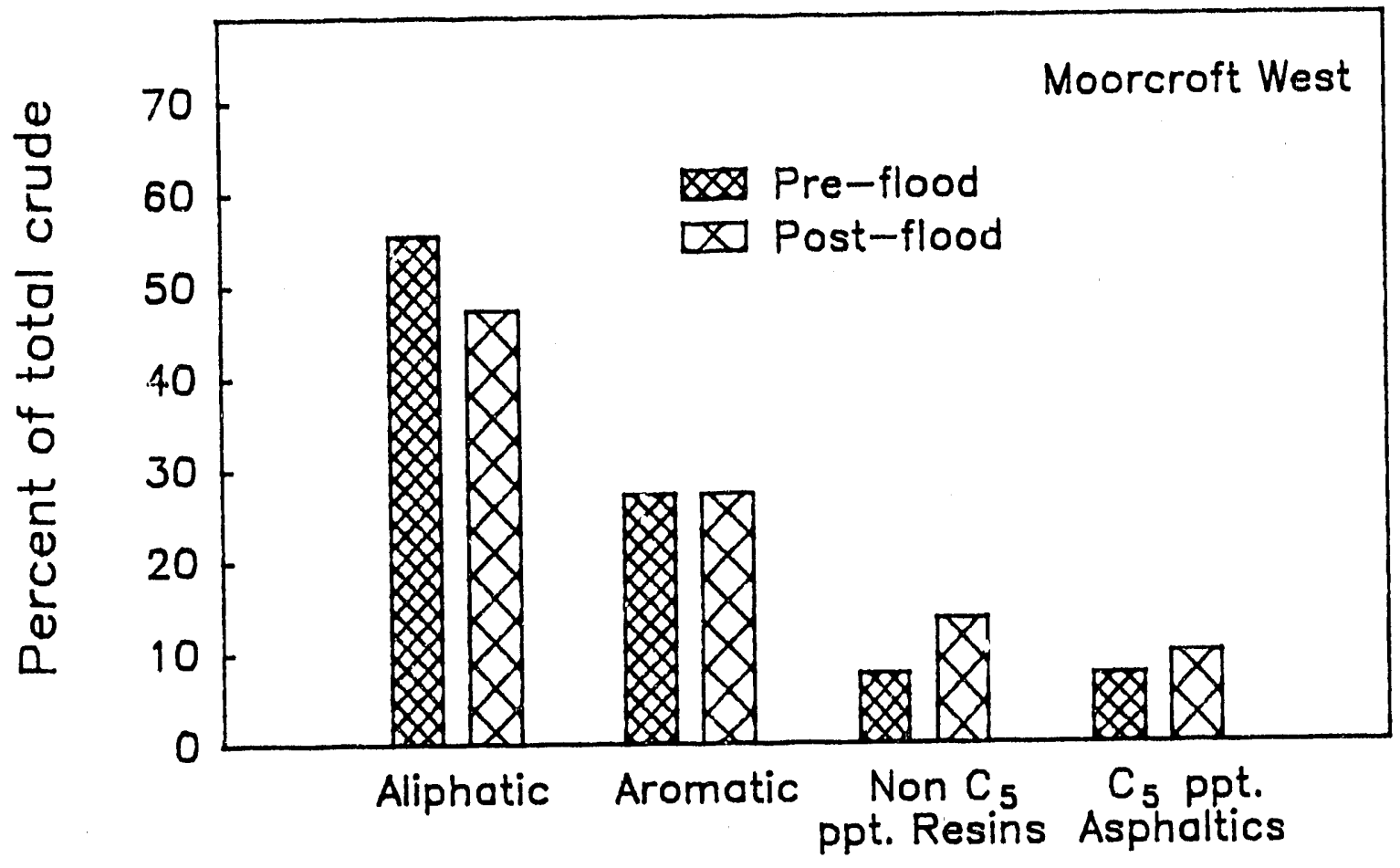

Figure 3-1b. Comparison of pre- and post-flood (microbial) chromatography fractions, Moorcroft West crude. 


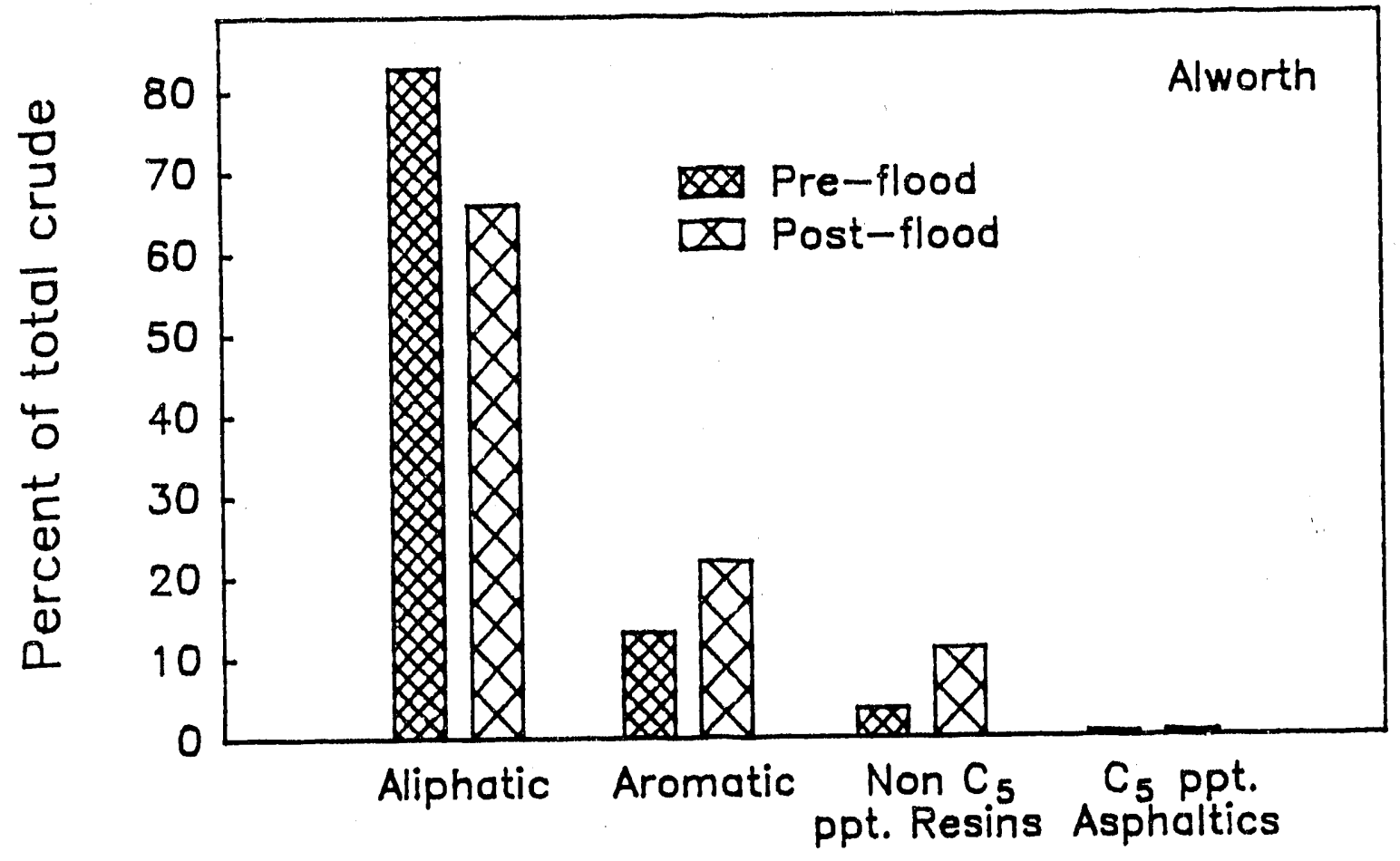

Figure 3-1c. Comparison of pre- and post-flood (microbial) chromatography fractions, Alworth crude. 


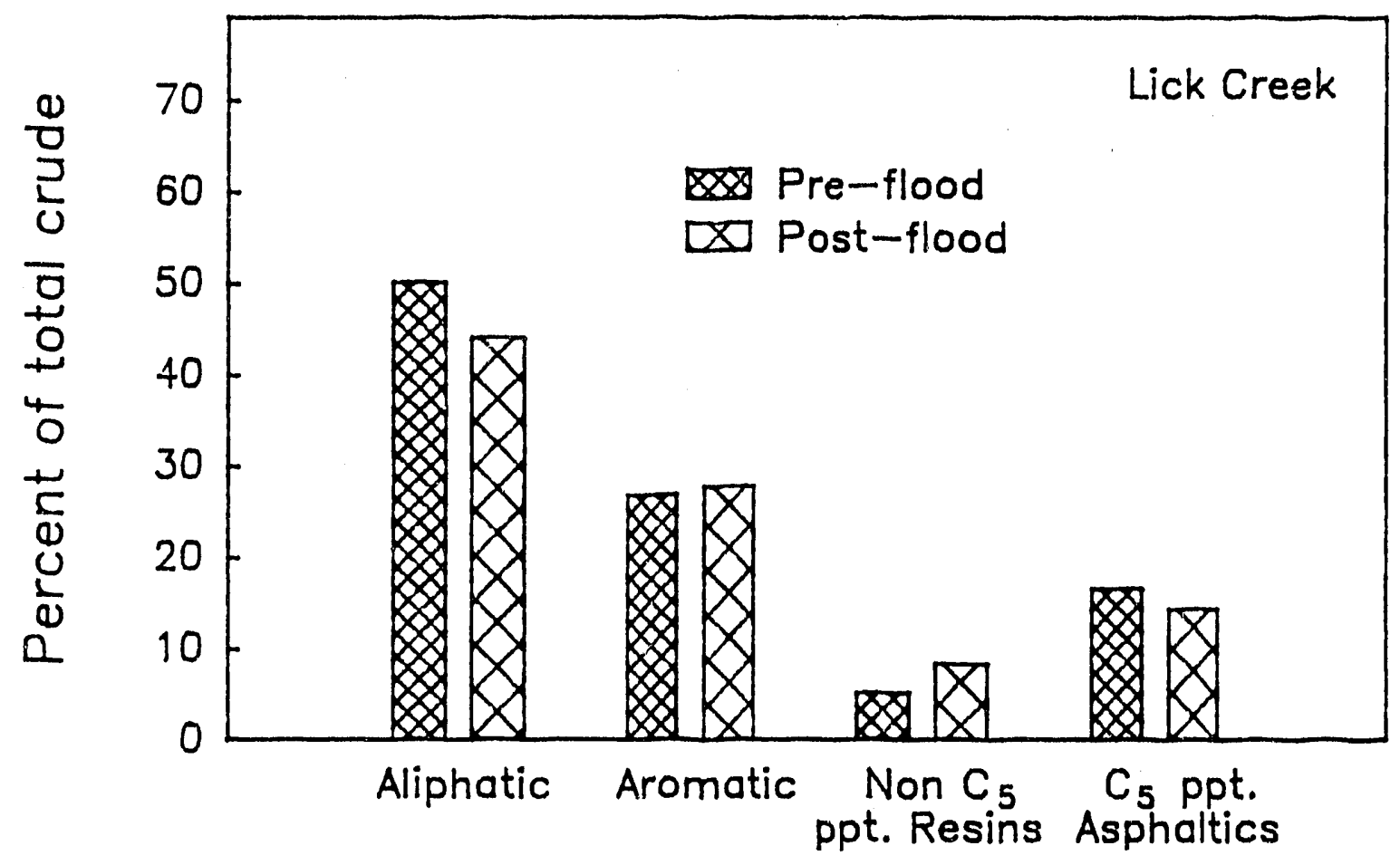

Figure 3-1d. Comparison of pre- and post-flood (microbial) chromatography fractions, Lick Creek crude. 


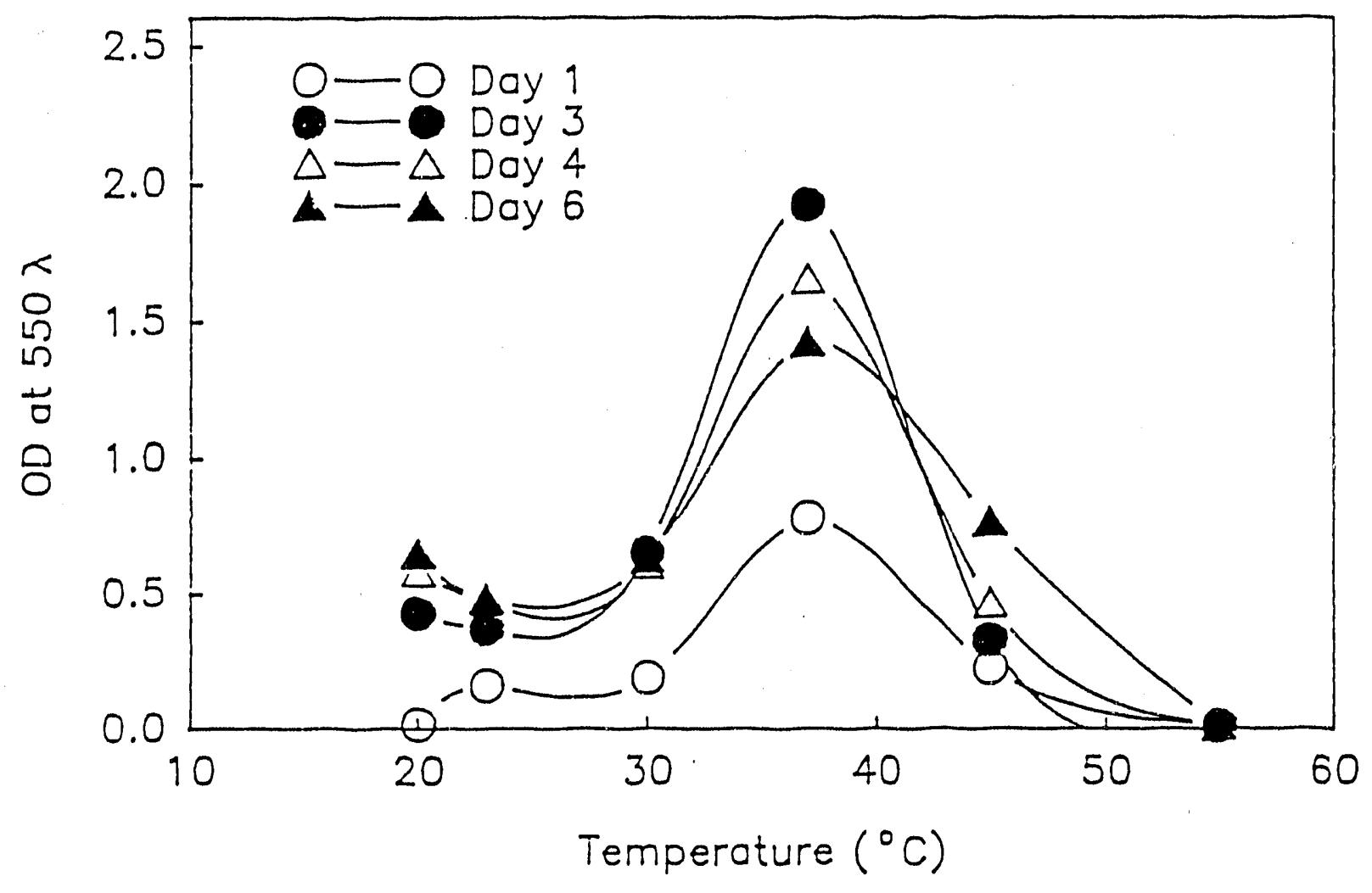

Figure 3-2. Growth response of Bacillus licheniformis JF-2 as a function of temperature. 


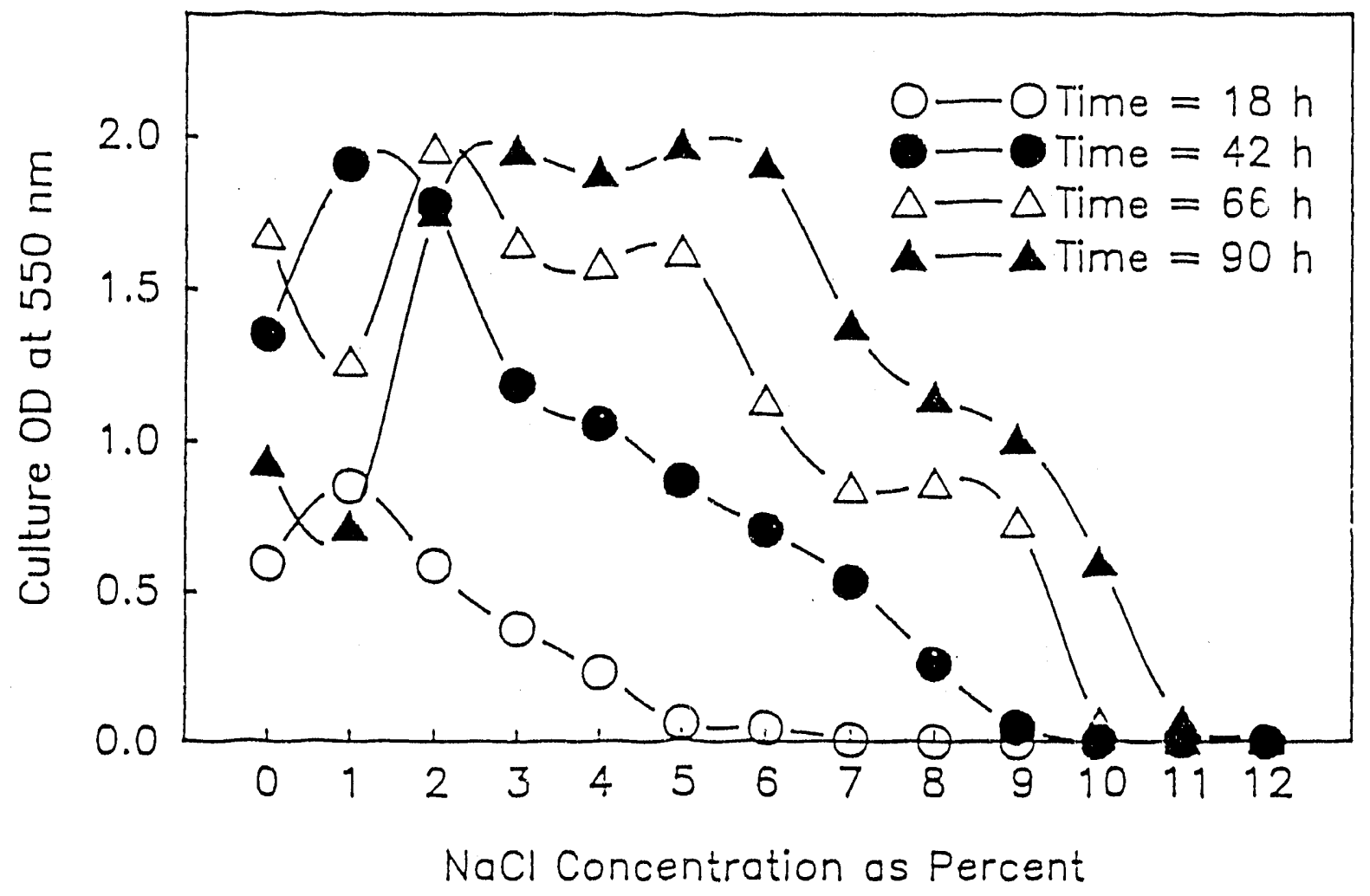

Figure 3-3. Growth response of Bacillus licheniformis JF-2 as a function of salt $(\mathrm{NaCl})$ concentration. 


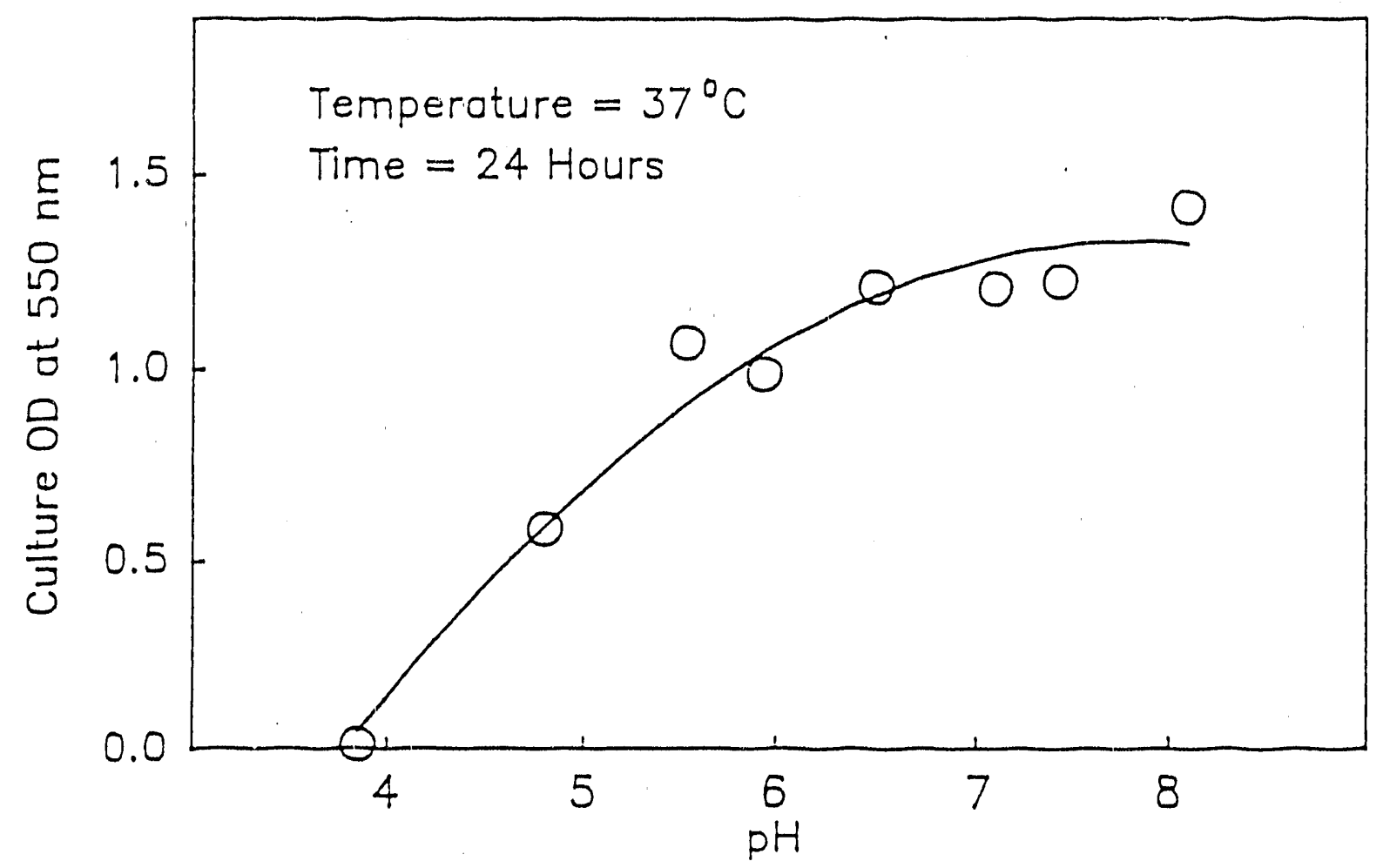

Figure 3-4. Growth response of Bacillus licheniformis JF-2 as a function of $\mathrm{pH}$. 


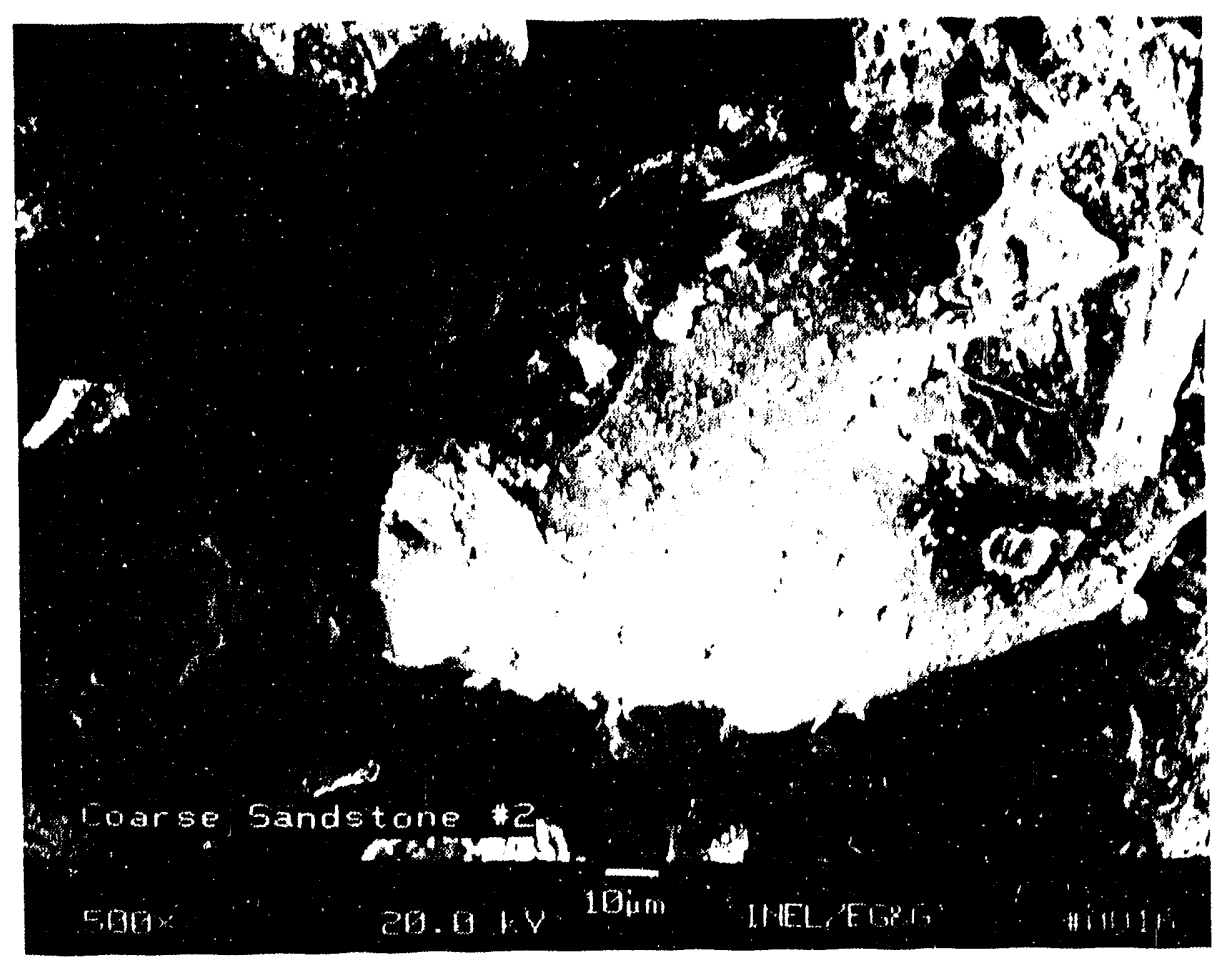

Figure 3-5. Scanning electron micrograph of virgin coarse $(300$ to $500 \mathrm{md}$ permeability) Berea sandstone. 


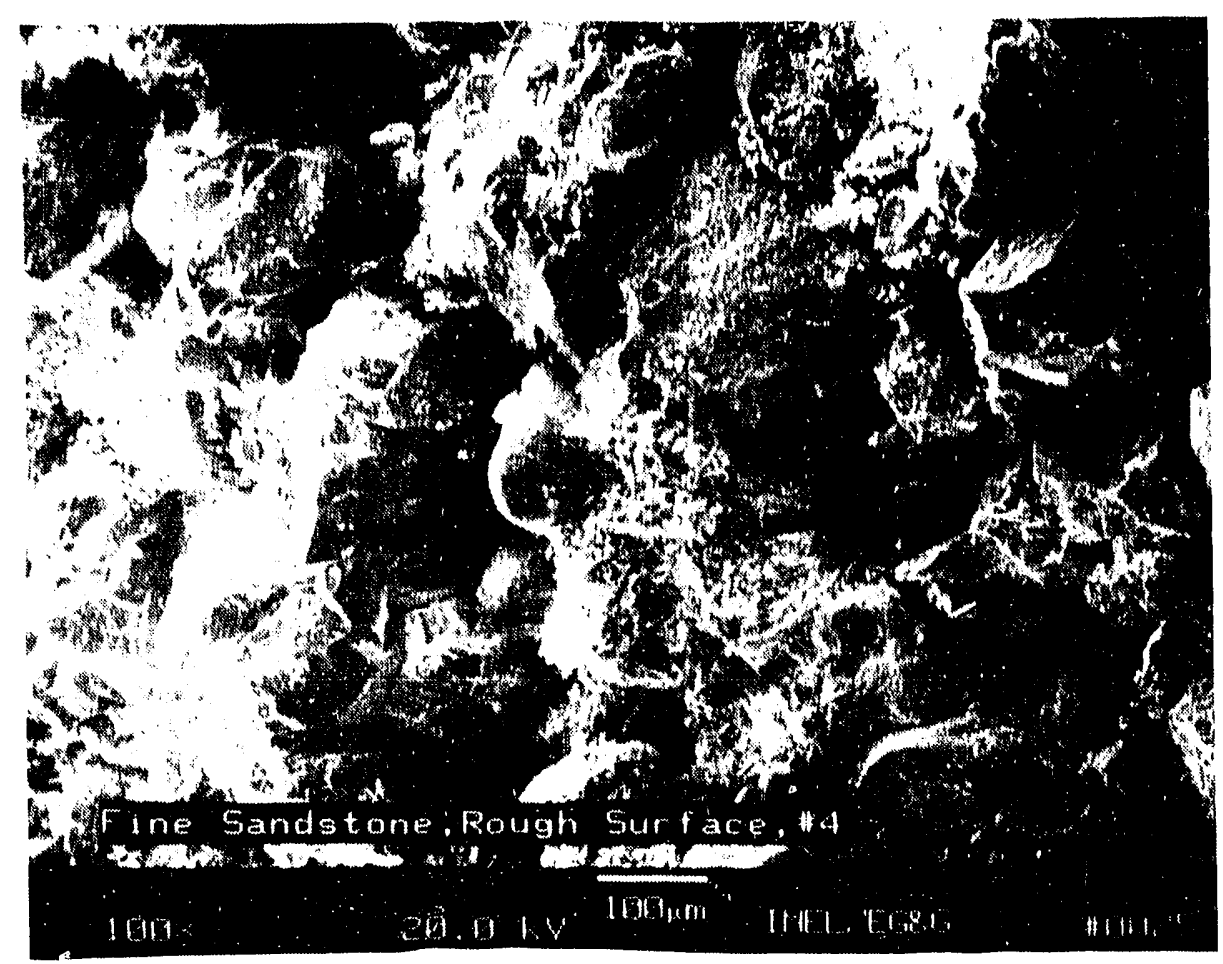

Figure 3-6. Scanning electron micrograph of virgin fine (100 to $300 \mathrm{md}$ permeability) Berea sandstone. 


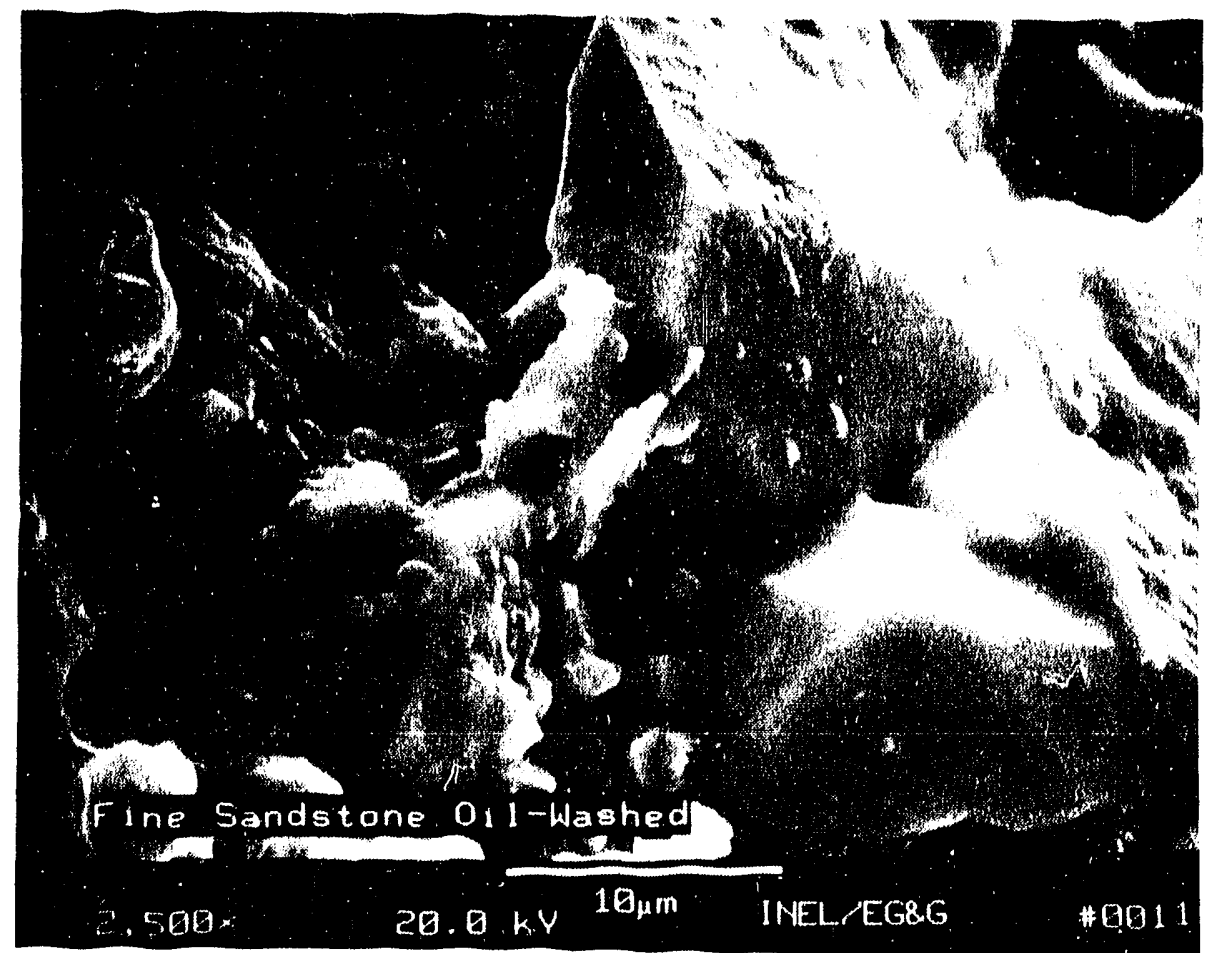

Figure 3-7. Scanning electron micrograph of oil coated (Schuricht) fine (100 to $300 \mathrm{md}$ permeability) Berea sandstone. 


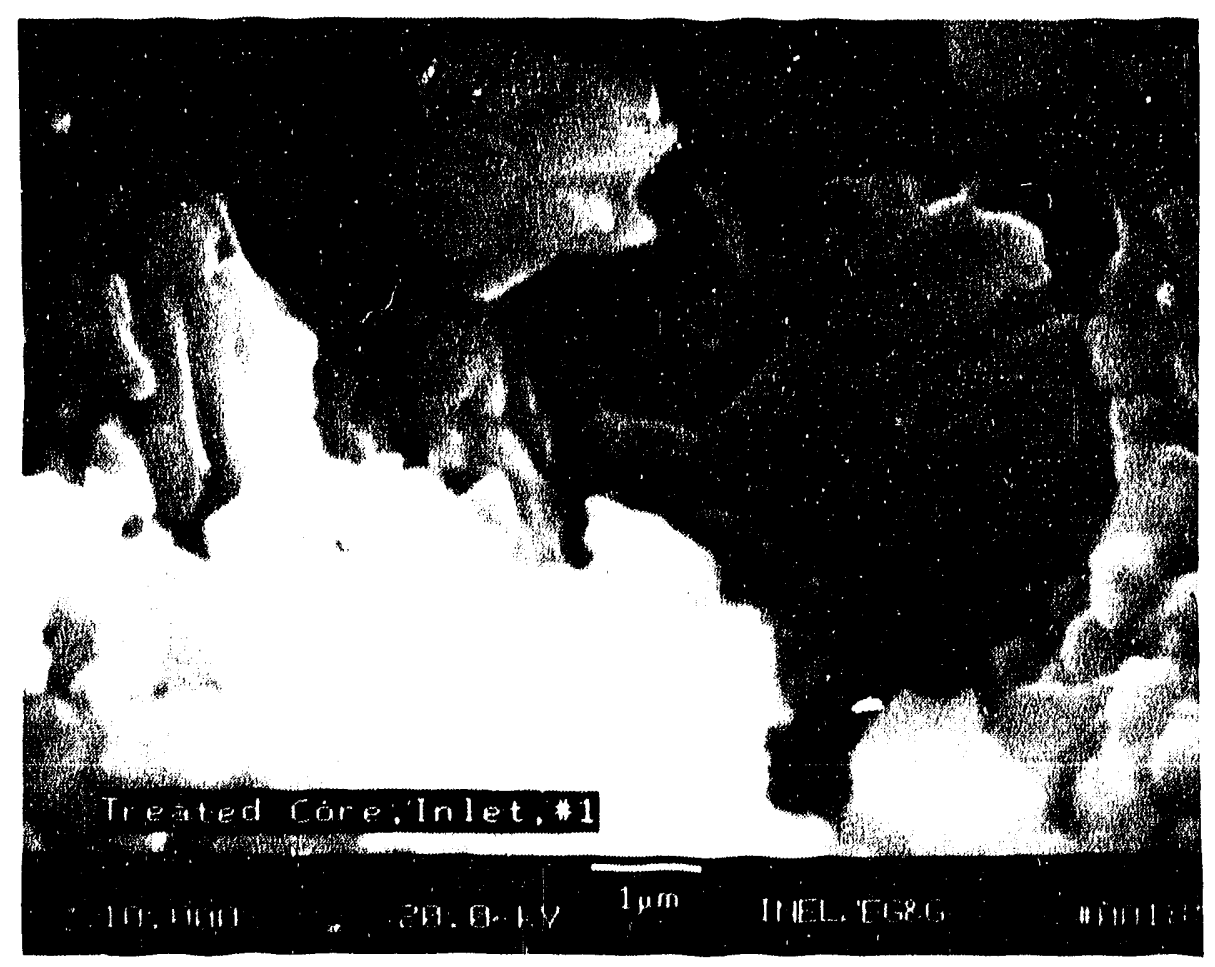

Figure 3-8. Scanning electron micrograph (inlet region) of a Berea sandstone core (fine) obtained from a microbial (Bacillus licheniformis JF-2) coreflood experiment. Schuricht crude at water flood residual. 


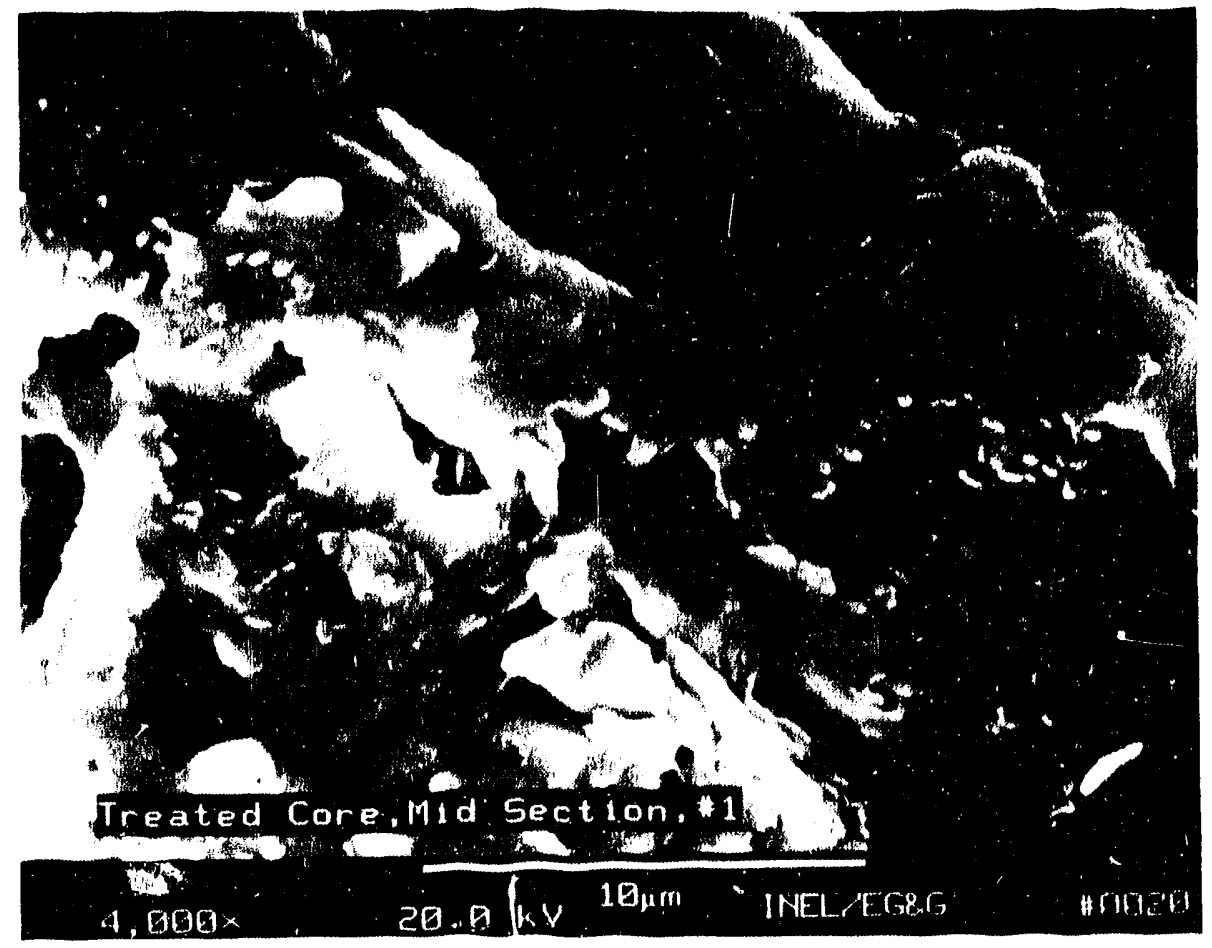

Figure 3-9. Scanning electron micrograph (mid region) of a Berea sandstone core (fine) obtained from a microbial (Bacillus licheniformis JF-2) coreflood experiment. Schuricht crude at water flood residual. 


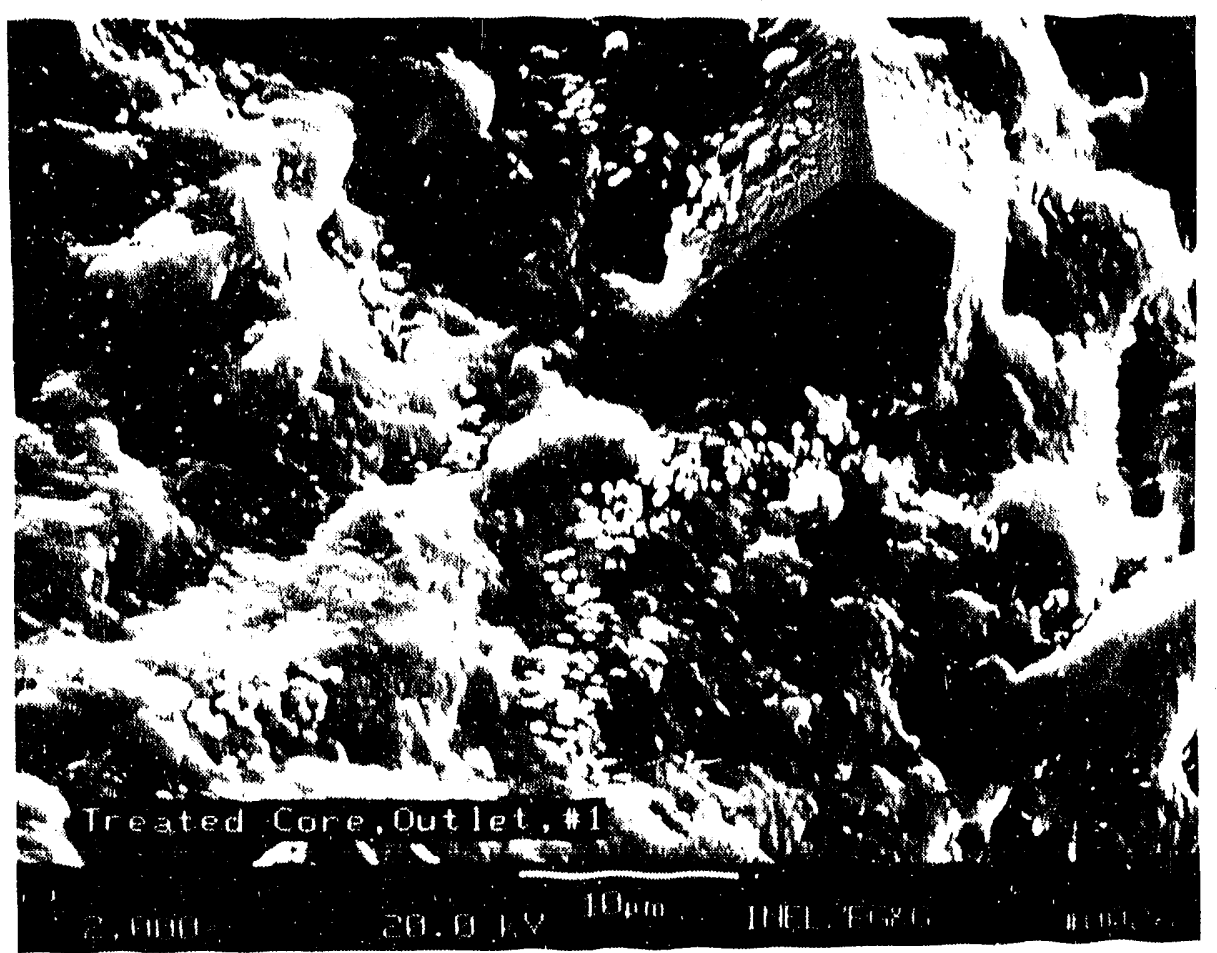

Figure 3-10. Scanning electron micrograph (outlet region) of a Berea sandstone core (fine) obtained from a microbial (Bacillus licheniformis JF-2) coreflood experiment. Schuricht crude at water flood residual. 


\subsection{References}

1. ATCC Catalog of Bacteria and Bacteriophages $17^{\text {th }}$ edition. $1989 \mathrm{pp} .32$.

2. M. J. McInerney, M. Javaheri, and D. P. Nagle, Jr. "Properties of the Biosurfactant Produced by Bacillus licheniformis Strain JF-2", Journal of Industrial Microbiology, 1990, 5:95-102.

3. M. Javaheri, G. E. Jenneman, M. J. McInerney, and R. M. Knapp, "Anaerobic Production of a Biosurfactant by Bacillus 11cheniformis Strain JF-2", Applied and Environmental Microbiology, 1985, 50:698-700.

4. R. S. Bryant, T. E. Burchfield, Microbial-Enhanced Waterflooding: Mink Unit Project, SPE/DOE \#17341, 1988.

5. ATCC Catalog of Bacteria and Bacteriophages $17^{\text {th }}$ edition. $1989 \mathrm{p} .357$

6. D. 0. Hitzman, "Petroleum Microbiology and the History of Its Role in Enhanced 011 Recovery", Proceedings of the 1982 International Conference on Microbial Enhanced 0il Recovery, Afton, OK, May 16-21, DOE Conf. 8205140, pp. 162-218.

7. G. Reed, Prescott \& Dunn's Industrial Microbiology, $4^{\text {th }}$ ed., Westport, Connecticut: AVI Publishing, Inc., 1983, p. 597.

8. M. Rosenberg, "Bacterial Adherence to Hydrocarbons: a Useful Technique for Studying Ce11 Surface Hydrophobicity", FEMS Microbiol. Lett. 9:29-33

9. M. Hayat, Principles and Techniques of Electron Microscopy, Vol. I Van Nostrand Reinhold Co.

10. J. A. Ramsay, G. G. Cooper, R. J. Neufeld, "Effects of 011 Reservoir Conditions on the Production of Water-Insoluble Levan by Bacillus licheniformis", Geomicrobiology Journal, 1989, 7:155-165.

11. P. M. Collins, Carbohydrates, London, New York: Chapman and Ha11, 1987, p. 317.

12. S. A. Leeper, H. J. Hatcher, K. B. Barrett, D. E. Engelgau, "Production of Levan, A Homopolymer of Fructose, From Sucrose in an Ultrafiltration Bioreactor", Blotechnology Letters. Submitted for publication.

13. M. F. Chaplin, J.F. Kennedy, 2.2.2, Dinitrosalicylic Acid Assay, Carbohydrate Analysis, 0xford, Washington DC: IRL Press, 1986 p. 3. 


\section{MEASUREMENT OF INTERFACIAL TENSIONS}

About $2 / 3$ of the oil that has been discovered remains trapped in the ciriginal reservoir. This oi: is trapped by capillary forces in the pore structure of the formation and is resistant to displacement by waterflooding techniques. Capillary fcrces between the $0 i 1$ and formation water determine the pressures needed to displace the oil from the rock. The pressure required to displace this oil is higher than can be gererated in secondary waterflood oil recovery operations. The pressure requirement can be lowered if the interfacial tension between the $0 i 1$ and water (typically $30-40 \mathrm{mN} / \mathrm{m}$ ) is lowered. Calculations using models of trapped $0 i 1$ have estimated that interfacial tension: lower than $0.1 \mathrm{mN} / \mathrm{m}$ are needed for improved $0 i 1$ recovery. $1,2,3,4$ Interfacial tension (IFT) is defined as the minimum amount of work required to create the boundary between two immiscible phases, such as oil and water. Ultralow IFTs (about $10^{-3} \mathrm{mN} / \mathrm{m}$ ) are capable of mobilizing the oil trapped by capillary forces. Lowering the IFT by use of surfactants (which align betwren the two phases at the boundary) decreases the pressure required to force a non-wetting phase (oil) through a small capillary. $0 i 1$ trapped in a reservoir can therefore be displaced by flooding the reservoir with a surfactant solution capable of lowering the IFT to the values required by the reservoir conditions.

Measurement of IFTs has been accomplished by a variety of methods, including pendant drop, $5,6,7$ sessile drop, ${ }^{8}$ ad spinning drop methods. The pendant or sessile drop methods of determining IFTs was first suggested by Worthingion ${ }^{10}$ and Ferguson. ${ }^{11}$ These methods place a drop of oil into a surfactant solution, and then measure the shape of the drop. All of these methods require difficult measurements to be performed on the drop that is formed. In the past, a photographic record was made of the drop size, and the measurements of drop shape were determined from this record. Current developments in personal computers coupled with the abilify to digitize video images makes it possible to automate the process, and to provide a faster means to determine the IFT. ${ }^{12,13,14}$ 


\section{1 Current Inel Interfacial Tension Measurement Technologi}

A simple automated system for measuring interfacial tensions using the sessile drop method has been developed at the INEL. ${ }^{15}$ The size and shape of a transparent or opaque drop of one fluid (crude oil) immersed in a second transparent fluid (surfactant solution) is displayed on a monitor with a CCD video camera. The video image is digitized and stored by a computercontrolled system. Custom software (developed at the INEL) determines various drop shape measurements and then computes the interfacial tension. The video image can be stored on the computer disk, or could be stored on video tape. In the sessile drop method, an outline of the drop is recorded and used to determine the IFT. The detailed theoretical derivations for the determination of the interfacial tension are given in different literature reports. ${ }^{16,17,18}$ The currently useú analysis utilizes an empirical procedure ${ }^{19}$ that defines a function, $S$, to determine the drop shape. The maximum diameter, de, of the drop is determined and then used in the determination of the horizontal dimension, ds, of the drop as shown in Figure 4-1. Using algorithms developed by Fordham, ${ }^{20}$ the IFT between the drop and the external solution can be estimated. The ratio of these two measurements, ds/de (called the drop shape factor, S) can be used to determine the IFT. The equation used to calculate the interfacial tension is given in Equation 1.

$$
\gamma=\Delta \rho \cdot g \bullet\left(\frac{d e^{2}}{H}\right)
$$

where

$$
\begin{aligned}
& \gamma=\text { interfacial tension } \\
& \Delta p=\text { density difference of the two liquids } \\
& g=\text { gravitational acceleration } \\
& \text { de }=\text { maximum diameter of drop } \\
& H=\frac{1}{0.312 \cdot S^{-2.64}} .
\end{aligned}
$$

The relationship between the drop shape factor $S$ and the IFT has been quantified in a look-up table resident in the computer. 
The complete IFT system consists of four major components: illumination, drop forming cell, video camera, and computer. These subsystems are described below.

The droplet cell is illuminated from behind so that the image of an opaque drop is black on a white background. Transparent drops appear as dark outlines surrounding a lighter interior caused by lensing effects. A fiber optics illumination system is used to provide the background light. The fiber optics source is desirable because of the reduced heating effects on the droplet cell and simplified mounting design. A ground glass diffusion lens is used to ensure uniform illumination of the drop.

The droplet forming cell has two windows and holds the surfactant solution to be tested (see Figure 4-2). The cell is backlit by the illumination system. For simplicity and cost, the windows are standard microscope slides. The windows can be easily removed for cleaning or can be replaced when contaminated. About $7 \mathrm{~mL}$ of surfactant solution is used in the test procedure. The crude oil is introduced into the cell through an injector situated at the bottom of the cell. External to the cell is a micrometer driven syringe used to inject a drop of oil (or other fluid) into the cell. In the sessile version, the drop floats above and is attached to the injector. The drop can be formed to any desired size (up to the buoyant release point) and the drop size and shape recorded. It is possible to record the sequence of such data with a video recorder while the drop is growing or changing shape because of equilibration or after terminal volume is reached.

The latest versions of the cell permits temperature control by flowing heated or cooled water through channels in the metal frame of the cell. Cells have been redesigned with a smaller path length in addition to the temperature control feature to permit IFT measurements of turbid bacterial cultures containing biosurfactants. These turbid bacterial cultures are translucent instead of transparent.

Various video cameras and lenses were used in developing the systen. The current camera utilized is a Cohu model 6515 CCD camera with external controls 
of gamma, black level, and AGC. Extension tubes provide various magnification ranges as required by different drop diameters (see Figure 4-3). Sensor pixe1 count and magnification are chosen so that one obtains at least 200 pixels across the minimum dimension to be measured. The goal is to have measurements of at 1 east $1 \%$ precision.

A PC based system was selected to control the video system and to perform the calculations. An IBM-AT personal computer was equipped with a Data Translation DT2853 video frame digitizer board. The computer controls data acquisition, computation, and display functions. An auxiliary video monitor displays the video image output by the DT2853. If desired, a video cassette recorder can be used to record longer image sets for later evaluation.

The suftware is designed to control the video frame digitizer and to acquire, reduce, and display the data. It uses commercially available Data Translation DT-IRIS device drivers. The software is a combination of Specifically developed routines intermixed with the DT-IRIS driver routines. The user interacts with the program by depressing special function keys indicated by the displayed menus. Among the functions available are calibration, video adjustments, and plots of video intensity. Other options include saving and restoration of video images or of reduced data and printing of IFT data and of two-dimensional blocks of pixel intensities centered on a user selected image point.

Before an actual series of tests, a calibration object consisting of a sphere of known diameter comparable to that expected for the drop is installed in the test cell (see Figure 4-4). An automated calibration procedure computes the number of pixels per millimeter at the object in both the $x$ and $y$ axes. These calibration values are used to convert all pixel measurements into actual dimensions. In wolit the calibration process and the interfacial tension measurements, the edge of the drop image is fit with a second order polynomial surve so that subpixel locations can be determined. The operator generates a drop of the test liquid in the cell and then adjusts the focus, magnification, and illumination to match predetermined criteria (see Figure 4-5). When the sample has equilibrated, an automated data acquisition and data reduction 
process is initiated. The system acquires a video image of the drop, then locates the maximum horizontal diameter, de, and the top of the drop. These values are then used to locate and measure the drop diameter ds. The program requests certain physical properties of the test fluids (density difference), then computes the IFT of the system.

\subsection{Interfacial Tension Measurements}

Bacillus licheniformis JF-2 is a known surfactant producing organism. The IFTs on culture supernatants of Bacillus licheniformis JF-2 (see Subsection 3.3.2 for growth parameters) were determined using various crude oils as the organic phase. The calibration of the tensiometer was verified using $n$ butanol/water and $n$-hexane/water, which have interfacial tensions of $1.8 \mathrm{mN} / \mathrm{m}$ at $20^{\circ} \mathrm{C}^{21}$ and $51.1 \mathrm{mN} / \mathrm{m}$ at $20^{\circ} \mathrm{C}^{22}$, respectively.

\subsubsection{Calibration of Interfacial Tensiometer}

Systems of known interfacial tensions were used to verify the accuracy of the system calibration. The system was verified to $1.8 \mathrm{mN} / \mathrm{m}$ using a system consisting of nano-pure water and $n$-butanol at $22.3^{\circ} \mathrm{C}$ following video calibration with 0.0625 and 0.1564 in. calibration standards. The IFT measurements were made using $0.22 \mu \mathrm{m}$ capillary tubing $(0.0625$ in. calibration ba11) and 0.0625 in. tubing ( 0.1564 in. calibration ba11). Data for the $n$-butanol system are given in Table 4-1. The system calibration was verified to an interfacial tension of $51.1 \mathrm{mN} / \mathrm{m}$ using nano-pure water and $n$-hexane at $22.3^{\circ} \mathrm{C}$ following video calibration with a 0.1564 in. calibration ball with $0.0625 \mathrm{in.}$ tubing. These data are given in Table 4-2.

\subsubsection{Determination of CMC for Bacillus licheniformis JF-2 Biosurfactant}

Bacillus licheniformis JF-2 was grown as delineated in Slibsection 3.4 .2 and the resulting cell free supernatant was used in a dilution experiment to determine the critical micelle concentration (CMC) of the biosurfactant. Schuricht crude was used as the organic phase. No effort was made to purify 
Table 4-1. IFT measurements for $n$-butanol/water $\left(1.8 \mathrm{mN} / \mathrm{m} \odot 20^{\circ} \mathrm{C}\right)$ systems (measurements made $022.3^{\circ} \mathrm{C}$ )

Trial IFT Calibratictistol Trial IFT Calibration Std.

$\begin{array}{llllll}1 & 1.9107 & 0.0625 & 1 & 1.3690 & 0.1564 \\ 2 & 1.9466 & 0.0625 & 2 & 1.8869 & 0.1564 \\ 3 & 1.9104 & 0.0625 & 3 & 1.9696 & 0.1564 \\ 4 & 1.9203 & 0.0625 & 4 & 1.8619 & 0.1564 \\ 5 & 1.8918 & 0.0625 & 5 & 1.9079 & 0.1564 \\ 6 & 1.7387 & 0.0625 & 6 & 1.8084 & 0.1564 \\ 7 & 1.8362 & 0.0625 & 7 & 1.9335 & 0.1564\end{array}$

a. Average $=1.8792 \mathrm{mN} / \mathrm{m}$, standard deviation $= \pm 0.0706 \mathrm{mN} / \mathrm{m}$.

b. Average $=1.8196 \mathrm{mN} / \mathrm{m}$, standard deviation $= \pm 0.2052 \mathrm{mN} / \mathrm{m}$.

Table 4-2. IFT measurements for $n$-hexane/water $\left(51.1 \mathrm{mN} / \mathrm{m} \mathrm{C} 20^{\circ} \mathrm{C}\right)$ system (measurements made $22.3^{\circ} \mathrm{C}$ )

Irial IFT Calibration Std. $^{\mathrm{a}}$ Irial IFT $^{\mathrm{a}}$ Calibration Std.

$\begin{array}{llllll}1 & 51.47 & 0.1564 & 8 & 48.96 & 0.1564 \\ 2 & 47.26 & 0.1564 & 9 & 47.91 & 0.1564 \\ 3 & 48.80 & 0.1564 & 10 & 47.20 & 0.1564 \\ 4 & 46.60 & 0.1564 & 11 & 47.61 & 0.1564 \\ 5 & 49.11 & 0.1564 & 12 & 45.69 & 0.1564 \\ 6 & 49.38 & 0.1564 & 13 & 48.08 & 0.1564 \\ 7 & 47.58 & 0.1564 & & & \end{array}$

a. Average $=48.12 \mathrm{mN} / \mathrm{m}$, standard deviation $= \pm 1.45 \mathrm{mN} / \mathrm{m}$. 
the biosurfactant and the resulting data could therefore more appropriately be labeled "CMC of cell free supernatant of Bacillus licheniformis JF-2". The CMC is taken as the inflection point of the curve. Graphical data are presented in Figure 4-6. The concentration of the undiluted biosurfactant produced under these conditions is 2.5 times the CMC.

\subsubsection{IFT Measurements of Bacillus licheniformis biosurfactant using various crude oils}

Cell free supernatants prepared from cells grown as delineated in Section 3.4.2 were used to establish IFTs relative to sterile Media E (1502). Without exception, the supernatants resulted in a decrease in IFT of about a factor of ten when tested against Moorcroft West, Schuricht, Alworth, and Lick Creek crude oils.

\subsection{Discussion}

A simple automated system to measure IFTs of two-phase liquid systems has been developed at the INEL. Data have been collected that proves validity of measurements between 1.8 and $51.1 \mathrm{mN} / \mathrm{m}$. Future efforts will center on lowering the limits of measurement through testing of systems with known IFTs. Although standardization experiments indicate a sensitivity to component purity and operator fidelity, it is believed that meaningful data have been (and can continue to be) generated with this instrument. U1tralow IFT measurements, in the $10^{-3} \mathrm{mN} / \mathrm{m}$ range, have been reported using pendant drops. ${ }^{16}$

Results from IFT experiments indicate a definitive lowering of IFTs of crude $0 i 1 /$ biosurfactant systems in comparison to crude $0 i 1 /$ Media $E$ controls. When Bacillus licheniformis JF-2 is grown as specified, the resulting surfactant (undiluted) is 2.5 times the CMC. Although IFTs in the $10^{-3} \mathrm{mN} / \mathrm{m}$ range are reported to be necessary for improved oil recovery, we believe the oil recovery mediated by Bacillus licheniformis JF-2 in experimental systems at the INEL to be surfactant mediated (see Section 5). The possibility of synergistic contributions of other cell mediated components, such as polymers, 
proteins, and biomass, cannot be overlooked. Future experiments will be designed to control these and other parameters. 


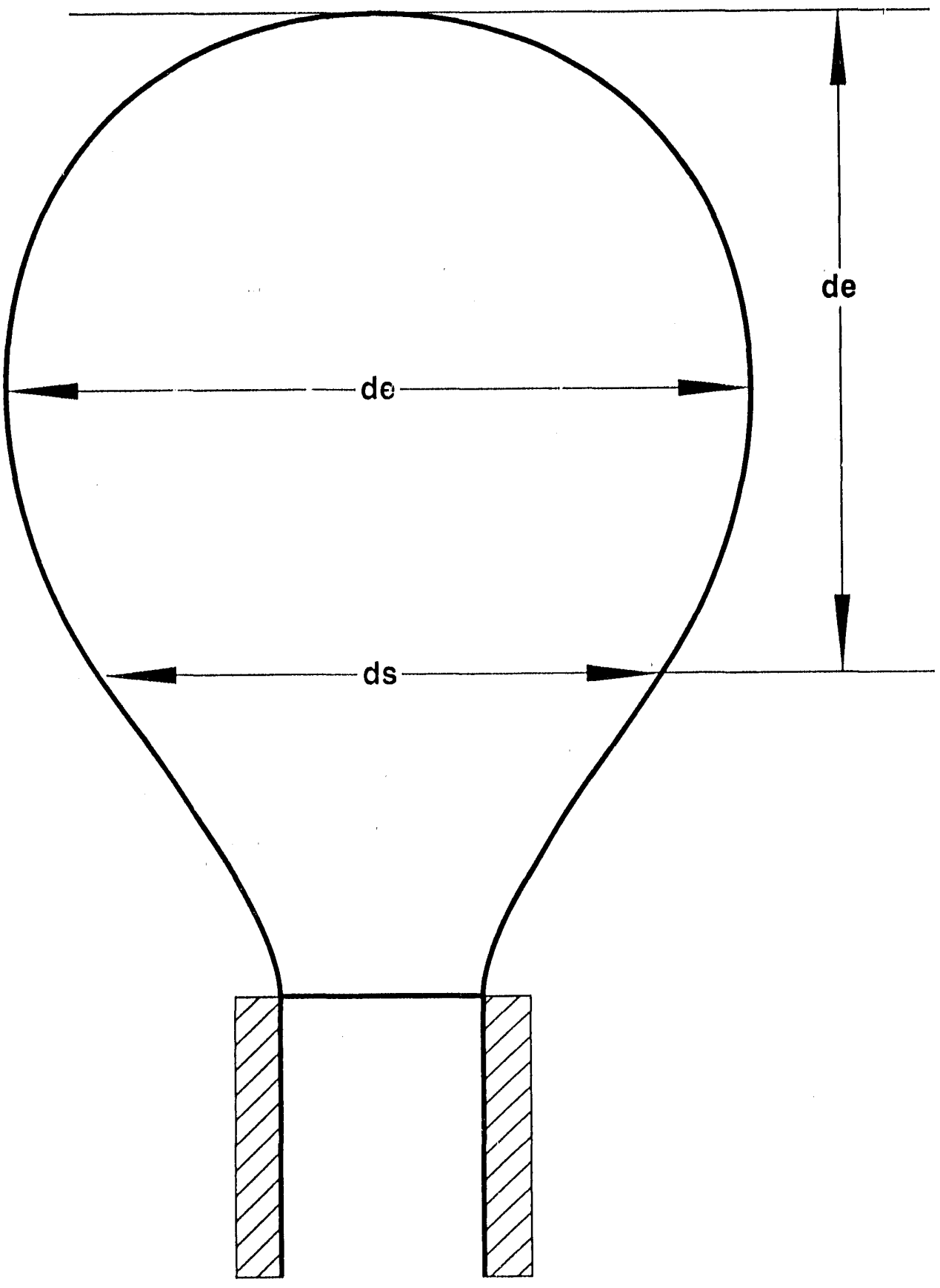

Figure 4-1. Critical dimensions used in calculating interfacial tensions. 


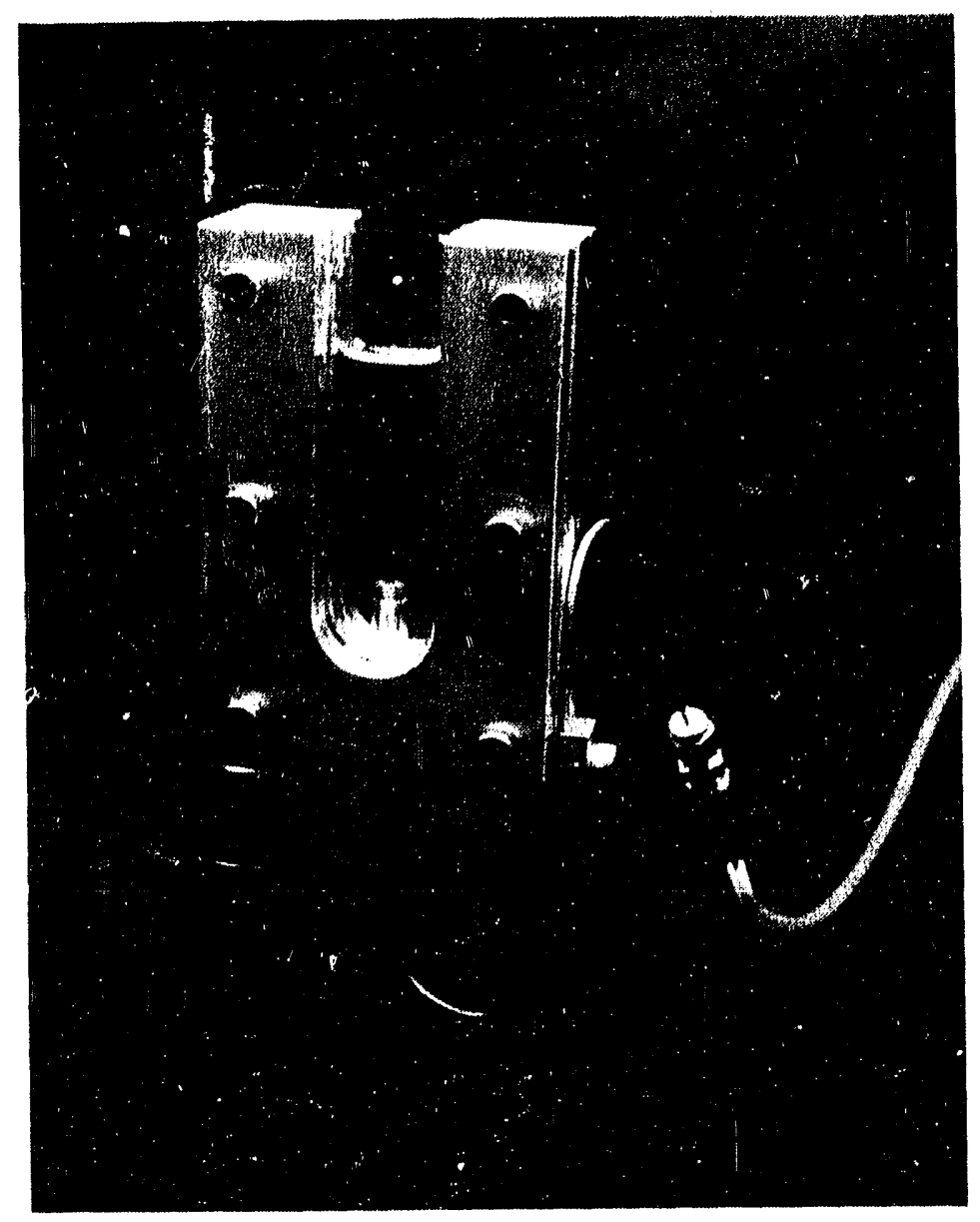

Figure 4-2. Drop forming cell for interfacial tensiometer. 


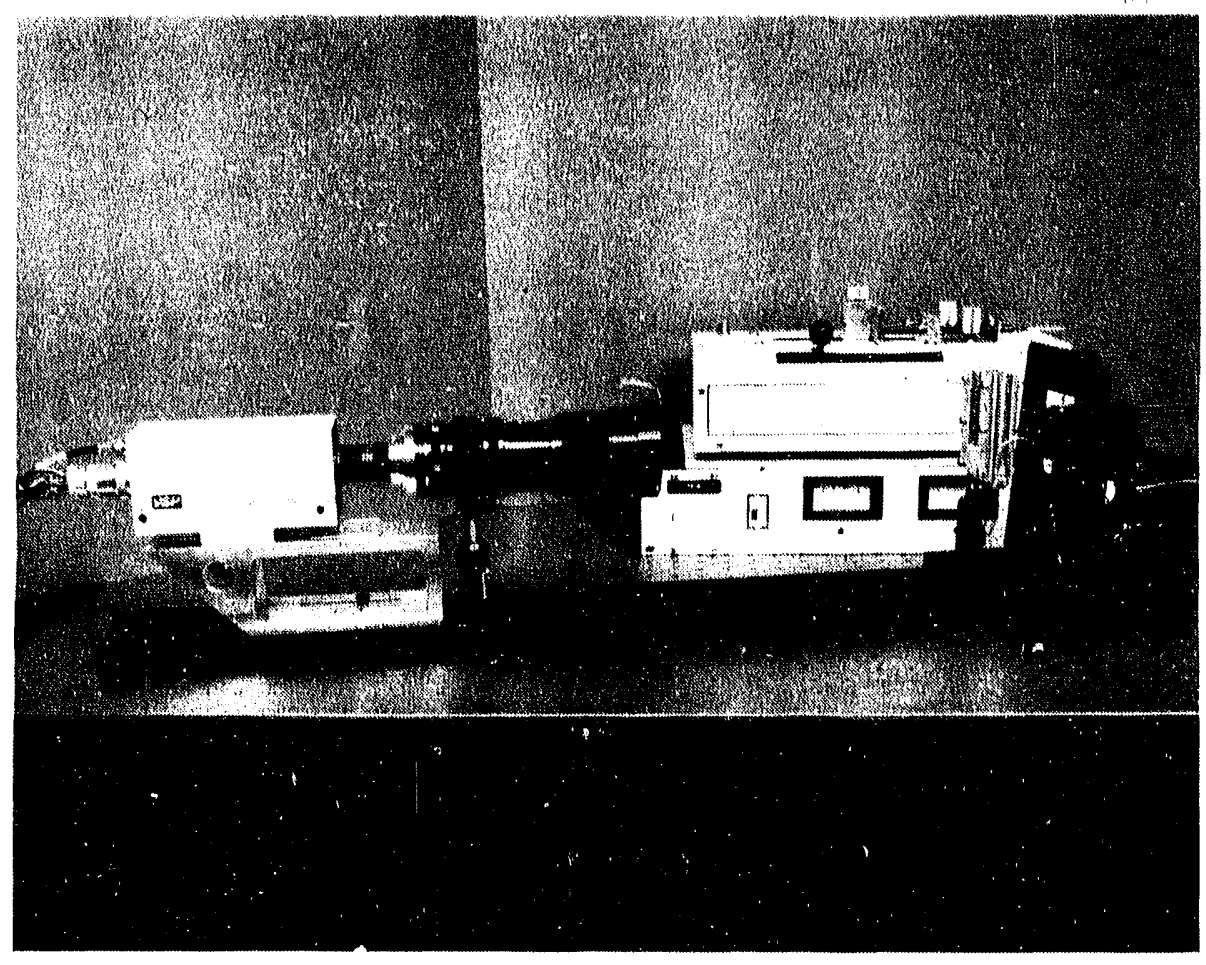

Figure 4-3. Video camera, lenses, magnification system setup for interfacial tensiometer. 


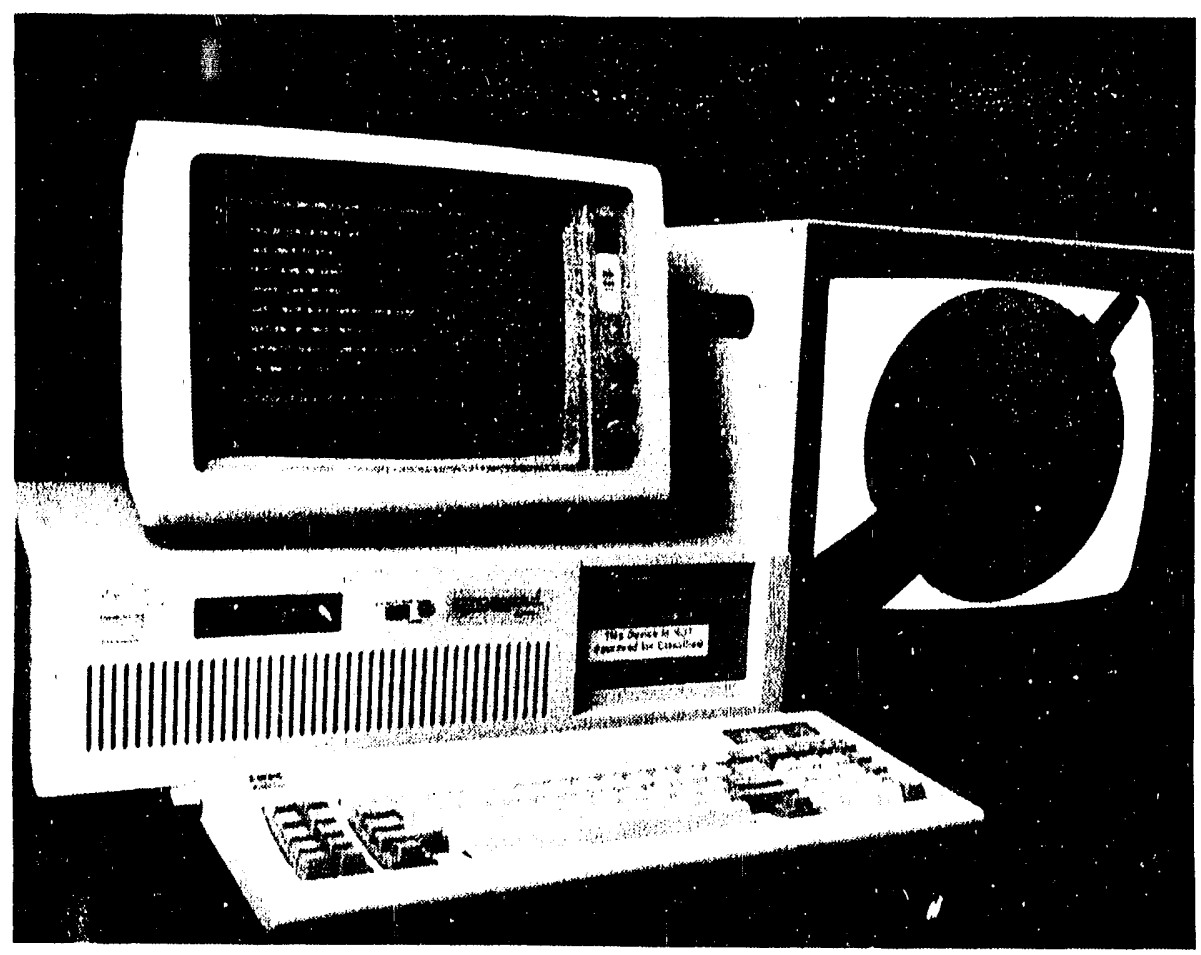

Figure 4-4. Calibration of interfacial tensiometer. 


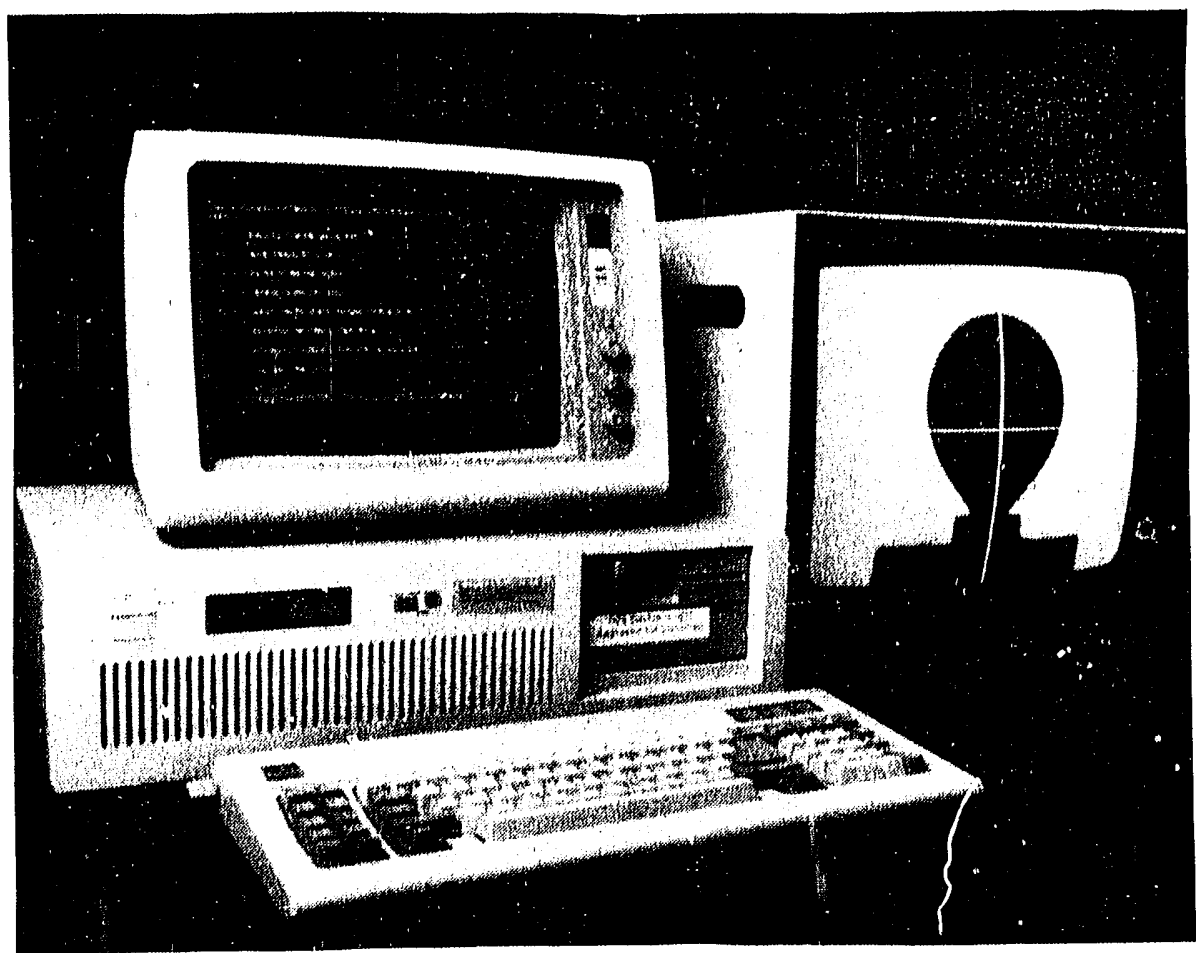

Figure 4-5. Video image of drop for interfacial tension measurement. 


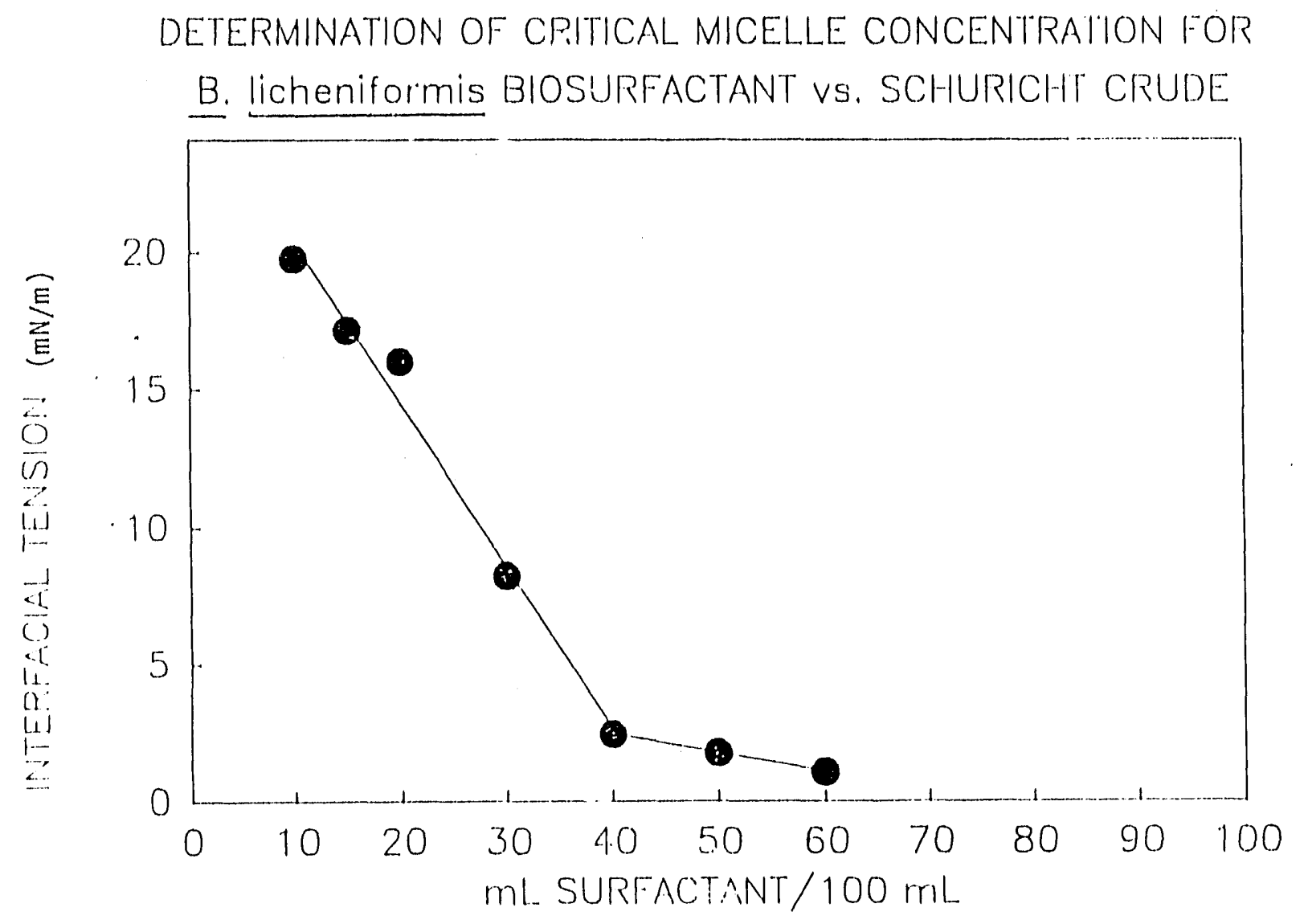

Figure 4-6. Determination of critical micelle concentration for cell free supernatants of Bacillus licheniformis JF-2. 


\subsection{References}

1. L. W. Lake, Enhanced 0il Recovery, New Jersey: Prentice Ha11, 1989.

2. J. C. Melrose, C. F. Brandner, "Role of Capillary Forces in Determining Microscopic Displacement Efficiency for 0il Recovery," J. Can. Pet. Tech., $\underline{13}, 54,1974$.

3. Improved Oil Recovery by Surfactant and Polymer Flooding, D. 0. Shah, ed., New York: Academic Press, 1977, p. 383.

4. R. N. Healy, R. L. Reed, C. W. Carpenter, "A Laboratory Study of Microemulsion Flooding," Soc. Pet. Eng. J., 15, 87, 1975.

5. K. S. Birdi, E. Stenby, Structure/Performance Relationships in Surfactants, M. J. Rosen, ed., American Chemical Society, Washington, D. C., 1984.

6. R. D. Bagna11, P. A. Arunde1, "The Profile Area of Pendant Drops," J. Physical Chemistry, 82, 898, 1978.

7. C. E. Stauffer, "The Measurement of Surface Tension by the Pendant Drop Technique," J. Physical Chemistry, 69, 1933, 1965.

8. C. Huh, R. L. Reed, "A Method for Estimating Interfacial Tensions and Contact Angles from Sessile and Pendant Drops," J. Coll. Inter. Sci., 91, $472,1983$.

9. J. L. Cayias, R. S. Schechter, W. H. Wade, "The Measurement of Low Interfacial Tension via the Spinning Drop Technique," Adsorption at Interfaces, K. L. Mittal, ed., American Chemical Society, Washington, D. C., 1974.

10. A. M. Worthington, "Pendant Drops", Proc. Roy. Soc., 32, 362, 1881.

11. A. Ferguson, "Photographic Measurements of Pendant Drops," Phil. Mag., $\underline{23}$, $417,1912$. 
12. J. Satherley, H. H. J. Girault, D. J. Schiffrin, "The Measurement of Ultralow Interfacial Tension by Video Degital Techniques," J. Coll. Inter. Sci., 136, 5741990.

13. S. H. Anastasiadis, J.-K. Chen, J. T. Koberstein, A. F. Siegel, J. E. Sohn, J. A. Emerson, "The Determination of Interfacial Tension by Video Image Processing of Pendant Fluid Drops," J. Coll. Inter. Sci., 119, 55, 1987.

14. H. H. J. Girault, D. J. Schiffrin, B. D. V. Smith, "The Measurement of Interfacial Tension of Pendant Drops Using a Video Image Profile Digitizer, " J.Coll. Inter. Sci., 101, 257, 1984.

15. V. A. Deason, R. L. Miller, A. D. Watkins, M. D. Ward, K. B. Barrett, "Measurement of Interfacial Tension by Automated Video Techniques," Society of Photo-Optical Instrumentation Engineers Conference, San Diego, CA, 1990.

16. A. W. Adamson, Physical Chemistry of Surfaces, New York: Interscience Publishers, 1976.

17. M. J. Jaycock, G. D. Parfitt, Chemistry of Interfaces, New York: John Wiley and Sons, 1981.

18. F. Bashford, J. C. Adams, An Attempt to Test the Theories of Capillary Action, University Press, Cambridge, England, 1983.

19. J. M. Andreas, E. A. Hansen, W. B. Tucker, "Boundary Tension by Pendant Drops, " J. Phys. Chem., 42, 1001, 1938.

20. S. Fordham, "On the Calculation of Surface Tension from Measurements of Pendant Drops," Proc. Roy. Soc., 194A, 1, 1948.

21. A. W. Adamson, Physical Chemistry of Surfaces, 3rd ed., New York, NY: Interscience Publishers, 1976.

22. R. C. Weast, CRC Handbook of Chemistry and Physics, 59th ed., CRC Press, Boca Raton, Florida, p. F-45. 


\section{LABORATORY CORE FLOODS WITH MICROBIAL SYSTEMS}

The objective of the core flooding program is to investigate the effect on oil recovery with selected microbial systems of parameters such as crude oil type, crude oil viscosity, aging and incubation time, IFT, and brine composition. All MEOR core floods completed to date have been flooded with the Bacillus licheniformis JF-2 microbial system (see Section 3). The core flooding apparatus, experimental procedures, and resulting core flood data are presented and discussed in this chapter.

\subsection{Experimental Program}

The experimental program consists of core floods being performed with six different oils. The six oils range in API gravity from 17.5 to $50.5^{\circ} \mathrm{API}$ at $60^{\circ} \mathrm{F}$. Five of the oils are crude oils and one is a refined oil (Soltrol 220). The selected oils are 7 isted in Table 2.1 and the analys is procedures and results were presented in Section 2 .

All of the experiments use non-fired Berea sandstone cores coated with epoxy and fitted with end plates. The dimensions of the cores are 1 in. in diameter and 6 in. in length. A 2.4 wt\% NaCl brine solution is used to saturate the cores and to displace the $0 i 1$ as the cores are flooded. The brine solution is filtered through a $0.45 \mu \mathrm{m}$ Millipore membrane and de-aerated. All core floods have been performed at room temperature, including the evacuation and saturation phase of the experimental work. All MEOR cores are incubated for 2 weeks at $37^{\circ} \mathrm{C}$ after the injection of the microbial system. Control experiments have been performed for each of the oils. The control cores were injected with nutrient only (Medium $E+1 \%$ sucrose - no microbes) and incubated at the same temperature and length of time as the MEOR cores. 


\subsection{Core flood Apparatus}

The core flood apparatus used for all core floods is similar to that used by other researchers ${ }^{1,2,3}$ and is shown in Figure 5-1. Milton Roy S10 Speed miniPumps are used for fluid delivery and Temco Floating Piston Accumulators are used to keep fluids separated. The accumulators have a floating piston that enables the injection of microbial solutions and other fluids into the cores while preventing corrosive fluids from contacting the pumps. Nupro pressure relief valves are used on the pump discharges as safety relief. Adjustable Nupro back pressure valves are used to provide back pressure on the cores as needed. All components of the system are connected using $1 / 8$ in. OD nylon tubing with Swagelok connectors. Effluent from the cores is collected at various time intervals in an automated tube collection device (fraction collector). Omega Type $T$ Test Gauges are utilized on both the inlet and outlet of the core. The differential pressure across the core is determined using a Validyne DP15TL differential pressure transducer coupled to a Validyne CD223 digital transducer indicator.

\subsection{Core Preparation And Handling}

Cores were cut from Berea sandstone blocks and air dried at room temperature for a minimum of $72 \mathrm{~h}$. End plates for the cores were made from brass or stainless steel bar-stock and were used for connection of injection and production lines to the cores. They were then placed in a suitable holder (vise or clamp) with the end plates positioned in preparation for epoxy application. The epoxy (Epoxy Patch made by the Dexter (0.) was prepared as outlined by the manufacturer. Working time of the epoxy was about $20 \mathrm{~min}$.

The end plates were mounted to the cores by applying epoxy along the edges of the plate using a wooden tongue depressor. After the epoxy was allowed to harden for a minimum of $2 \mathrm{~h}$ at room temperature, it was wiped with alcohol to ensure the removal of all debris and oils caused by handling. A new batch of epoxy was mixed and applied to the core using a wooden tongue depressor to evenly spread the epoxy over the entire core and edge of the end plates. This 
was done with an end-to-end motion over the core. The second coat was applied following the same precautions and guidelines used for the first coat and was allowed to age at room temperature for a minimum of $24 \mathrm{~h}$ before proceeding with further core preparation procedures.

\subsection{Brine Saturation of Cores}

With end plates and connections in place, the core was weighed and the weight recorded as the dry weight of the core (Wd). Care was taken to ensure the surface of the core and the associated connections and hardware were free of debris and any external adhering fluids. The core was then placed in the evacuation/saturation apparatus and evacuation was initiated. Brine solution to be used for saturating the core was prepared, filtered through a $0.45 \mu \mathrm{m}$ Millipore membrane, and de-aerated.

After the core was saturated by passing a minimum of 10 pore volumes (PV) of brine through the core, the core was weighed and the weight recorded as the initial saturation weight. The saturation procedure continued for a minimum of $3 \mathrm{~h}$ or 10 PV throughput, whichever occurred last. The total volume of brine that had passed through the core was recorded.

\subsection{Determination of Core Parameters}

The core was placed in the core flood apparatus once the saturation procedure had been completed. A back pressure valve was installed on the outlet end of the core and set to apply a minimum constant back pressure of $15 \mathrm{psig}$ against the outlet of the core while flooding. The injection pump was set at a constant rate for the permeability determination procedure. Several time intervals were recorded during the procedure with a minimal 10 pore volumes being pumped through the core. Darcy's law was used to determine the absolute permeability to brine of the core. The core was then re-weighed and if the weight had increased from the initial saturation weight, additional brine was pumped through the core. The core was weighed an additional time and this procedure of pumping brine through the core and re-weighing continued until 
the core weight was unchanged after consecutive trials. This final weight was recorded as the saturated core weight (WW).

After the true saturated weight of the core had been determined, the porosity $(\phi)$ and PV of each core were determined using the dry (Wd) and saturated weights (Ww) of each core and the dimensions of the core $(R=$ radius of core, $L=$ length of core, $\mathrm{eb}=$ density of brine). This gives

$$
P V=\frac{W W-W d}{Q b} \quad \text { and } \quad \phi=\frac{P V}{\pi R^{2} L} \text {. }
$$

\subsection{Initial Core Saturation Conditions}

$0 i 1$ was then pumped through each core (oil flood) to establish an initial oil saturation condition in the core. A total throughput of 10 pore volumes (minimum) of oil was pumped through each core to ensure proper oil saturation of the core. After the core had been oil saturated, the oil saturated weight (Wo) was recorded. The initial (connate) water saturation (Swi) and initial (original) oil saturation (Soi) of the cores were determined by material balance ( $\mathrm{Q} w=$ water density, $\varrho 0=0 i 1$ density). This gives

$$
S w i=\frac{P V-\frac{W w-W O}{Q W-Q O}}{P V} \quad \text { and } \quad \text { So } i=1-S w i \text {. }
$$

\subsection{Waterf LoOd Residual OIl Saturation}

The core was then placed in the core flooding apparatus in preparation for waterflooding. Pump rates were set to ensure a 1 to $2 \mathrm{ft} / \mathrm{d}$ frontal advance rate in the core. The waterflood continued until no oil was visible in several consecutive collection tubes or at least 10 PV had been injected, whichever occurred last. After the waterflood was completed, the core was 
weighed and the weight recorded as the waterflood weight (Wwf). The waterflood residual oil saturation was then determined gravimetrically (see subsection 2.1.6). Waterflood residual oil saturation (Sorwf) was checked by material balance (Swwf = waterflood water saturation). This gives

$$
S W W I=\frac{P V-\frac{W W-W W f}{\varrho W-\varrho O}}{P V} \text { and sorwf }=1-S w W f \text {. }
$$

\subsection{Microbial flood Residual Oil Saturation}

The core was then in a waterflood residual oil saturation condition and ready for injection of microbes. The Bacillus licheniformis JF-2 microbial system was injected into the core by use of a small accumulator (see Figure 5-1). The volume of injected microbes and nutrient was $60 \%$ PV for each core.

After the Bacillus licheniformis JF-2 microbial system had been injected into the core, it was placed in incubation for $14 \mathrm{~d}$ at $37^{\circ} \mathrm{C}$. Any pressure increase in the core during the incubation period was monitored to determine the presence of any microbial gas production.

The core was then placed in the core flood apparatus in preparation for the microbial flood. The core was flooded with filtered and de-aerated brine of the same composition as that used in the earlier waterflood. The brine injection rate was identical to that used for the previous waterflood, and core effluent was collected and handled in the same method as for the waterflood. The microbial flood continued until oil production ceased or until 10 PV of throughput were realized, which ever occurred last. When the microbial flood was completed, the core was weighed and the weight recorded as the microbial flood weight (Wmf). The microbial flood residual oil saturation (Sormf) was then determined gravimetrically (see subsection 2.1.6). The 
microbial flood residual oil saturation was checked by material balance, which gives (Swmf = microbial flood water saturation)

$$
S w m f=\frac{P V-\frac{W W-W m f}{Q W-\varrho O}}{P V} \text { and Sormf }=1-\text { Swmf } .
$$

\subsection{Core Flood Results}

The cores used (including the control cores) had fairly consistent porosity values from 21.7 to $23.8 \%$. Permeabilities ranged from a low of $85 \mathrm{md}$ to a high of $510 \mathrm{md}$ with an average for all cores of $216 \mathrm{md}$. Initial oil saturations varied from 53.3 to $79.3 \%$ PV. The MEOR cores averaged $68.6 \%$ PV initial oil saturation and the control cores averaged $65.6 \%$ PV initial $0 i 1$ saturation. Waterflood residual oil saturations varied from 11.9 to $41.3 \%$ PV. The MEOR cores averaged $28.8 \%$ PV waterflood residual oil saturation and the control cores averaged $28.9 \%$ PV waterflood residual oil saturation.

Of the 11 MEOR core floods, 9 produced $0 i 1$ by microbial injection (see Table 5-1). One of the cores containing Burbank oil (Core 14) and the core containing Soltrol 220 (Core 15) did not produce oil. These were both early tests where microbes may have been poisoned with toluene. Bacillus

licheniformis JF-2 has been shown to grow in the presence of either of these oils and the repeat core flood test with Burbank crude did produce oil beyond waterflood with the Bacillus licheniformis JF-2 system. Schuricht, Moorcroft West, Alworth, and Lick Creek produced additional $0 i 1$ beyond waterflood in all cores inoculated with the Bacillus licheniformis JF-2 microbial system. Only Moorcroft West and Lick Creek produced oil from their control core (nutrient only injection).

Plots of brine injection versus residual $0 i 1$ saturation for the MEOR core floods are shown in Figures 5-2 through 5-10. $0 i 1$ production rate for two core floods, Core 13 (Moorcroft West) and Core 23 (Alworth) lagged that of the other MEOR core floods. The residual oil saturations for these two cores dropped rapidly once 2 to 3 PV of brine were injected. The other MEOR core 
Table 5-1. MEOR core flood recovery data ${ }^{\mathrm{B}}$

\begin{tabular}{|c|c|c|c|c|c|c|c|c|c|c|}
\hline $\mathrm{CORE}^{\mathrm{b}}$ & MICROBE $^{\mathrm{C}}$ & $\underline{O I L}^{d}$ & $\begin{array}{l}\text { VIS } \\
(\mathrm{Pa} \cdot \mathrm{s})\end{array}$ & $\begin{array}{l}\text { PERM } \\
\text { (md) }\end{array}$ & $\begin{array}{c}\text { Soi } \\
\text { (\%PV) }\end{array}$ & $\begin{array}{l}\text { Sorwf } \\
\text { (\%PV) }\end{array}$ & $\begin{array}{l}\text { Sormf } \\
\text { (\%PV) }\end{array}$ & $\begin{array}{l}\text { MEOR }^{\mathrm{e}} \\
\text { REC } \\
(\% 00 \text { IP })\end{array}$ & $\begin{array}{c}\text { MEOR } \\
\text { REC } \\
\$ \% 00 I \\
\end{array}$ & $f$ \\
\hline $\begin{array}{l}15 \\
16^{i} \\
14 \\
22 \\
20^{i} \\
10 \\
25^{i} \\
19^{i} \\
12 \\
23 \\
18^{i} \\
13 \\
24 \\
17^{i} \\
11 \\
26 \\
21^{i}\end{array}$ & 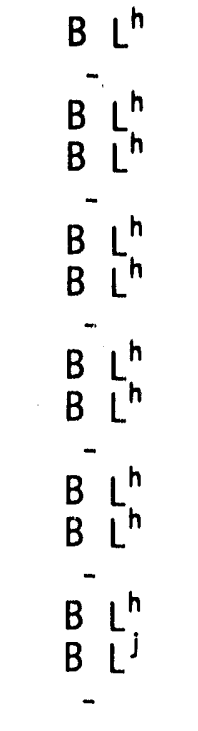 & $\begin{array}{l}\text { SOL } \\
\text { SOL } \\
\text { BUR } \\
\text { BUR } \\
\text { BUR } \\
\text { SCH } \\
\text { SCH } \\
\text { SCH } \\
\text { ALW } \\
\text { ALW } \\
\text { ALW } \\
\text { MOO } \\
\text { MOO } \\
\text { MOO } \\
\text { LIC } \\
\text { LIC } \\
\text { LIC }\end{array}$ & $\begin{array}{l}0.003 \\
0.003 \\
0.006 \\
0.006 \\
0.006 \\
0.054 \\
0.054 \\
0.054 \\
0.134 \\
0.134 \\
0.134 \\
0.142 \\
0.142 \\
0.142 \\
0.288 \\
0.288 \\
0.288\end{array}$ & $\begin{array}{r}86 \\
94 \\
195 \\
214 \\
323 \\
267 \\
85 \\
432 \\
119 \\
311 \\
134 \\
123 \\
115 \\
190 \\
109 \\
359 \\
510\end{array}$ & $\begin{array}{l}57.9 \\
58.6 \\
63.2 \\
65.8 \\
70.7 \\
76.7 \\
72.3 \\
64.1 \\
72.6 \\
53.3 \\
66.6 \\
78.8 \\
72.3 \\
58.9 \\
79.3 \\
62.8 \\
74.7\end{array}$ & $\begin{array}{l}25.9 \\
24.3 \\
25.8 \\
32.6 \\
34.0 \\
33.4 \\
39.5 \\
27.0 \\
18.6 \\
11.9 \\
25.5 \\
25.6 \\
39.4 \\
26.1 \\
39.2 \\
22.3 \\
36.5\end{array}$ & $\begin{array}{r}25.9 \\
24.3 \\
25.8 \\
29.6 \\
34.0 \\
29.9 \\
37.9 \\
27.0 \\
14.1 \\
7.7 \\
25.5 \\
14.7 \\
38.3 \\
23.2 \\
35.8 \\
4.2 \\
33.2\end{array}$ & $\begin{array}{r}0 \\
0 \\
0 \\
4.6 \\
0 \\
2.7 \\
1.4 \\
0 \\
4.2 \\
7.1 \\
0 \\
9.9 \\
1.3 \\
-- \\
2.6 \\
11.5 \\
--\end{array}$ & $\begin{array}{r}0 \\
0 \\
0 \\
4.6 \\
0 \\
4.6 \\
2.2 \\
0 \\
6.2 \\
7.9 \\
0 \\
13.8 \\
1.4 \\
4.9 \\
4.3 \\
28.8 \\
4.4\end{array}$ & $\begin{array}{r}(8) \\
(9+) \\
(9) \\
(12) \\
(9+) \\
(8) \\
(14.5) \\
(9+) \\
(9.5) \\
(6.5) \\
(9+) \\
(15.5) \\
(12) \\
(9+) \\
(9.5) \\
(25) \\
(9+)\end{array}$ \\
\hline
\end{tabular}

a. Core parameters; 00IP = original oil in place, VIS $=0 i 1$ viscosity, PERM $=$ absolute brine permeability of core, Soi = initial oil saturation, Sorwf = waterflood residual oil saturation, Sormf = microbial flood residual oil saturation, PV = pore volume of core.

b. For all core floods, temperature $=23^{\circ} \mathrm{C}$ and brine $=2.4 \mathrm{wt} \% \mathrm{NaCl}$.

c. Bacillus licheniformis JF-2 microbial system.

d. Crude oil type; SOL = Soltrol 220, BUR = Burbank, SCH = Schuricht, $A T W=$ Alworth, MOO = Moorcroft West, LIC = Lick Creek.

e. $0 i 1$ recovery at six pore volumes of brine injected.

f. 0 il recovery with brine injection until oil production ceases.

g. PV of brine injected.

h. Washed cells re-suspended in Medium $E+1 \%$ sucrose.

i. Control floods - oil recovery when oil production ceases.

j. Unwashed cells in Medium $E+1 \%$ sucrose. 
floods tended to have a large reduction in the residual oil saturation earlier in their flood life at about 1 PV of brine injection.

Total recovery data for all oils are plotted as percent of the original 011 in place (00IP) for each core (Figure 5-11). Multiple sets of data are shown for each oil; waterflood recovery for the MEOR cores (Cores $A$ and $B$ ), microbial flood recovery for cores $A$ and $B$, waterflood recovery for the control core (Core C), and recovery of the nutrient only flood for Core $C$ (control core). Only one MEOR core flood was performed with the Soltrol 220. These cores were flooded with brine until oil production ceased. This was at least 10 PV of brine injection in all cases to obtain a waterflond residual oil saturation condition in the cores. After the waterflood residual oil saturation condition had been obtained, cores were either injected with the MEOR system or injected with nutrient only. The MEOR cores (Cores $A$ and $B$ ) were injected with the Bacillus licheniformis JF-2 microbial system and placed in incubation at $37^{\circ} \mathrm{C}$ for $14 \mathrm{~d}$ before the reinstatement of waterflooding. The control cores were injected with nutrient only and placed in incubation at the same temperature and for the same period of time as the MEOR cores. Like the MEOR cores, waterflooding was reinstated when the control cores were removed from incubation. Recoveries for both the MEOR and the control cores can be seen in Figure 5-11. The oil recovery efficiencies for each of the microbial flood cores is presented in Figures 5-12 through 5-20. The recovery efficiency for the microbial floods is defined as the fraction of waterflood residual oil that is recovered by the microbial flood. The recovery efficiencies for the microbial floods are plotted for 10 PV of injection, although many of the microbial floods exceeded the 10 PV of throughput for the microbial flood.

Core 26 (Lick Creek oil) produced more microbial oil than the others, $28.8 \%$ 00IP or $81.2 \%$ of the waterflood residual 011 . This was the only core inoculated with unwashed Bacillus licheniformis JF-2 cells. The injectant included the bioproducts produced during the aerobic growth process outside the core in addition to the cells. As a direct comparison, Core 11 (also with Lick Creek 0i1) using washed and resuspended cel1s, produced $4.3 \% 00 \mathrm{IP}(8.7 \%$ of waterflood residual 0i1). As discussed in Section 4 , the supernatant is capable of significantly reducing the interfacial tension between the aqueous

$$
5-8
$$


phase and crude 0il. All other cores were inoculated with washed Bacillus licheniformis JF-2 cells resuspended in fresh Medium E $+1 \%$ sucrose.

\subsection{Future EXperimental Work}

The reason for the observed variation in microbial oil recovery with oil type will be investigated further. Additional core floods and other experimental work such as interfacial tension measurements will be performed to evaluate the variation in oil recovery with oil type. More experimental data points are needed before any definitive correlation of oil recovery with oil type can be made.

An additional series of core flood experiments have been initiated that utilize injection of only bioproducts of Bacillus licheniformis JF-2. These core floods will be used to investigate the recovery of waterflood residual oil with the injection of bioproducts followed by waterflood. Four crude oils ranging in gravity from 19.1 to $38.1^{\circ} \mathrm{API}$ at $60^{\circ} \mathrm{F}$ will be utilized in these experiments.

\subsection{CONCLUSIONS}

Based on the core flood experimental work performed, the following conclusions can be made.

1. The waterflooding characteristics of Berea sandstone vary for the different oil tested. This may indicate that different wettability characteristics are being established in the Berea cores because of the differences in oil properties of the various oils.

2. The Bacillus licheniformis JF-2 system used will recover waterflood residual oil for the crude oils tested. It appears to be less effective for the higher gravity crude oils, al though oil recovery has been seen with all oils tested with the exception of Soltrol 220, which is thought to be a bad test. 
3. Control experiments are critical to separate the effects of the microbial system from other displacement effects.

4. The difference in oil recovery from cores injected with unwashed cells compared to those injected with washed cells of the Bacillus licheniformis JF-2 system is very significant, $28.8 \% 00 \mathrm{IP}$ as compared to $4.3 \% 00 \mathrm{IP}$ (Cores 11 and 26). 


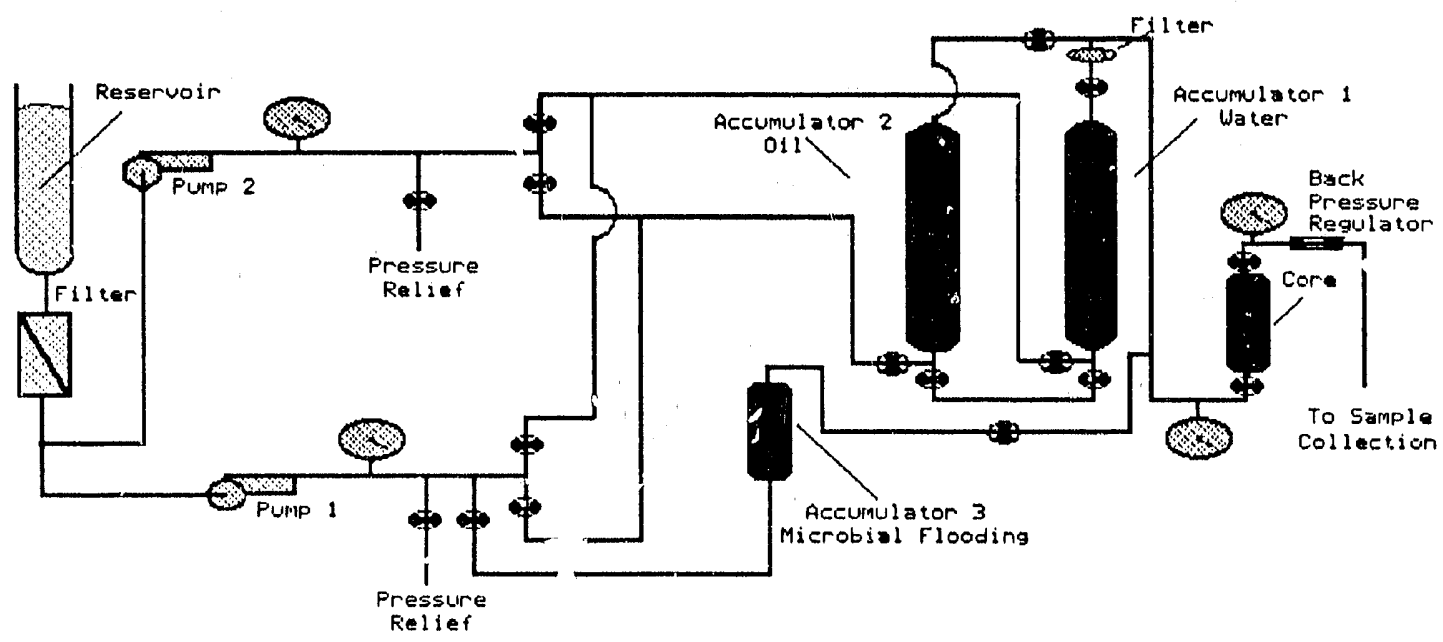

Figure 5-1. Core flood apparatus.

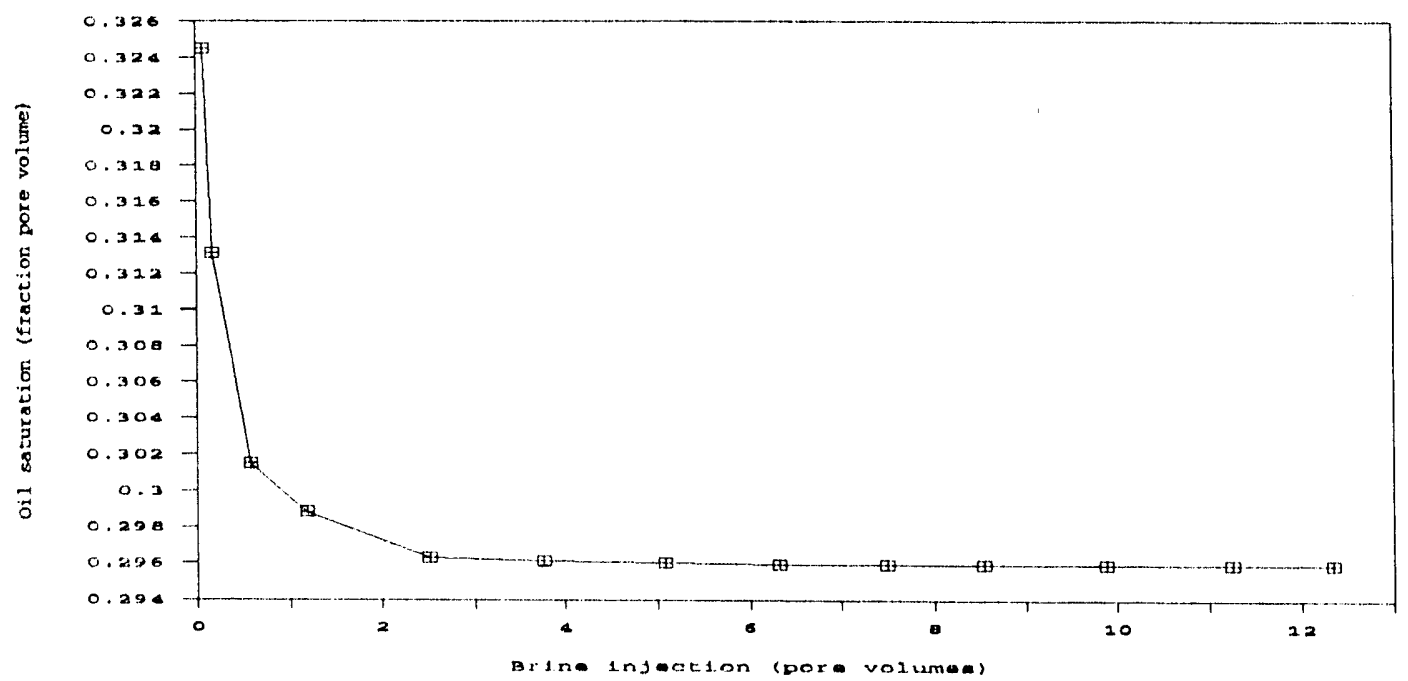

Figure 5-2. Microbial flood oil recovery - Burbank oil - Core 22. 


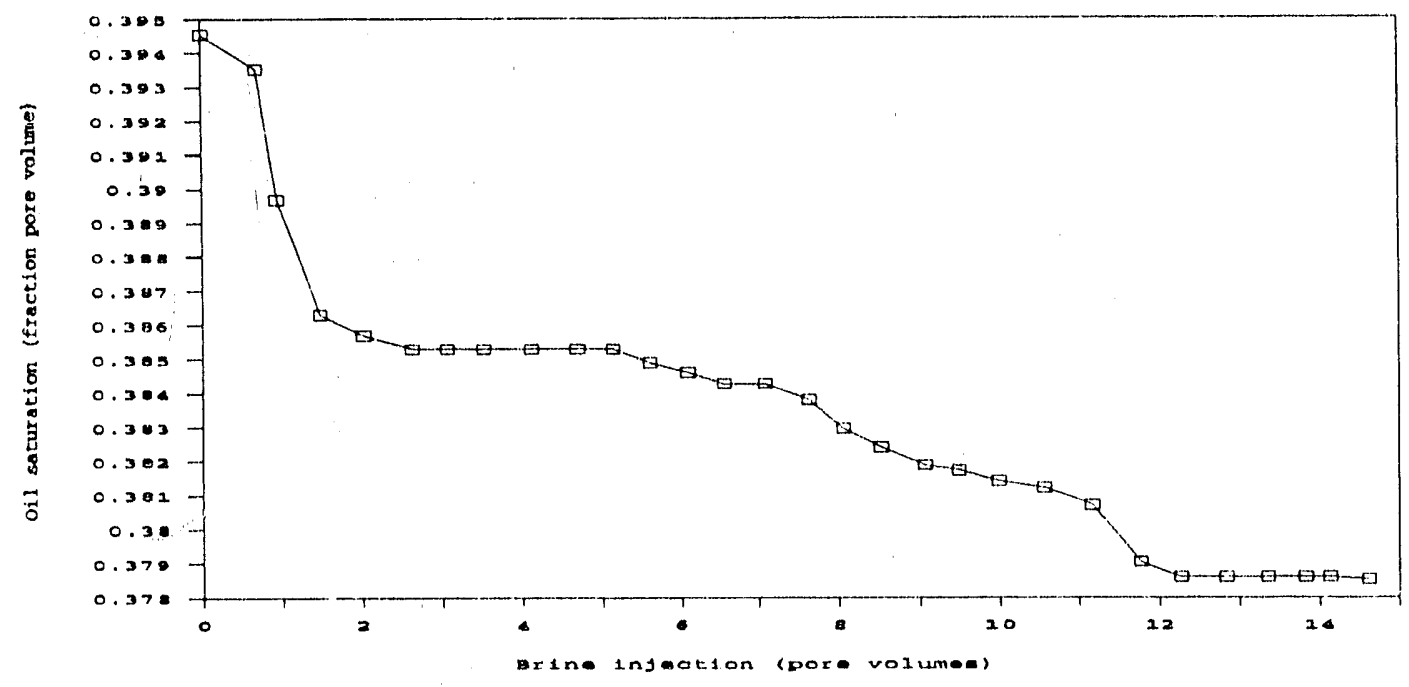

Figure 5-3. Microbial flood oil recovery - Schuricht oil - Core 25.

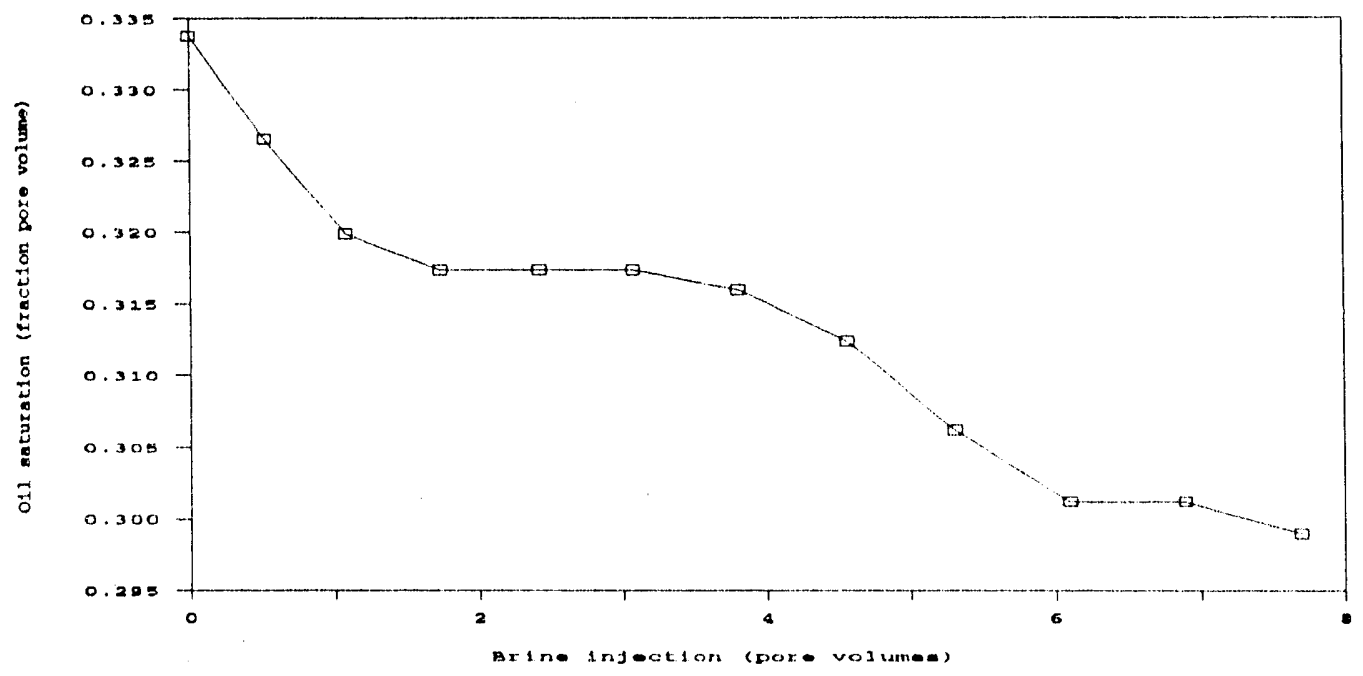

Figure 5-4. Microbial flood oil recovery - Schuricht oil - Core 10. 


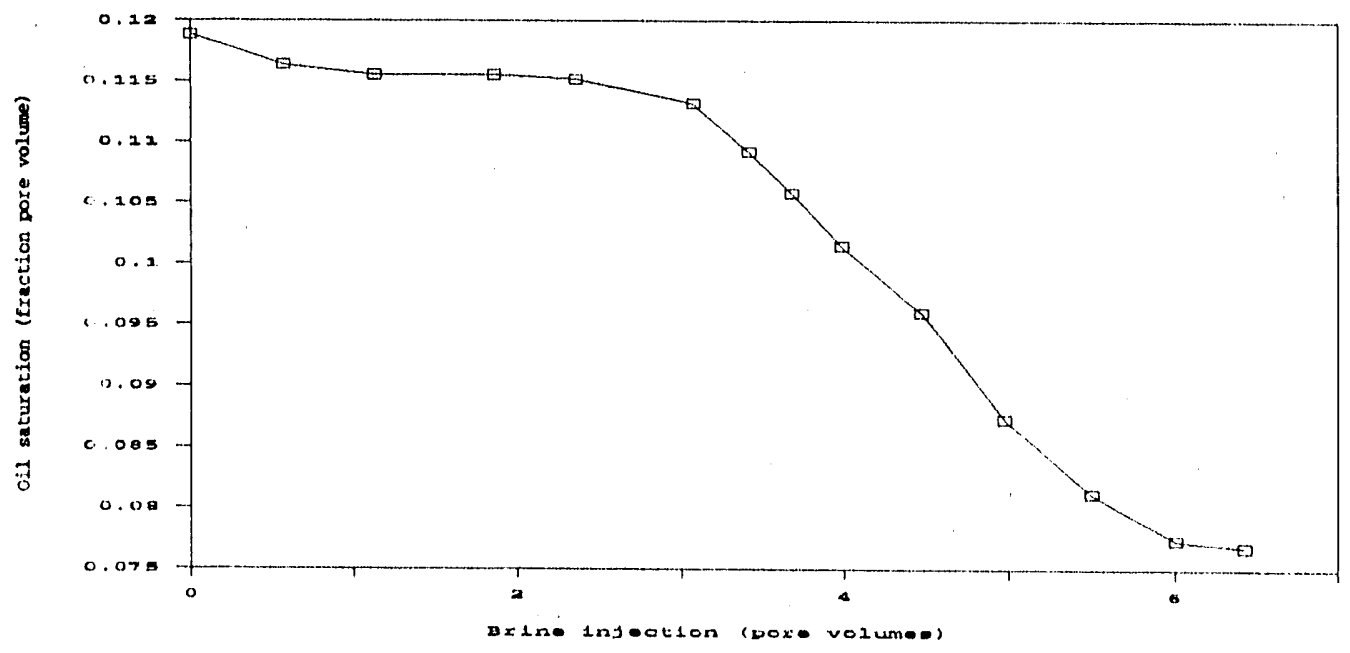

Figure 5-5. Microbial flood oil recovery - Alworth oil - Core 23.

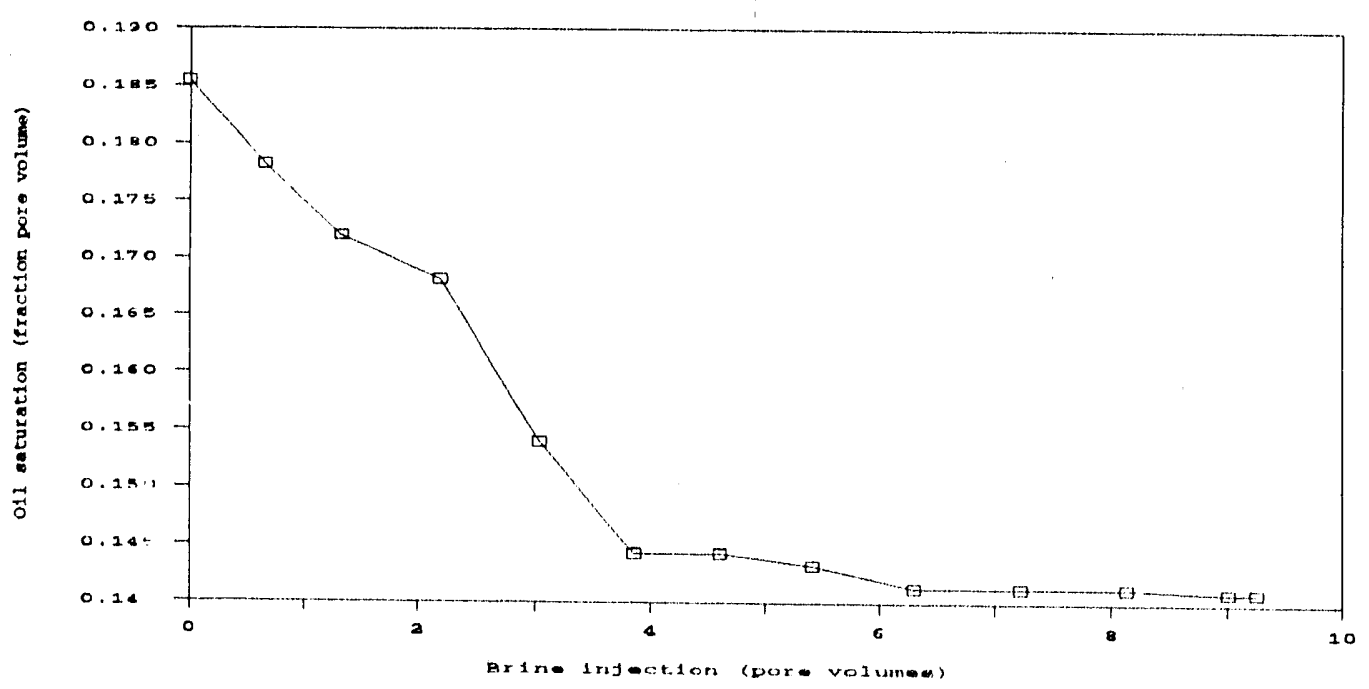

Figure 5-6. Microbial flood oil recovery - Alworth oil - Core 12. 


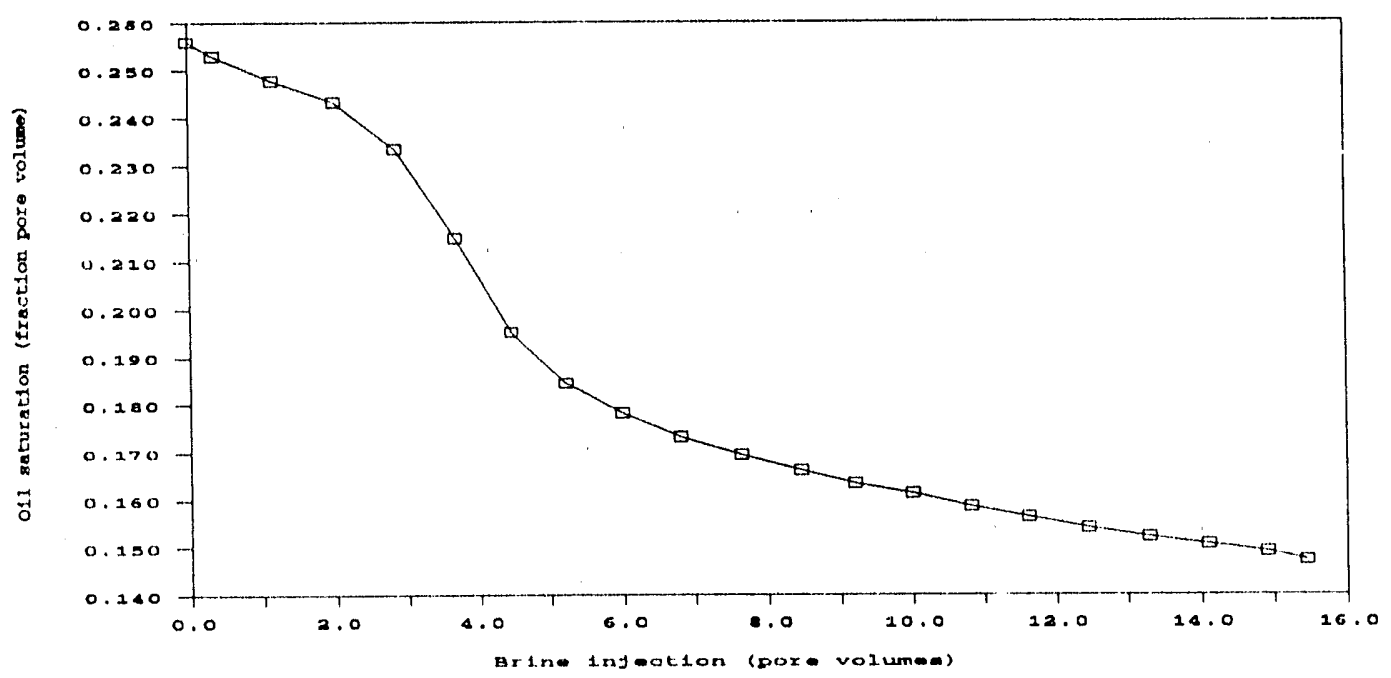

Figure 5-7. Microbial flood oil recovery - Moorcroft West oil - Core 13.

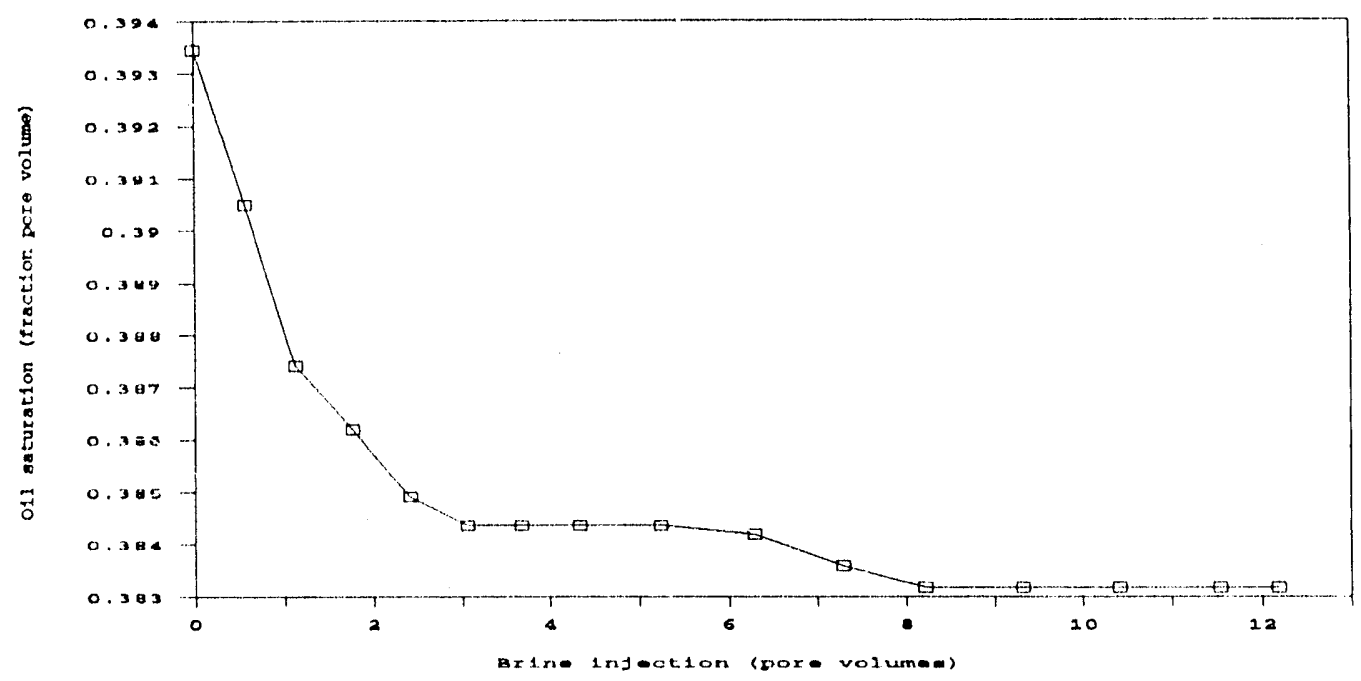

Figure 5-8. Microbial flood oil recovery - Moorcroft West oil - Core 24. 


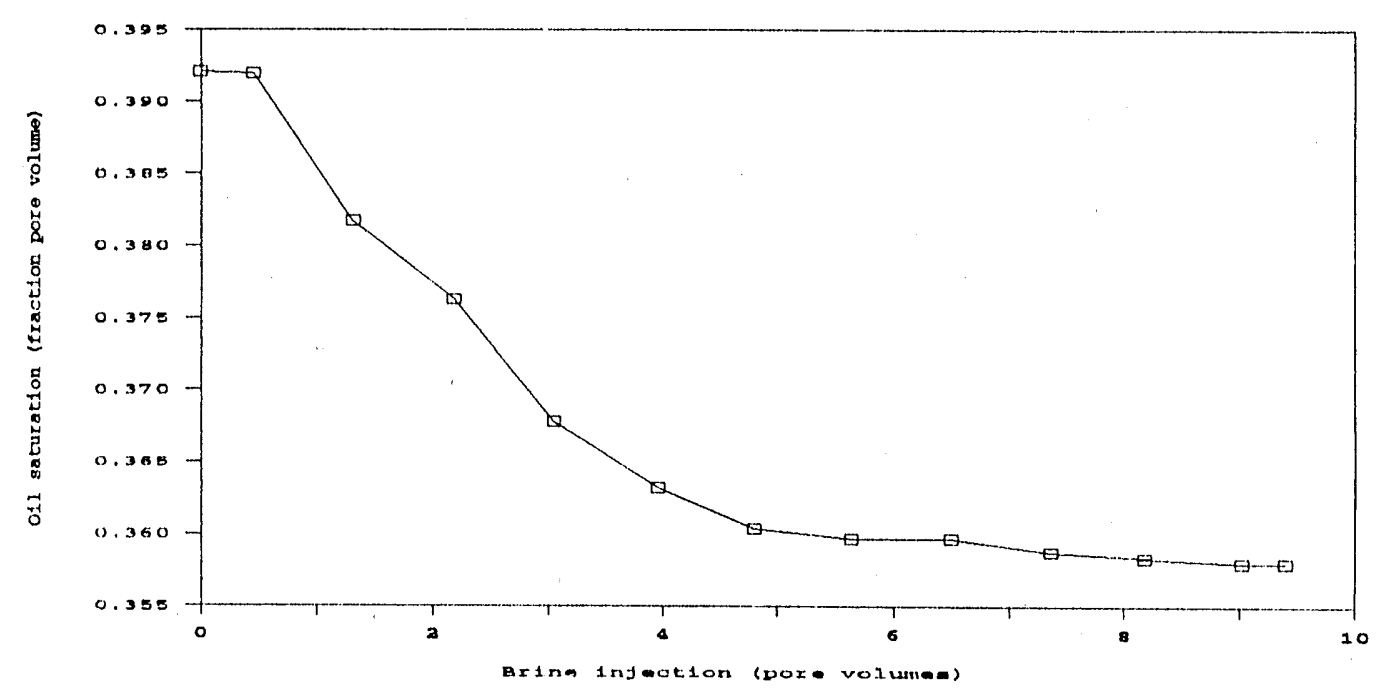

Figure 5-9. Microbial flood oil recovery - Lick Creek oil - Core 11.

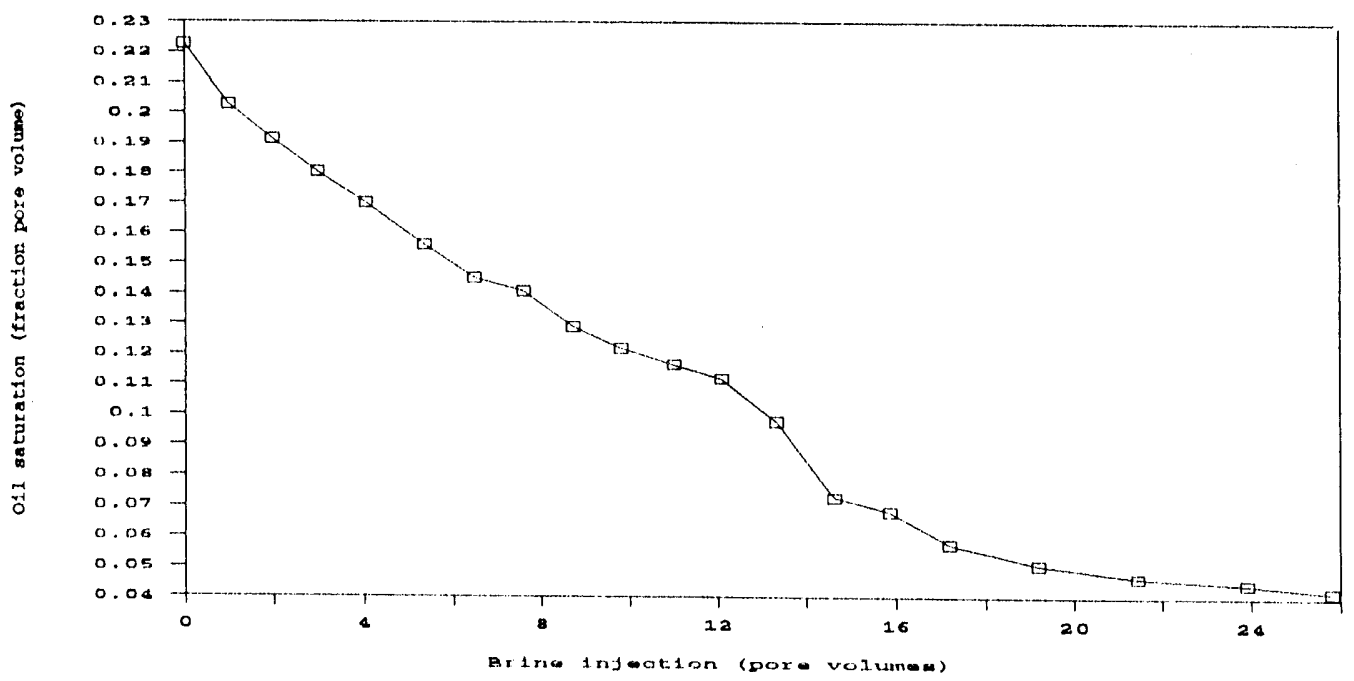

Figure 5-10. Microbial flood oil recovery - Lick Creek oil - Core 26. 


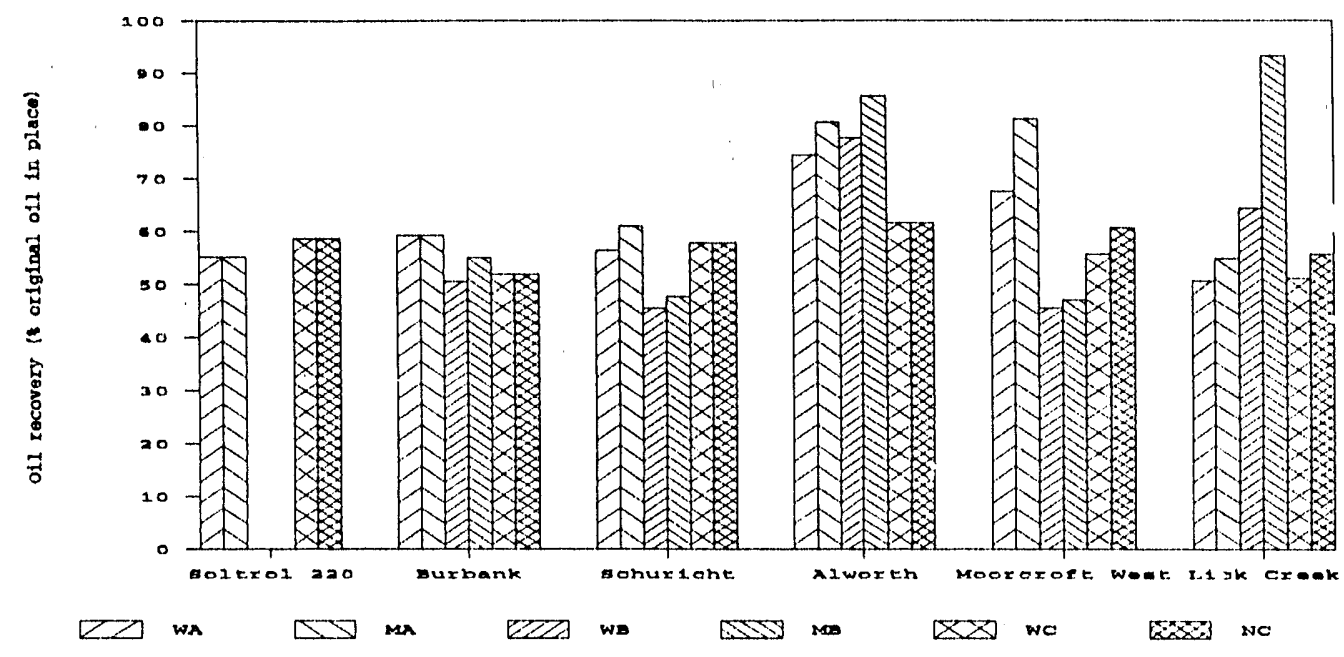

Figure 5-11. Core flood total oil recovery for all oils. ( $W=$ waterflood, $M=$ microbial flood,$N=$ nutrient flood, $A=$ first core, $B=$ second core, $C=$ third core - control).

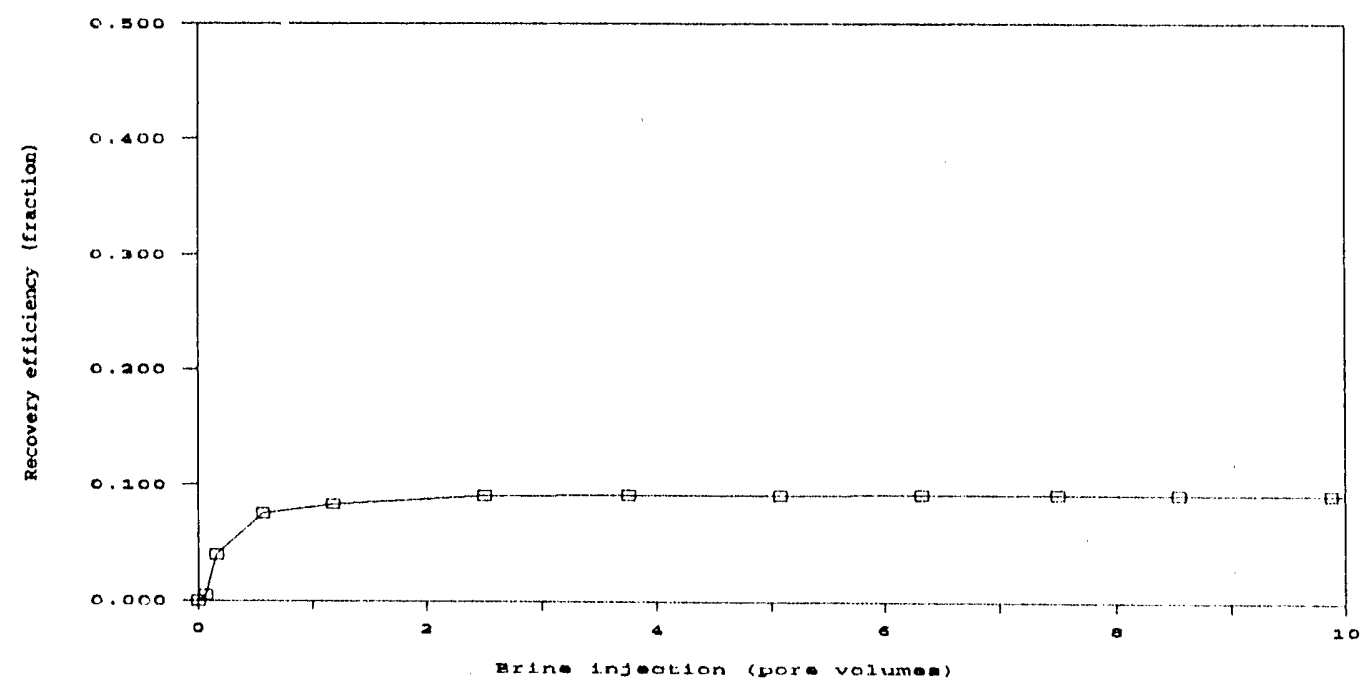

Figure 5-12. Recovery efficiency - Burbank oil - Core 22. 


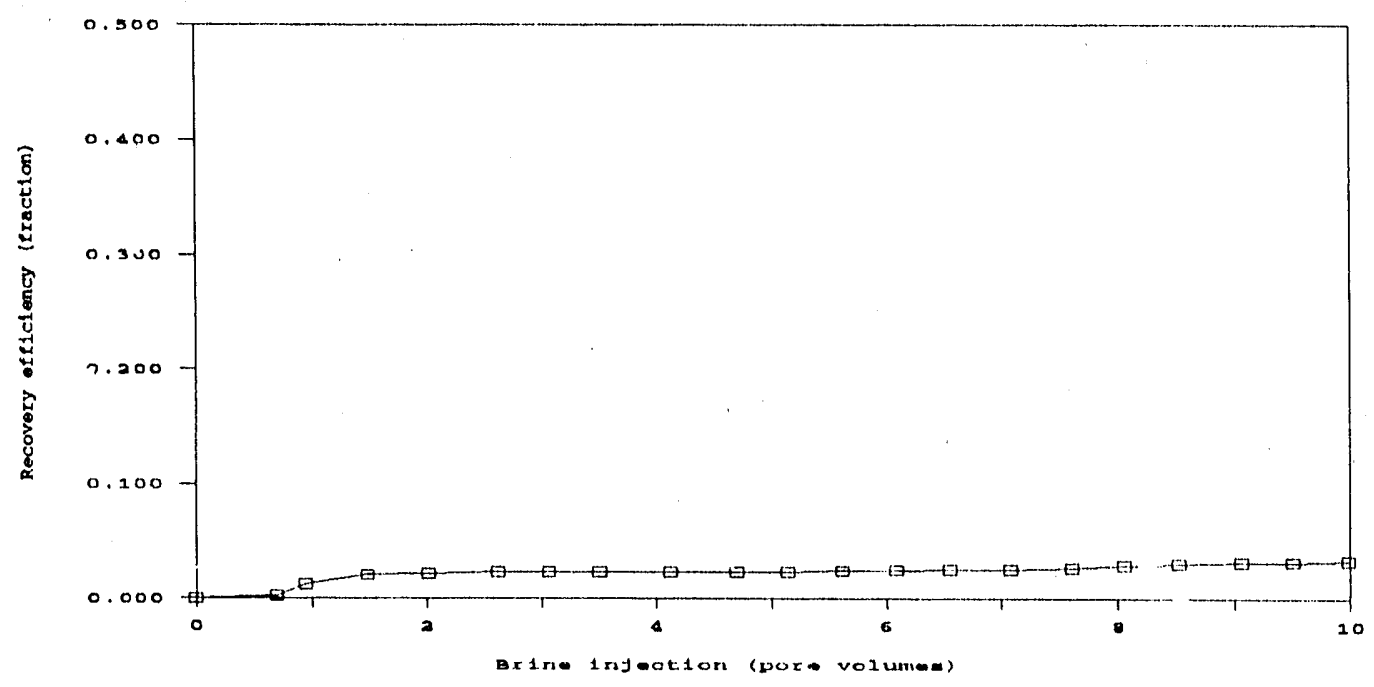

Figure 5-13. Recovery efficiency - Schuricht oil - Core 25.

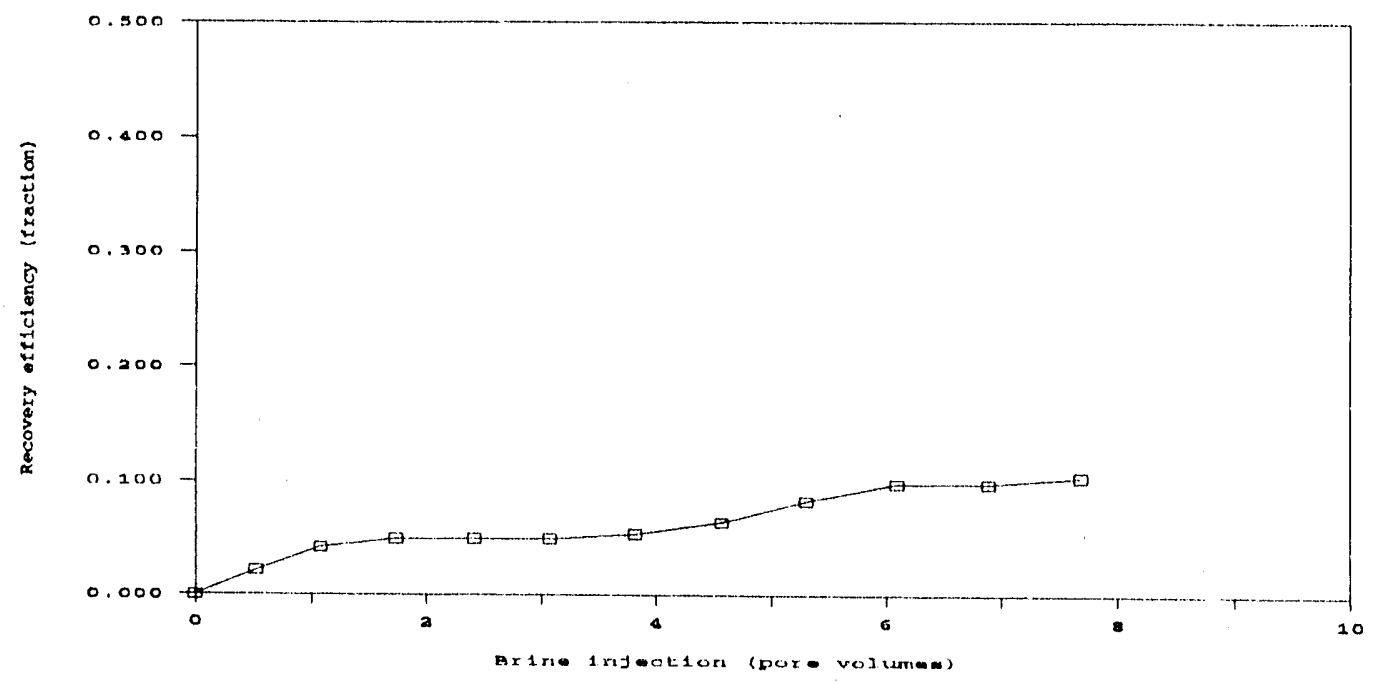

Figure 5-14. Recovery efficiency - Schuricht oil - Core 10. 


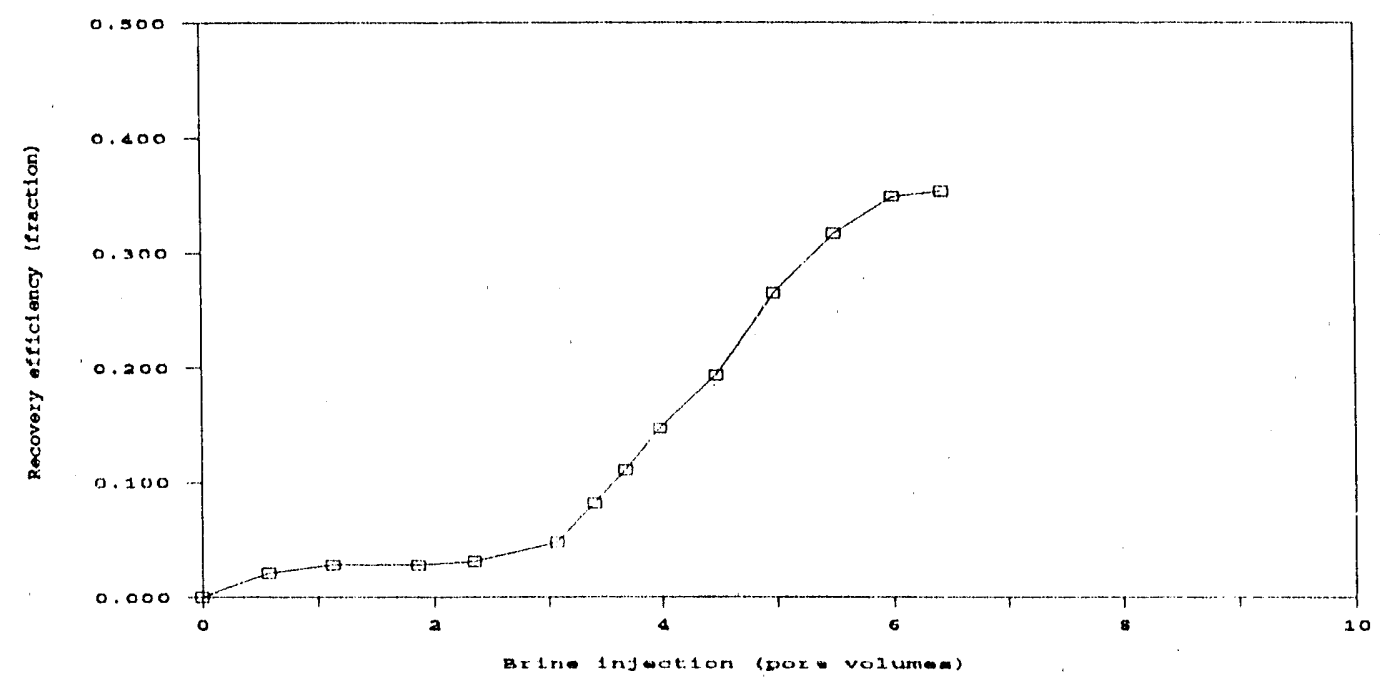

Figure 5-15. Recovery efficiency - Alworth oil - Core 23.

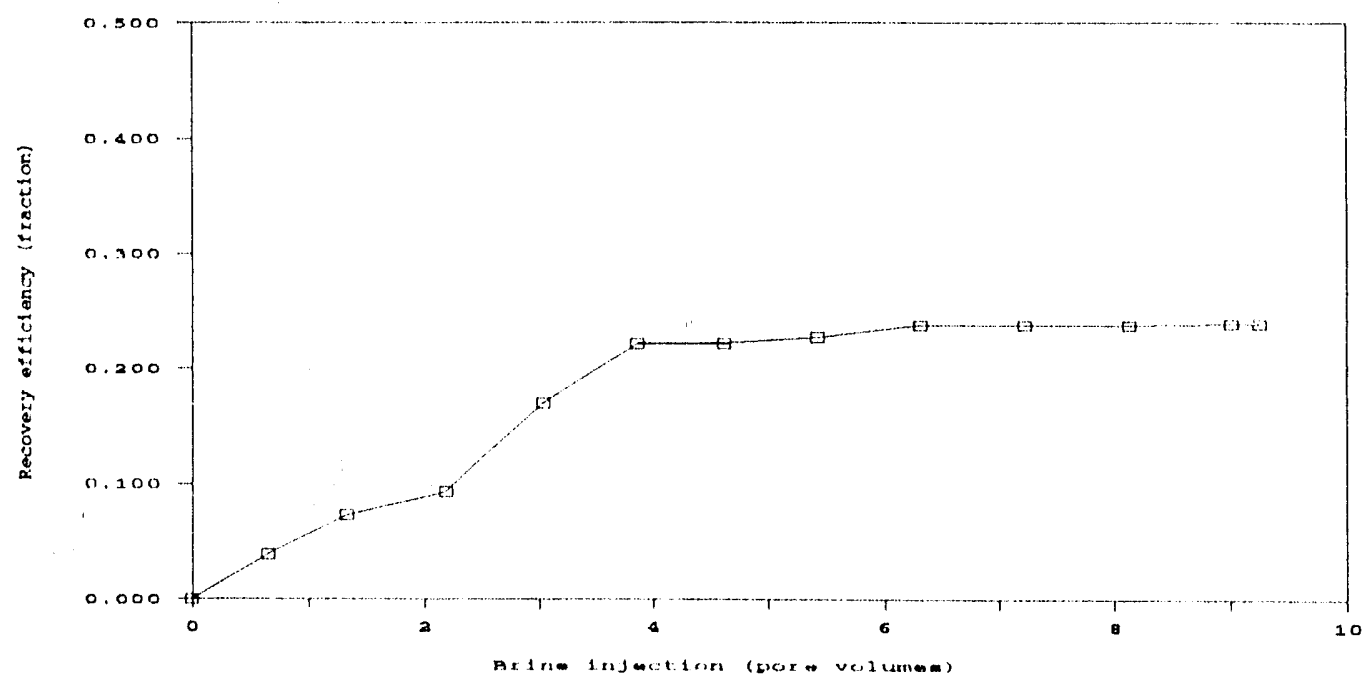

Figure 5-16. Recovery efficiency - Alworth oil - Core 12. 


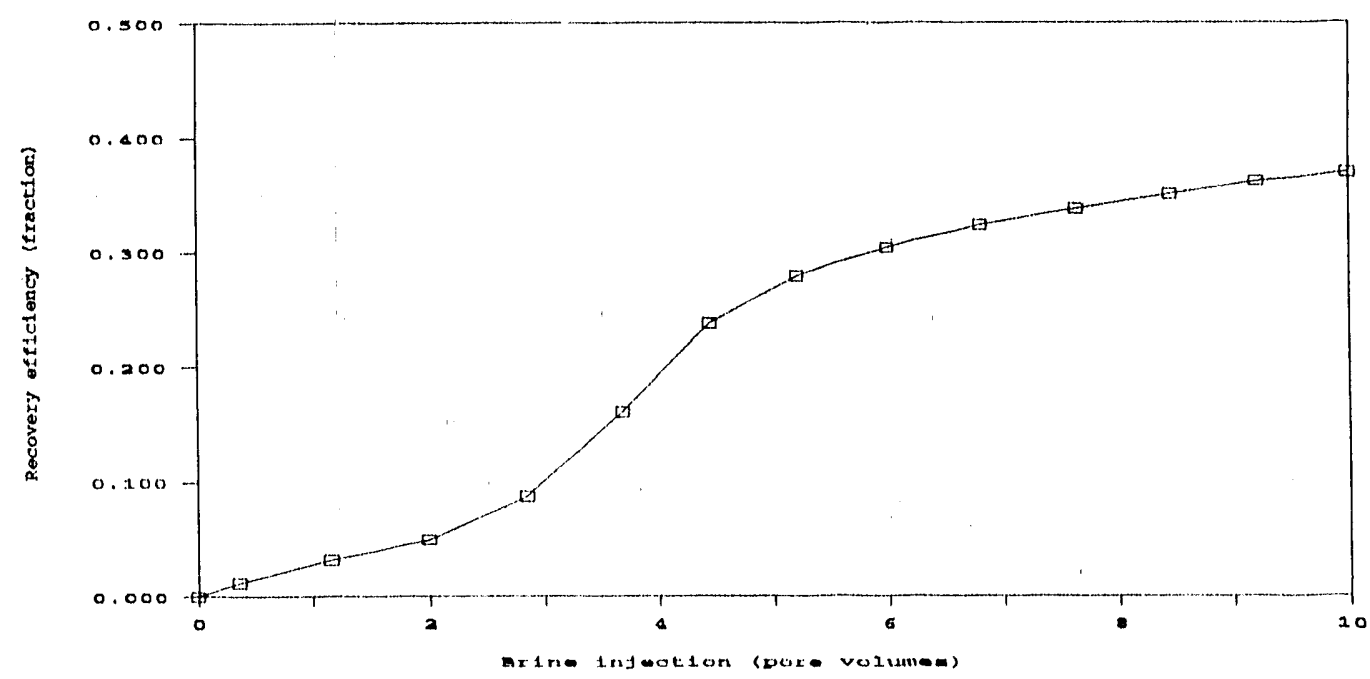

Figure 5-17. Recovery efficiency - Moorcroft West 011 - Core 13.

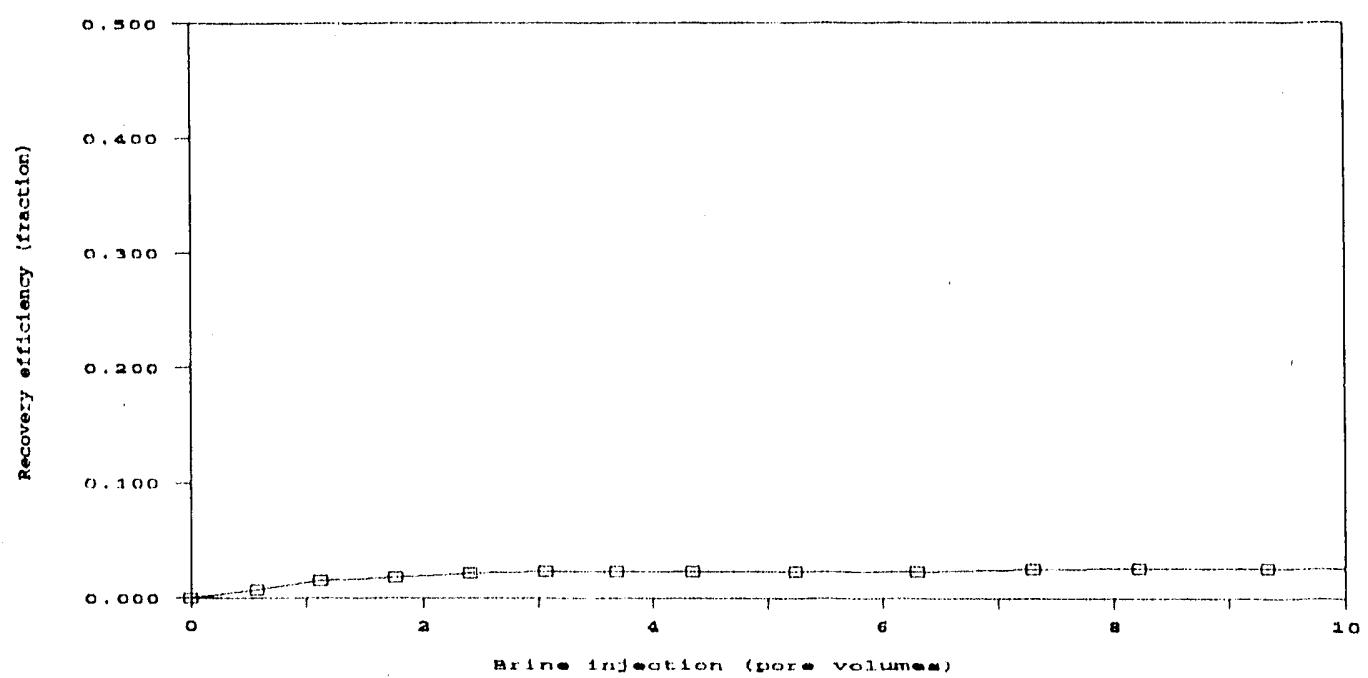

Figure 5-18. Recovery efficiency - Moorcroft West 011 - Core 24. 


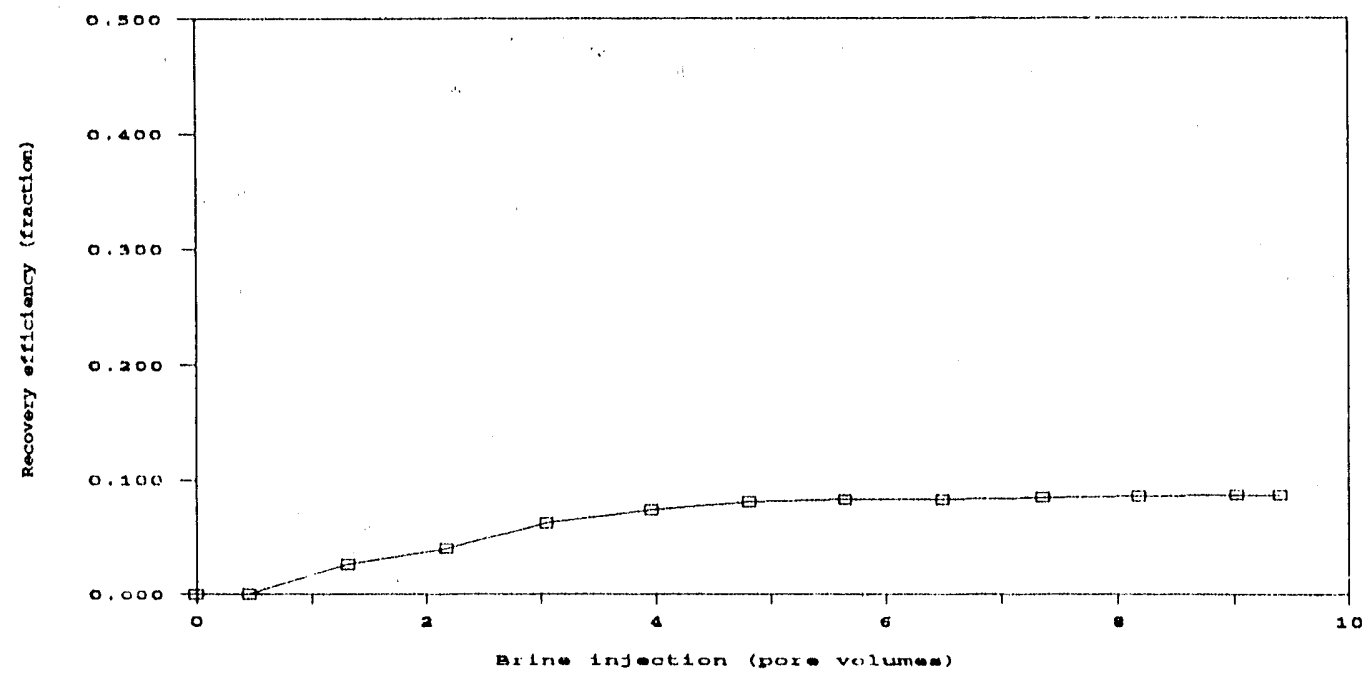

Figure 5-19. Recovery efficiency - l.ick Creek oil - Core 11.

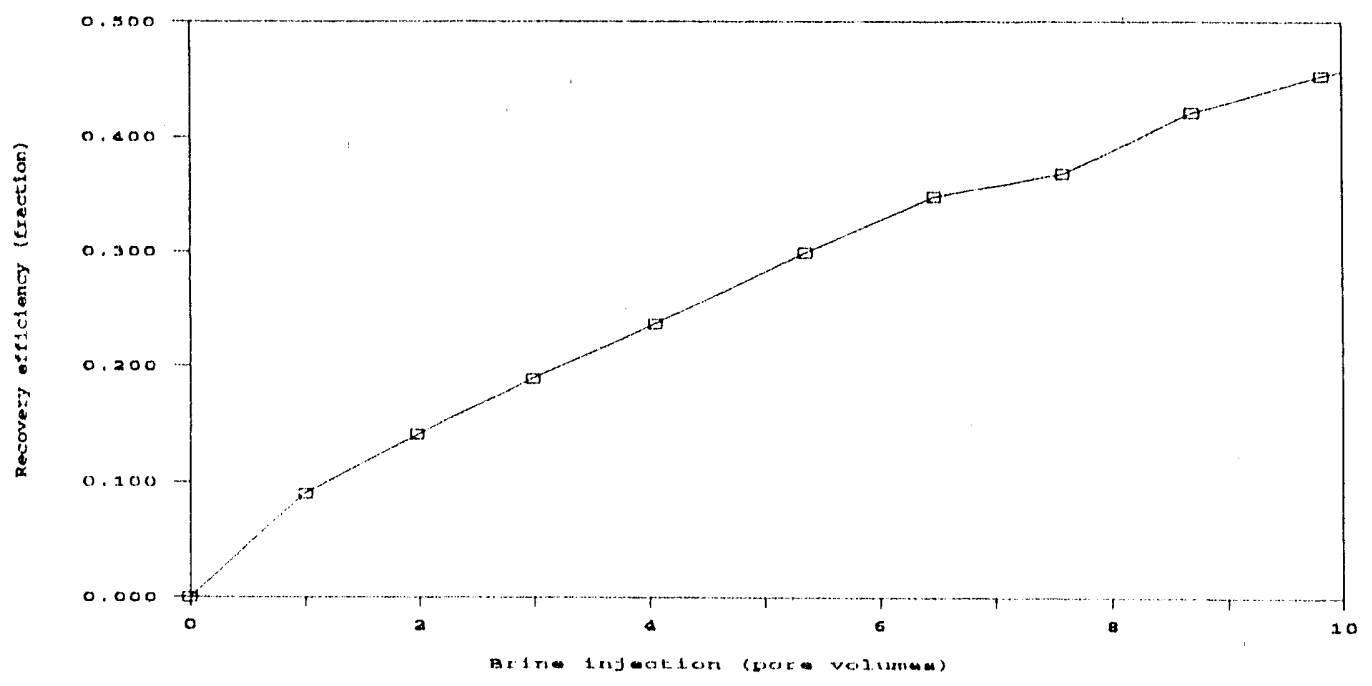

Figure 5-20. Recovery efficiency - Lick Creek oil - Core 26. 


\subsection{References}

1. R. S. Bryant and J. Douglas, "Evaluation of Microbial Systems in Porous Media for EOR, "Society of Petroleum Engineers Reservoir Engineering, 3 , 2, 1988, pp. 489-495.

2. R. M. Knapp, M. J. McInerney, D. E. Menzie, J. L. Chisholm, Microbial Field Pilot Study - Quarterly Technical Progress Report for the Period March 1, 1989 - June 30, 1989, DOE/BC/14246--T2, Ju1y 1989.

3. D. Jia, J. S. Buckley, and N. R. Morrow, "Control of Core Wettability with Crude $0 \mathrm{i1}$, " Society of Petroleum Engineers International Symposium on 0ilfield Chemistry, Anaheim, California, February 20-22, 1991, SPE 21041. 


\section{TARGET RESERVOIR SELECTION}

The guidance received in early 1989 for the EOR and Applied Geoscience Research Program at the INEL was to investigate the application of MEOR to reservoirs containing medium to heavy crude oils in the 12 to $20^{\circ} \mathrm{API}$ gravity range. Dwight's Energydata database was used to review existing field data in search of fields that contain medium to heavy oils that fit the published criteria ${ }^{1}$ for MEOR field applications (see Table 6-1).

Table 6-1. Criteria for reservoir selection for MEOR processes ${ }^{a}$

$\begin{array}{lr}\text { Total dissolved solids in brine (ppm) } & <100,000 \\ \left.\text { Usual reservoir temperatures ( }{ }^{\circ} \mathrm{F}\right) & <160 \\ \text { Usual reservoir depths (ft) } & <10,000 \\ \text { Residual oil saturation (\%) } & >25 \text { to } 30 \\ \text { Usual brine permeability (md) } & >100\end{array}$

a. From Bryant and Burchfield, 1989. ${ }^{1}$

The states of Colorado, Montana, North Dakota, Utah, New Mexico (northern) and Wyoming were searched using an API gravity cut-off of $>10^{\circ}$ and $<22^{\circ}$. These states were chosen because they are all oil producing states within reasonable proximity to the INEL. Having target reservoirs in relative close proximity to the INEL improves ease of accessibility and decreases travel expenses for field fluid sampling and data collection.

The database search of these six states revealed that Wyoming had the largest number of reservoirs with oil in this API gravity range. Numerous reservoirs with appropriate API gravities were found in the Powder River Basin of 
Wyuming. Most of the Powder River Basin reservoirs were in the Minnelusa formation with a few in the Tensleep formation.

\subsection{Candidate Reservoir Selection For Focus Of MeOR Research}

Several operators of Minnelusa and Tensleep Formation fields in the Powder River Basin of Wyoming were contacted. Home Petroleum Corporation and KSL Enterprises, Inc. Were both willing to allow sample collection and to cooperate in a study of their reservoirs for potential MEOR application. During this initial stage of MEOR research and process design, operator cooperation is critical to ensure field availability and accessibility for fluid sampling and field and reservoir data collection. Six Minnelusa fields were initially chosen for field fluid sample collection based on operator cooperation and field accessibility. These reservoirs were also screened using reservoir and field data to determine if they contained sufficient residual oil and were viable cardiúutis for application of MEOR technology.

Based on the screening results, three fields in the Powder River Basin, Wyoming were selected as candidates for focus of MEOR research at the INEL. These reservoirs, South Rozet Unit (Section 25-50N-70W, Campbell County, Wyoming), Moorcroft West Unit (Section 12-51N-68W, Crook County, Wyoming), and the Schuricht Lease (Section 24-52N-68W, Crook County, Wyoming) all produce from the Minnelusa formation. When field and reservoir data were obtained and analyzed on these fields, the South Rozet Unit was dropped as a current target reservoir for focus of MEOR research at the INEL. This decision was made because of the $80^{\circ} \mathrm{C}$ reservoir temperature that may be too high for MEOR applications. During this time period, the South Rozet Unit was also sold and a new operator took over operation of the field. Work continues to determine if Moorcroft West and Schuricht are viable targets for focus of MEOR research and process application.

These two fields provide the opportunity to study and evaluate reservoirs in two stages of depletion. The reported API gravities in Dwight's Fnergydata database for the crude oils from these fields are below the $22^{\circ}$ API gravity 
cut-off. Produced fluid samples have been obtained from these fields. The API gravities measured on the crude oil samples are $25.4^{\circ} \mathrm{API}$ at $60^{\circ} \mathrm{F}$ for the Schuricht Lease (primary recovery) and $22.3^{\circ} \mathrm{API}$ at $60^{\circ} \mathrm{F}$ for the Moorcroft West Unit (waterflood/polymer-augmented waterflood). Produced water quantities at the Schuricht lease are minimal and a sample could not be obtained. The viscosity measurements for the crude oils and brines at temperatures ranging from room temperature to reservoir temperature are shown in Figures 6-1 through 6-3, 2-11, and 2-12. Viscosity data are included for the South Rozet Unit for comparative purposes since it is located in the middle of the Minnelusa trend at a greater depth (about $8000 \mathrm{ft}$ ). Arialysis of the produced brine and injection water from the Moorcroft West Unit and the South Rozet Unit are shown in Tables 6-2 and 6-3.

Table 6-2. Produced water analys is

Field
Operator
County, State
Location
Producing Formation
Approximate Depth (ft)
Sample Point
pH
TDS (mg/L)
$\mathrm{Na}(\mathrm{ppm})$
$\mathrm{Ca}(\mathrm{ppm})$
$\mathrm{Mg}(\mathrm{ppm})$
$\mathrm{Ba}(\mathrm{ppm})$
$\mathrm{Fe}(\mathrm{ppm})$
$\mathrm{C}$ (ppm)
$\mathrm{SO}_{4}(\mathrm{ppm})$

Moorcroft West Unit KSL Enterprises, Inc. Crook County, Wyoming Section 12-51N-68W Minnelusa "A" 5900 subsurface Texas Trail \#1 wellhead 6.7 46,000

15,000

1320

625

0

0

23,800

1800
South Rozet Unit Home Petroleum Corp. Campbel1 County, Wyoming Section 25-50N-70W Minnelusa "B" 8000 subsurface Heater Treater wells $3 \& 4$ 7.3 134,000 51,000 1370 448

0

0 78,200

2650 
Table 6-3. Injection water analysis

$\begin{array}{ll}\text { Field } & \text { Moorcroft West Unit } \\ \text { Operator } & \text { KSL Enterprises, Inc. } \\ \text { County, State } & \text { Crook County, Wyoming } \\ \text { Location } & \text { Section 12-5iN-68W } \\ \text { Producing Formation } & \text { Unknown shallow sand } \\ \text { Approximate Depth (ft) } & 200 \text { subsurface } \\ \text { Sample Point } & \text { Wellhead } \\ \text { pH } & 7.3 \\ \mathrm{TDS}(\mathrm{mg} / \mathrm{L}) & 366 \\ \mathrm{Na}(\mathrm{ppm}) & 93.0 \\ \mathrm{Ca}(\mathrm{ppm}) & 31.3 \\ \mathrm{Mg}(\mathrm{ppm}) & 14.6 \\ \mathrm{~K}(\mathrm{ppm}) & 5.4 \\ \mathrm{Fe}(\mathrm{ppm}) & 0 \\ \mathrm{Cl}(\mathrm{ppm}) & 1.94 \\ \mathrm{SO}_{4}(\mathrm{ppm}) & 101\end{array}$

South Rozet Unit Home Petroleum Corp. Campbe11 County, Wyoming Section 25-50N-70W Foxhills 3500 subsurface Wellhead

8.4

800

301

1.7

0.04

1.6

0

19.4

107

\subsection{Analysis of Schuricht and Moorcroft West Crude Oils}

0ils have been analyzed with open column liquia chromatography (LC) for separation and quantification of the paraffinic, aromatic, non-pentane precipitable asphaltics, and pentane precipitable asphaltics. Component fractions from this procedure were analyzed with gas chromatography (GC). $A$ de-asphalnated (pentane precipitable) sample of Schuricht was also analyzed by coupled gas chromatography/mass spectroscopy (GC/MS). Data resulting from the crude oil analyses are presented in Section 2. of this report.

\subsection{The Powder River Basin, Wyoming}

The Powder River Basin is the second largest structural basin in the Rocky Mountain Structural Province. It includes the Northeastern quarter of Wyoming and a small portion of Southeastern Montana. The Basin is bounded structurally and topographically on the east by the broad asymmetric arch of the Black Hills and on the west by the Big Horn Mountains. The northern 
Laramie Range and the structural Hartville uplift lie to the south. The northern limit of the Powder River Basin is less defined, but may logically be placed at the south flank of the broad, north-trending arch separating the Sheep Mountain syncline from the Tongue River syncline (see Figure 6-4). ${ }^{2}$ It is a deep, asymmetric, elongated, syncline about $230 \mathrm{mi}$ long and $100 \mathrm{mi}$ wide.

\subsection{The Minnelusa Formation}

The Minnelusa formation lies in the northeastern portion of the Powder River Basin east of Gillette, WY. The formation outcrops in the Black Hills at Rapid River above Rapid City, SD. ${ }^{3}$

The first well in the Minnelusa having commercial significance was completed in 1957. Exploration for additional Minnelusa discoveries has continued into the 1990s with an extremely high increase in exploration activities with the higher oil prices of the early 1980s. Most of the larger Minnelusa reservoirs were discovered in the earlier phase of Minnelusa exploration, during the $1960 \mathrm{~s}$, but numerous smaller discoveries have continued into the 1990s. The original oil in place for the Minnelusa in the Powder river Basin has been estimated at 629 million barrels. ${ }^{4}$ With the increased Minnelusa exploration activities starting in the early 1980 s and the high degree of acceptance of EOR technology by independent oil producers operating in the Basin, an updated assessment of the remaining primary, secondary, and tertiary reserves is needed.

The Minnelusa formation is comprised predominantly of a white crystalline sandstone containing little clay and is loosely cemented by carbonate and anhydrite. The formation is of Pennsylvanian and Lower Permian age and is entirely marine in origin with the possible exception of the lower basal Bell Sandstone. The upper portion of the Minnelusa formation (Upper Minnelusa) usually contains two producing zones ( $A$ and $B$ ) and a third major sand (C) which is usually nonproductive and frequently wet. ${ }^{5,6}$ A generalized stratigraphic column of the northeastern portion of the Powder River Basin is shown in Figure 6-5 and type logs of the Minnelusa are shown in Figure 6-6.

$$
6-5
$$


The $C$ sand is separated from the $B$ sarid by alternating intervals of dolomites and anhydrites. The most predominant of the two producing zones is the $B$ sand which generally thins from the southwest to the northeast. The $A$ sand (which is the upper bench) generally thins from the south to the north and from the west to the east.

The Upper Minnelusa consists of shallow marine sandstone, carbonates, and evaporites and the top zone is an erosion surface overlain by impervious red shale of the opeche formation. A variety of trapping mechanisms exist in the Minnelusa including permeability barriers within the sand lenses, truncation by pre-Opeche erosion, structural closure, and sand wedge-out against older topographic highs. Most of the active fields show both truncation and differential sand deposition on an uneven existing topography. ${ }^{4} 7$

During Minnelusa time, open sea existed to the southeast. The Minnelusa sediments in the Powder River Basin indicate a more restricted marine environment. Sandstones in the Upper Mirnelusa can be $100 \mathrm{ft}$ thick and topographic relief of up to $75 \mathrm{ft}$ is common at unconformities. Lithology indicates a sandstone capped by dolomites and arihydrites. These caps are harder than the underlying sandstones and the caps are generally more resistant to erosion than the underlying sandstones. Decrease in interval thickness is usually caused by erosion at the top of the Minnelusa. The Minnelusa dips about $5 \mathrm{ft} / \mathrm{mi}$ with regard to the Minnelusa surface and is essentially flat at the unconformity surface."

At the end of Minnelusa time, the entire region was sub-aerially exposed and subjected to erosion. Subsequently, the Opeche sea invaded the area, and deposition continued until Laramide time. Paleotopography developed on the Upper Minnelusa unconformities reflects thick intervals in the overlying Opeche Shale representing valleys in the Upper Minnelusa and thins in the Opeche representing hills in the Upper Minnelusa.

Lithologically, the Upper Minnelusa consists of hard dolomite-anhydrite, alternating with softer sandstones with the practically flat bedding at unconformities indicating essentially a mesa or tableland topography (see

$$
6-6
$$


Figure 6-7). The hills are remnants of erosion resistant caprocks, while the valleys are usually eroded into the softer sandstones. ${ }^{4}$ In the eastern portion of the area, paleo-highs or hills tend to be relatively small and isolated within broad topographic depressions. A decrease in intensity of relief is seen from east to north and west. The long axes of these hills or mesas tend to be oriented to the northeast or to the northwest. To the west, the paleo-hills merge into larger elevated areas and the valleys become better defined. The northwest-southeast orientation of the long axes of the hills appears to be more prevalent in the western portion than in the east.

A north-south line separates the strongly dissected eastern portion from the lesser dissected western portion. About $85 \%$ of the 600 plus million barrels of Minnelusa $0 i 1$ in place (1971 data) has been found in the eastern portion. ${ }^{4}$ Erosion apparently proceeded westward and northward until the Opeche sea started to invade the Minnelusa surface. It is not known whether postMinnelusa topography was produced by water or wind erosion. The Permian period was very arid and wide shallow depressions and isolated hills in the eastern portion make it difficult to place these features within a logical drainage system. This (with the presumably arid climate) may point to the presence of a desert-type of erosion cycle during the late Upper Minnelusa time. Most Minnelusa accumulations occur on the updip or northeast side of the paleo-highs that tend to be orientated in a northwest-southeast or northeast-southwest direction.

\subsection{Minnelusa Reservoir Characteristics}

In a study of Minnelusa reservoirs, average values were determined for the reservoir characteristics of these fields and are listed in Table 6-4.8

Primary recovery averages $11 \%$ of the original $0 i 1$ in place (00IP). ${ }^{8}$ Because of the dead oil and low gas/oil ratios, recovery because of solution gas drive is limited. The primary production mechanism is fluid expansion. Original oil-in-place is usually difficult to estimate and experience in determining this value shows the estimate to be low in many cases. 9 
Table 6-4. Average reservoir characteristics of Minnelusa reservoirs ${ }^{\theta}$

$\begin{array}{ll}\text { Average reservoir permeability (md) } & 50-657 \\ \text { Porosity (\%) } & 16.2 \\ \text { Dykstra-Parsons permeability coefficient } & 0.75 \\ \text { Connate water saturation (\%) } & 25.5 \\ \text { Pay thickness (ft) } & 29.3 \\ \text { API gravity } & 18^{\circ} \text { to } 40^{\circ} \mathrm{API} \\ \text { Initial formation volume factor (bbl/STB) } & 1.087 \\ \text { Solution gas/oil ratio (ft } / \mathrm{bbl}) & 61.5 \\ \text { 0il viscosity at reservoir temperature (cP) } & 3.6 \text { to } 38 \\ & \text { (average } 15.2 \mathrm{cp} \text { ) } \\ \text { Produced water chloride content (mg/L) } & 2000 \text { to } 200,000\end{array}$

a. After Mack and Duva11, $1984 .^{8}$

Secondary recovery operations are usually initiated early in reservoir 1 ife and are very successful because reservoir fill-up is small caused by low primary recoveries. Response to injection usually occurs soon after the initiation of water injection. Because of reservoir heterogeneity and fairly viscous crude oils (average mobility ratio of 9.9), polymer-augmented waterflooding technology is a natural fit for improving ultimate recoveries from these reservoirs through sweep improvement technology. Polymer-augmented waterflooding technology has been accepted and incorporated in the exploitation profile of most Minnelusa reservoirs to maximize ultimate recoveries.

\subsection{The Schuricht Lease}

of the three fields that were initially considered for focus of the MEOR research, the Schuricht Lease is in the earliest stages of exploitation. Schuricht Well 21-24, completed in December 1983, is the only well in the reservoir and is presently under primary recovery. Schuricht Well 21-24 produces from the Minnelusa A sand at 6500 to $6508 \mathrm{ft}$ subsurface. The

$$
6-8
$$


Schuricht is arsut $15 \mathrm{mi}$ north of Moorcroft, WY and is in the northeastern corner of the Minnelusa trend.

The Schuricht Lease has potential for additional we 11 locations and to date, primary production has been low. No associated gas or active water drive is present in this reservoir and to date, no water has been produced. Reservoir temperature is estimated at $130^{\circ} \mathrm{F}$. The Schuricht is presently being pumped 2 to $3 \mathrm{~d} /$ week and is producing about 90 BOPM (barrels oil per month). Existing reservoir data on this field is limited and the full reservoir potential has not been defined.

The Schuricht Lease provides an ideal opportunity to drill a well in an effort to obtain reservoir rock and indigenous microbes from the reservoir. This would be the second well in the reservoir and would make it possible to sample a previously unperturbed region of the reservoir.

\subsection{The Moorcroft West Unit}

The Moorcroft West Unit was discovered in February 1983 and is located in Crook County, WY south (3-4 mi) of the Schuricht Lease. There is one producing well and one injection well in the reservoir. Water injection vegan in April of 1989 and a polymer-augmented waterflood was initiated in November of that year. Production is 40 BOPD from the Minnelusa A sand at $5890 \mathrm{ft}$ subsurface with an average thickness of $8.43 \mathrm{ft}$. Injection is into the Evans 1 at 60 bpd water/polymer with a surface injection pressure of 1000 psig. Primary production from this reservoir was 1ow (about $6 \%$ of the original oil in place) and field production had dropped to about 3 BOPD before initiation of water injection. There is very little associated gas and no apparent active water drive in this reservoir. Water has been produced from the Moorcroft West Unit (trace) but, so far there is no evidence of injection fluid breakthrough. There is potential for drilling an additional production well in the Moorcroft West Unit.

The primary producing mechanism in the Moorcroft West Unit is rock and fluid 
expansion and the uriginal oil in place (0.J1P) has been estimated at 508,485 stock tank barrels of oil (STBO). No water/oil contact is evident in either wel1. The porosity and water saturation for the reservoir as determined froin $\log$ calculations is 15.2 and $28.1 \%$, respectively. ${ }^{10}$ Permeability for the field is 114 ma and reservoir temperature is $120^{\circ} \mathrm{F}$.

Uitimate recovery from the polymer-augmented waterflood has been estimated to be 109,112 STBO or $21.5 \%$ 00IP. Alkaline-Surfactant-Polymer (A-S-P) technology is planned at the conclusion of the polymer-augmented water flood. The A-S-P technology is predicted to increase ultimate recovery to 117,096 STBO or $23.0 \%$ 00IP. ${ }^{10}$

The reservoir trends northeast-southwest and the hydrocarbon trapping mechanism is controlled by stratigraphy. It appears that the reservoir is bounded to the northeast and southwest by truncation of the permeable sand and subsequent in-filling by the Opeche Shale. ${ }^{10}$ The sand pinches out to the southeast and is also thought to pinch out to the northwest.

\subsection{FUTURE WORK}

The Moorcroft West Unit or the Schuricht Lease will be chosen as the target reservoir for research and field application of MEOR technology unless they are found to be unacceptable for technical or other reasons. Operator cooperation and willingness is critical to the application of MEOR technology through a field demonstration project.

Geological, biological, chemical, and engineering data will be analyzed for the target reservoir. Characterization and quantification of reservoir heterogeneity and permeability variation will be determined. This will provide the basis for design of the anticipated MEOR pilot field test.

Gathering of additional field and reservoir data and characterization of the candidate reservoirs will continue. A testing and evaluation program developed in cooperation with the operators of the candidate reservoirs will 
be designed and implemented to supplement the existing geological profile. Additional reservoir evaluation testing programs will be designed and implemented as necessary to obtain needed data for the selection of a target reservoir for application of the developed MEOR process design.

In a cost-sharing arrangement with the operator, a new we 11 will be drilled in the target reservoir to obtain reservoir rock and indigenous microbes from a previously unperturbed area of the reservoir. The reservoir core will be used to test, optimize, and scale developed MEOR systems through the use of laboratory core floods at reservoir conditions. Samples of reservoir fluids from an un-swept region of the reservoir can possibly be collected from this new wellbore. Core analysis work will provide needed rock and fluid properties of the target reservoir and will be used in the field process design of the pilot and demonstration field tests.

A study to determine the MEOR potential for the target reservoir type and region will be performed. This study will provide an evaluation of potential MEOR reserves and an economic evaluation of the developed MEOR process design and EOR potential for fields of the target reservoir type. This may require that a limited number of laboratory experiments with other applicable EOR techniques be performed for comparison purposes unless such data can be obtained from other sources. The investigation of the potential use of MEOR processes in combination with other EOR techniques may lead to the application with or following existing EOR field projects.

\subsection{Summary and Conclusions}

Waterflooding is a common and long-standing successful practice for increasing oil recovery in the Powder River Basin and especially in the Minnelusa formation. Polymer-augmented waterflooding is the most common EOR technology in use in the Minnelusa. The Powder River Basin is an area that has a significant and successful history of EOR technology application and is primarily operated by independent producers who appear willing and eager to cooperate in the application of EOR technology. 
It was determined that the Minnelusa formation in the Powder River Basin of Northeastern WY contained many good candidates for EOR processes. ${ }^{B}$ The primary recovery in these reservoirs is generally low because of heterogeneity of reservoirs and the oil viscosity. Operators (mostly independents) in the area are familiar with the application of polymer technology in conjunction with or following waterflooding and are, therefore, receptive to EOR technology.

The Moorcroft West Unit and the Schuricht Lease have been chosen for focus of laboratory MEOR research at the INEL based on known reservoir characteristics, field availability and accessibility, field fluid sample analysis, and operator cooperation. These fields will also be considered as possible candidates for field application of an MEOR process. Both produce from the Minnelusa formation ( $A$ sand) and are located in the Powder River Basin, WY. From available reservoir, field, and fluid data, both fit the published criteria of reservoir selection for MEOR processes. " These reservoirs are small confined reservoirs that provide ideal pilot testing opportunities because there would be minimal opportunity for off pattern operations to influence interpretation of results.

The MEOR research using Upper Minnelusa Reservoirs (Lower Permian : Pennsylvanian age) should be easily transferred to application in other sands of the same age and character such as the Tensleep and Leo sands of the Powder River and Big Horn Basins of WY. 2,3,5 With cross-cutting technology such as MEOR, transition of the technology to other sandstone reservoirs that fit the criteria for MEOR application should be achievable. 


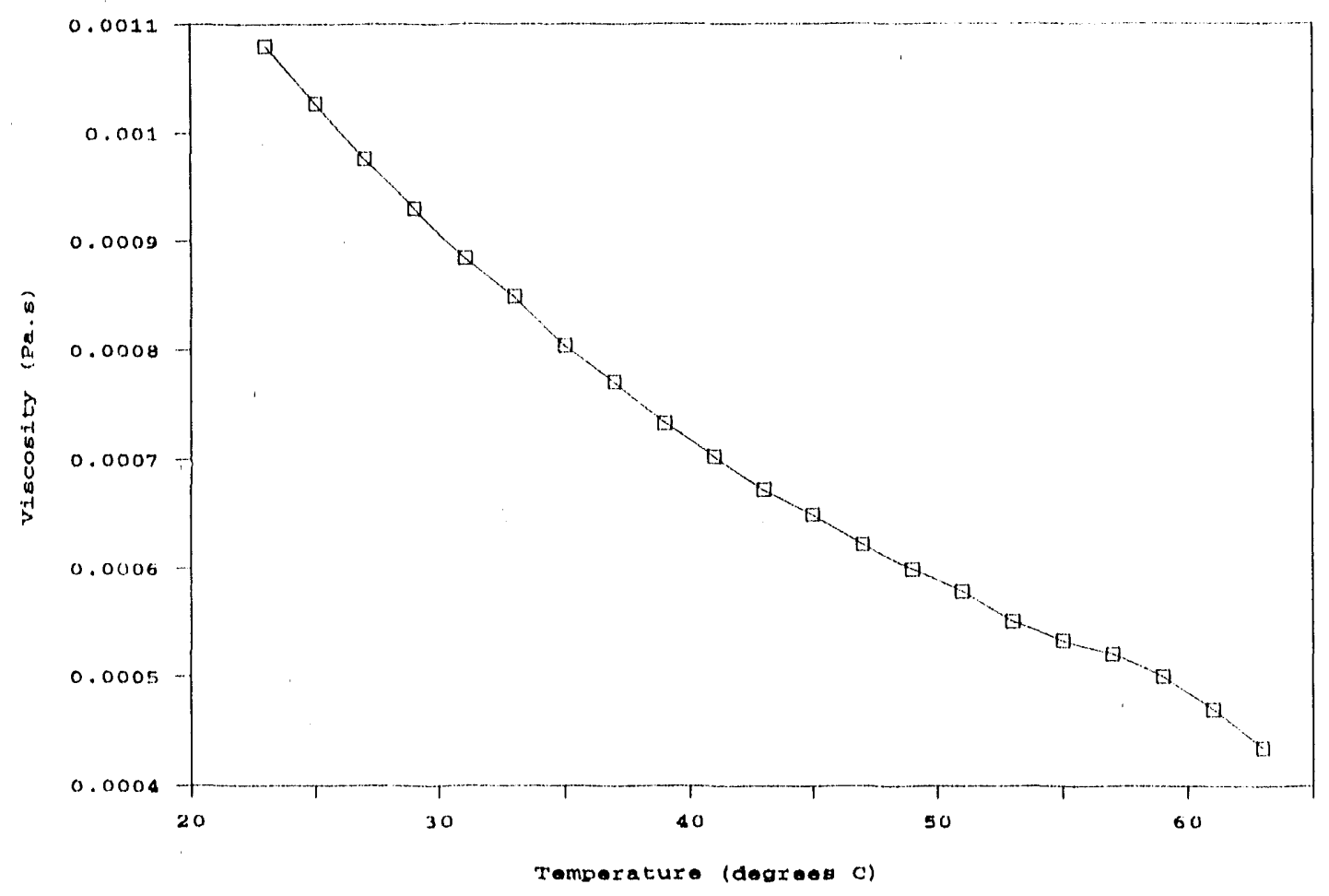

Figure 6-1. Produced brine viscosity - Moorcroft West Unit. 


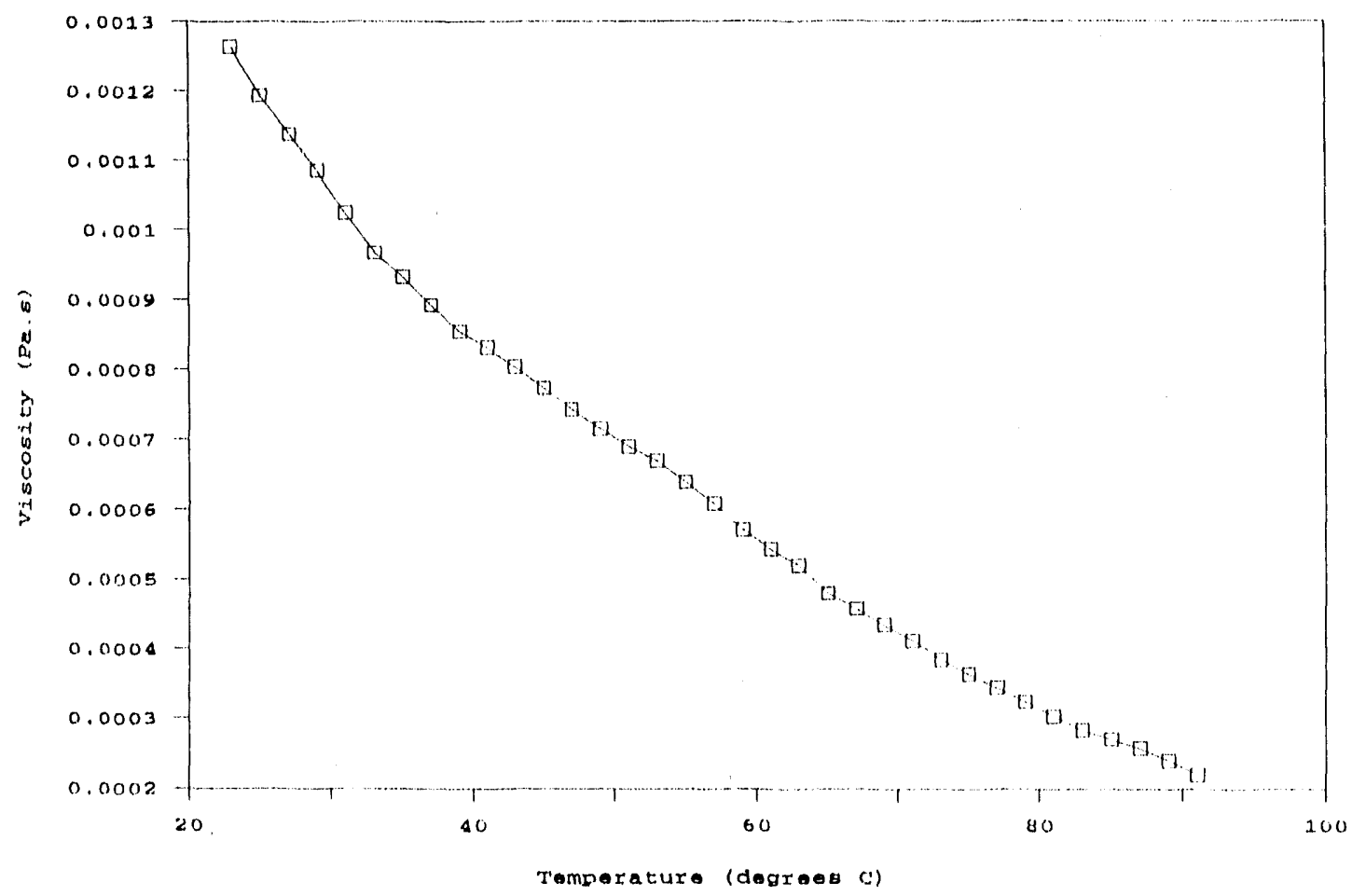

Figure 6-2. Produced brine viscosity - South Rozet Unit. 


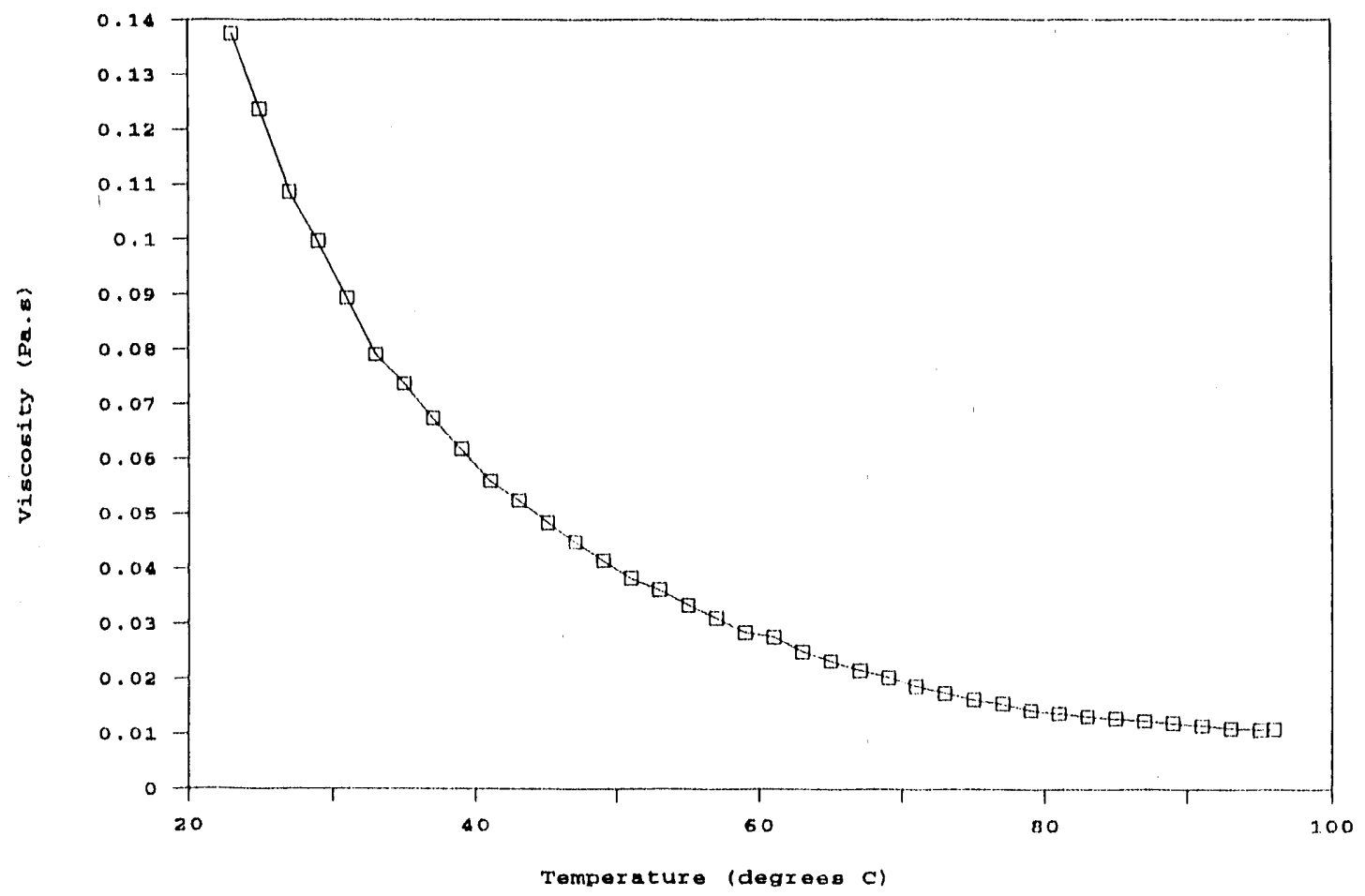

Figure 6-3. Crude oil viscosity - South Rozet Unit, $22.1^{\circ}$ API $060^{\circ} \mathrm{F}$. 


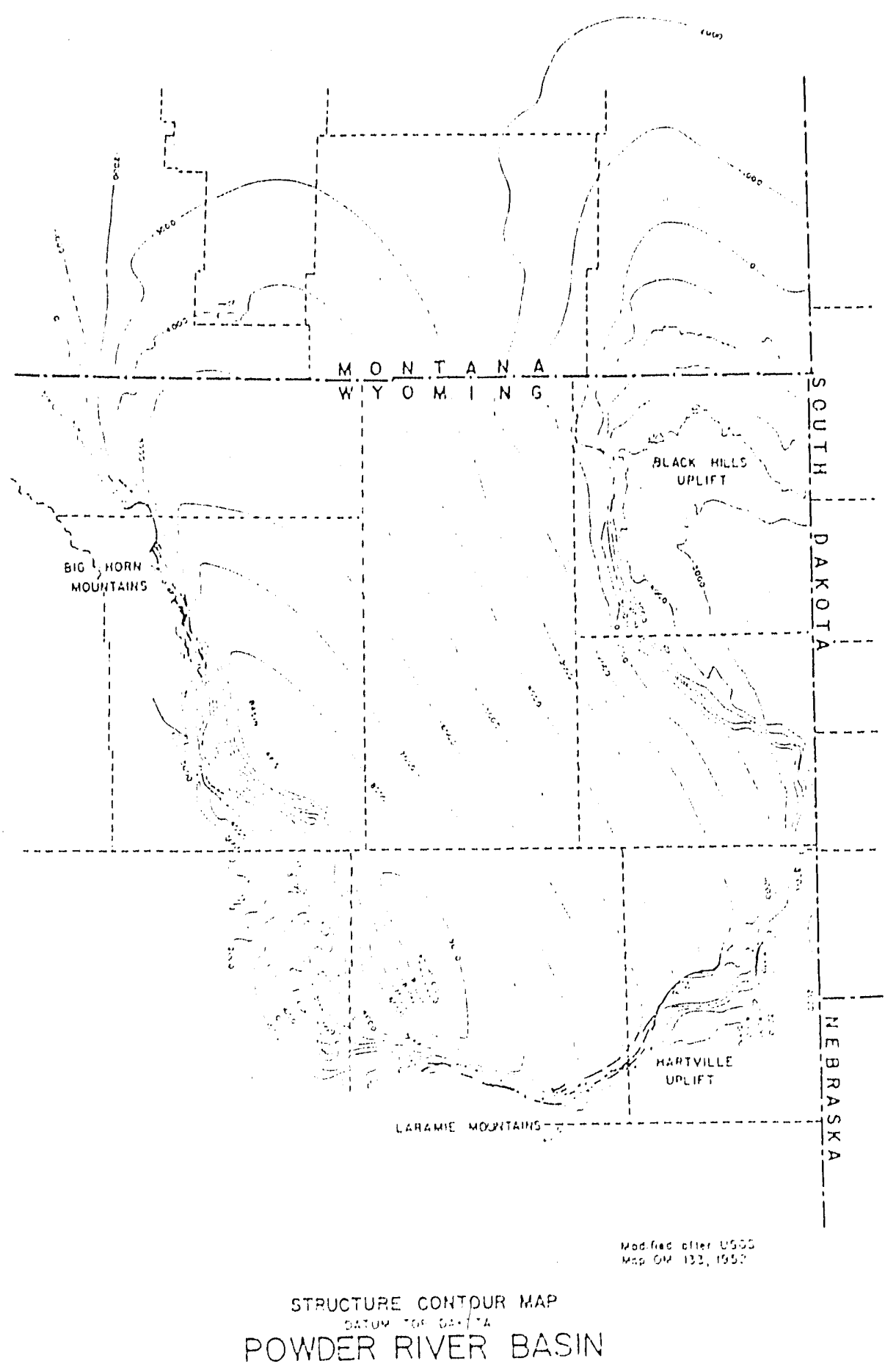

Figure 6-4. Structure contour map - Powder River Basin, from Strickland, $1958 .^{2}$ 


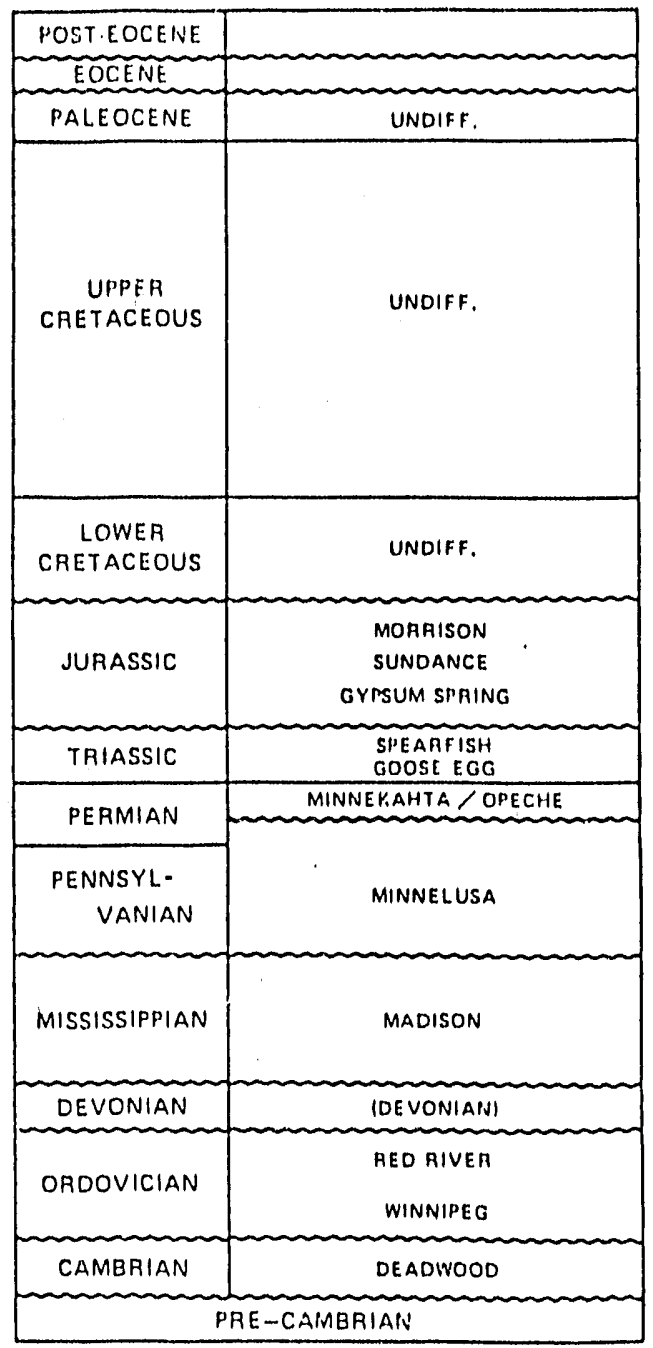

GENERALIZED STRATIGRAPHIC COLUMN NE POWIDER RIVER BASSIN, WYOMING

Figure 6-5. Generalized stratigraphic column - NE Powder River Basin, from Van West, 1972.4 


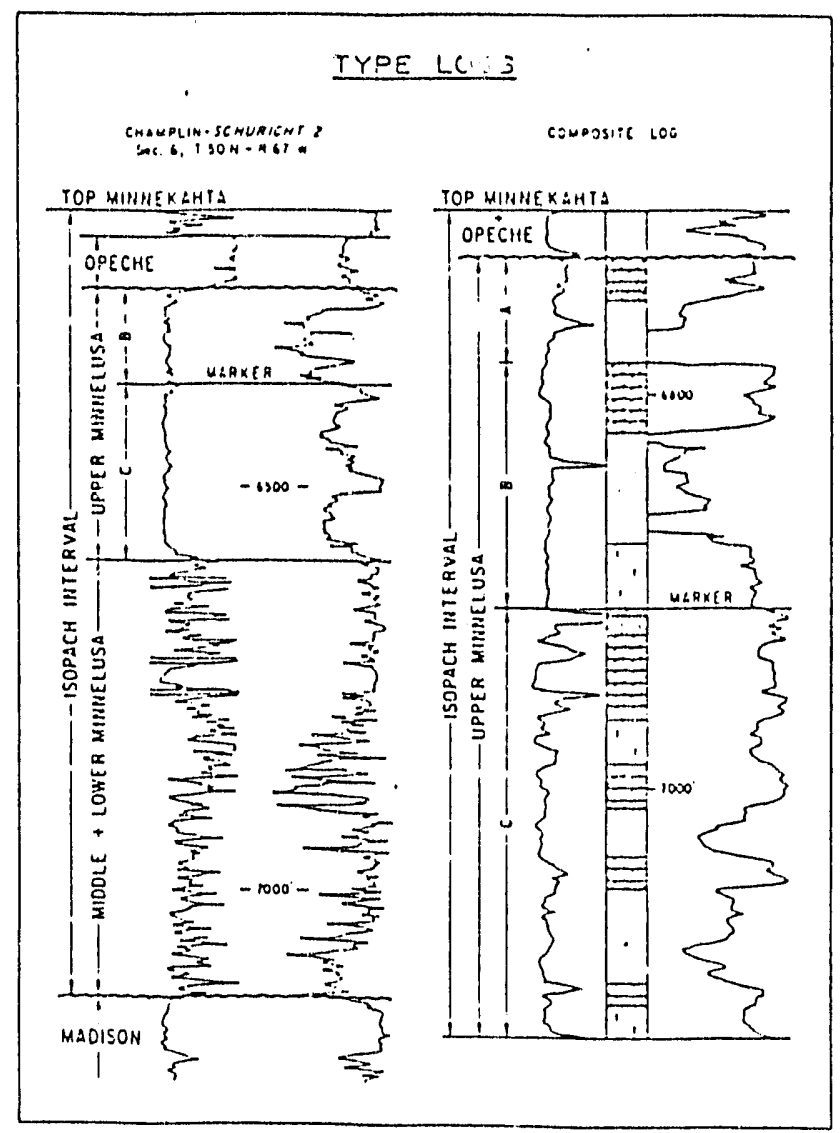

Figure 6-6. Minnelusa type logs, from Van West, $1972 .{ }^{4}$ 

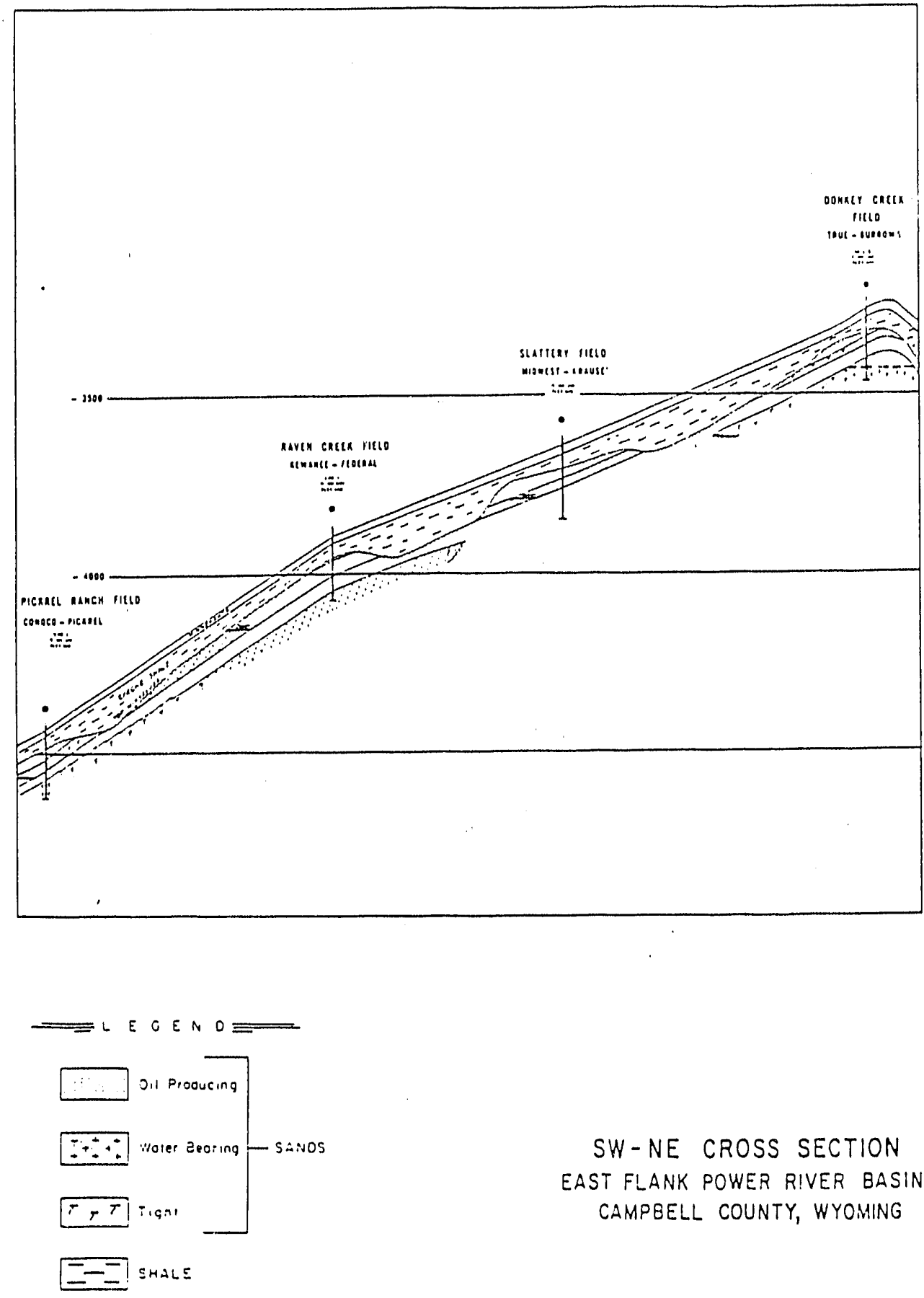

SW-NE CROSS SECTION EAST FLANK POWER RIVER BASIN CAMPBELL COUNTY, WYOMING

Figure 6-7. SW-NE cross section - east flank Powder River Basin, Campbell County, Wyoming, from Van West, 1972." 


\subsection{References}

1. R. S. Bryant and T. E. Burchfield, "Review of Microbial Technology for Improving 0 il Recovery," Society of Petroleum Engineers Reservoir Engineering, 4, 2, 1989, pp. 151-154.

2. J. W. Strickland, "Habitat of $0 i 1$ in the Powder River Basin," Wyoming Geological Association Guidebook, 13th Annual Field Conference, 1958, pp. 132-147.

3. A. G. Randa 11, "Catalog of Formation Names for Powder River Basin, Wyoming," Wyoming Geological Association Guidebook, 13th Annual Field Conference, 1958, pp. 280-287.

4. F. P. Van West, "Trapping Mechanisms of Minnelusa 0il Accumulations, Northeastern Powder River Basin, Wyoming," The Mountain Geologist 9, 1, 1972, pp. 3-20.

5. D. I. Foster, "Summary of the Stratigraphy of the Minnelusa Formation, Powder River Basin, Wyoming," Wyoming Geological Association Guidebook, 13 th Annual Field Conference, 1958, pp. 39-44.

6. T. E. Doll and M. T. Hanson, "Performance and Operation of the Hamm Minnelusa Sand Unit, Campbe11 County, Wyoming," Society of Petroleum Engineers Journal of Petroleum Technology, 39, 12,1987, pp. 1565-1570.

7. K. V. Tholstrom, "Performance History and Operations of Two Minnelusa Reservoirs - West Semlek Field, Crook County, Wyoming, " Society of Petroleum Engineers Annual Fall Technical Conference, New Orleans, Louisiana, October 3-6, 1976, SPE 6164. 
8. J. C. Mack and M. L. Duvall, "Performance and Economics of Minnelusa Polymer Floods," Society of Petroleum Engineers Rocky Mountain Regional Meeting, Casper, Wyoming, May 21-23, 1984, SPE 12929.

9. S. M. Hochanade1, M. L. Lunceford, and C. W. Farmer, "A Comparison of 31 Minnelusa Polymer Floods with 24 Minnelusa Waterfloods," Society of Petroleum Engineers/Department of Energy Seventh Symposium on Enhanced 0il Recovery, Tulsa, Oklahoma, April 22-25, 1990, SPE/DOE 20234.

10. J. A. McCartney, Waterflood Feasibility Study - Moorcroft West Field, Crook County. Wyoming, June, 1988. 


\section{RESERVOIR WETTABILITY AND ITS EFFECT ON OIL RECOVERY}

This section contains a summary of the reports, publications, and presentations resulting from research performed under the INEL Contract C89102443 at the New Mexico Petroleum Recovery Research Center (NMPRRC) in Socorro, NM for the period October 1, 1989 to September 30, 1990. The principal investigators for the research project are Dr. N. R. Morrow ard Dr. J. S. Buckley. Contributors at NMPRRC are Nouraddine Benali1, Martha Cather, Mary Graham, Pudji Jadhunandan, Duo Jia, Xuan Lu, Shouxiang Ma, Yiping Xuan, and Xiaoyun Zhang.

\subsection{BACKGROUND}

Study of reservoir wettability and its effect on oil recovery concerns the interactions between crude $0 i 1$ and mineral surfaces. The problem is being approached from a number of directions. These fall under two main tasks such as surface phenomena studies and oil displacement studies.

Task. 1 focuses on surface phenomena including simple observations of adhesion or lack of adhesion when a drop of crude oil contacts a smooth solid surface covered with brine. Changes in surfaces because of adsorption from crude oil, as well as the persistence of such changes under various cleaning conditions are observed. The effect of changing crude $0 i 1$ composition, either by dilution with solvents, fractionation, or evaporation of the lighter components has also been investigated. Studies of the surface charge at crude $0 i 1 /$ brine and solid/brine interfaces have been made using electrophoresis techniques.

The emphasis in Task 2 was to relate flow behavior and oil recovery to the wetting conditions prevailing in a porous medium. This task was attacked on several fronts. The work included determination of core wettability, extrapolation of laboratory tests to in situ conditions, and preparation of 
cores of known and reproducible wetting properties over the range of intermediate and mixed-wet conditions for study of displacement mechanisms. Displacements were studied through flow visualization in glass micromodels and laboratory flow tests in cores with cores exposed to crude oil to alter wettability.

\subsection{Reporting}

The results of this research effort have been reported in detailed quarterly reports that have been summarized and included in the quarterly progress reviews published by the U.S. DOE, Office of 0 il, Gas, and Shale Technology and Bartlesville Project Office (BPO), and in several presentations and contributions to the permanant technical literature as listed below.

\subsubsection{Quarterly Reports}

Work has been reported in detail in a series of four quarterly reports to the INEL and to BPO and included in the INEL quarterly technical progress reports. Each report describes general progress and includes a detailed thematic report as outlined below. The quarterly reports are also distributed to corporate sponsors of the NMPRRC research program.

\subsubsection{October Through December 1989: Surface Phenomena. Maps of} adhesion of crude $0 i 1$ to glass as a function of brine composition were reviewed in detail in the report for the previous quarter ending in September 1989. This quarter adhesion results were presented for Moutray crude oil with the oil altered by both dilution and evaporation to simulate possible effects of exposure of oil to microorganisms. The effects on adhesion of evaporation of about $20 \%$ of the lighter crude oil components and of dilution of the oil by toluene to as much as $1: 1$ oil to toluene were minor, as evaluated by the adhesion test. Electrophoresis measurement conditions for 12 oils (including evaporated and diluted Moutray) were outlined, as were drilling fluid additives and filtrates prepared for use in a study of the effects of waterbased drilling fluids on wettability. 
7.2.1.2 January Through March 1990: Surface Phenomena. Adhesion of Schuricht crude 0i1, supplied by INEL was reported. Electrophoretic mobitities as a function of oil type, ionic composition of brine, emulsion age, temperature, and emulsion concentration were reported in detail.

7.2.1.3 April Through June 1990: 0il Recovery. The report for this quarter focused on a study entitled "Crude $0 i 1$ Recovery in Laboratory Waterfloods." Imbibition rate and extent were reported for two crude oils (Moutray and an oil from the North Sea), with varying conditions of brine composition, aging temperature, and initial water saturation. Imbibition is used as a measure of wetting for cores after exposure to crude $0 i 1$ and is correlated to oil recovery in subsequent waterflood tests. These data provide the most extensive set of experimental work available yet that relates recovery of crude oil to wettability.

\subsubsection{July Through September 1990: Wettability Control. A study of} the use of crude oils to produce cores of altered wettability from strongly water-wet to intermediate in wetting as measured by the Amott imbibition test was reported. This method is being developed as part of the study of drilling fluid filtrates. Crude oils are used to produce Berea sandstone cores of altered wettability in a reasonably reproducible fashion, so that the effect of exposure to drilling fluids and their component chemicals can be assessed for non-water-wet cores.

\subsubsection{General Communication of Project Results in the Public Domain}

Communication of results of the Petrophysics and Surface Chemistry Group in the public domain through presentations and contributions to the permanent literature are listed below. 


\subsubsection{Publications.}

1. J. S. Buckley and N. R. Morrow, "Characterization of Crude $0 i 1$ Wetting Behavior by Adhesion Tests, " Society of Petroleum Engineers/Department of Energy Seventh Symposium on Enhanced 0il Recovery. Tulsa, Oklahoma, April 22-25, 1990, SPE/DOE 20263, to be published, Society of Petroleum Engineers Formation Evaluation.

2. N. R. Morrow, "Introduction to Interfacial Phenomena in $0 i 1$ Recovery," Interfacial Phenomena in 0il Recovery, Ed. N. R. Morrow, Marcel Dekker, 1990, pp. 1-21.

3. J. S. Buckley, "Multiphase Displacements in Micromodels," Interfacial Phenomena in 0 il Recovery, Ed. N. R. Morrow, Marcel Dekker, 1990, pp. $157-189$.

4. N. R. Morrow and J. C. Melrose, "Application of Capillary Pressure Data to the Determination of Connate Water Saturation, "Interfacial Phenomena in 0il Recovery, Ed. N. R. Morrow, Marcel Dekkar, 1990, pp. 257-287.

5. D. Jia, J. S. Buckley, and N. R. Morrow, "Control of Core Wettability with crude 0i1," Society of Petroleum Engineers International Symposium on 0ilfield Chemistry, Anaheim, California, February 20-22, 1991, SPE 21041.

6. S. Ma and N. R. Morrow, "Effect of Firing on Fluid Flow Properties in Berea Sandstone, " Society of Petroleum Engineers International Symposium on 0ilfield Chemistry, Anaheim, California, February 20-22, 1991, SPE 21045.

7. N. R. Morrow, "Wettability and Its Effect on 0il Recovery, " Society of Petroleum Engineers Distinguished Author Series, Journal of Petroleum Technology, 42, 12, 1990, pp. 1476-1484. 
8. G. Mason and N. R. Morrow, "Captllary Behavior of a Wetting Liquid in Irregular Triangular Tubes," to be published, Journal of Collotd and Interface sicience.

\subsubsection{Presentations}

1. N. R. Morrow, "Surfaces and Interfaces," keynote address, Fifth IFP Research Conference on Exploration and Production, Fundamentals of Fluid Iransport in Porous Medta, Arles, May 14-18, 1990.

2. P. Jadhunandan and N. R. Morrow, "Crude $0 i 1$ Recovery in Laboratory Water Floods, " Fifth IFP Research Conference on Exploration and Production, Fundamentals of Fluid Transport in Porous Media, Arles, May 14-18, 1990.

3. N. R. Morrow and J. C. Me1rose, "Application of Capillary Pressure Data to the Determination of Connate Water Saturation," keynote address, European Core Analys is Symposium, London, May, 1990.

4. M. E. Cather, N. R. Morrow, and I. Klich, "Characterization of Porosity and Pore Quality in Sedimentary Rocks, " Second IUPAC Symposium on Characterization of Porous Solids, Alicante, May, 1990.

5. J. S. Buckley, "Wettability Effects of Crude 0ils, "American Geophysical Union Spring Meeting, Baltimore, Maryland, May 29-June 1, 1990.

6. J. S. Buckley and N. R. Morrow, "Crude $0 i 1$ Wetting, "poster, International Symposium on Contact Angles and Wetting Phenomena, Society of Chemical Industry, Toronto, Canada, June 21-23, 1990.

7. J. S. Buck7ey, "Prediction of Crude 0i1/Rock Wettability, " Society of Core Analysts Fourth Annual Technical Conference, Dallas, Texas, August 14-16, $\underline{1990}$.

(See Table 7-1 for additional presentations made at the First International Symposium on the Effect of Wettability on 0il Recovery.) 


\subsubsection{First International Symposium on the Effect of Wettability on 011 Recovery}

The First International Symposium on the Effect of Wettabt1ity on 011 Recovery was sponsored by the New Mexico Petroleum Recovery Research Center (NMPRRC) and held at the New Mexico Institute of Mining and Technology in Socorro New Mexico on September 18 to 21, 1990. Ninety participants from 6 countries and 32 different organizations including 17 major oil companies participated in the symposium. The program included presentations on work by the Petrophysics and Surface Chemistry Group at NMPRRC.

Table 7-1. Presentation program for the First International symposium on the Effect of Wettability on 011 Recovery held September 18 to 21, 1990 in Socorro, NM

Measurement of Wettability and its

Effect on 011 Recovery

The Role of Surface Structural Forces in Wettability

Wetting Behavior of Crude 011/Brine/Solid Surfaces from Adhesion Tests and Electrophoretic Mobilities ${ }^{\text {a }}$

Effect of Microbial Activity on the Wettability of Surfaces by Water and $0 i 1$

Control of Core Wettability with Crude $011^{\mathrm{a}}$

Wettability Alteration by Asphaltine Deposition

Using Cryomicroscopy to Visualize $0 i 1$ and Brine in Porous Media
Norman Morrow

NMPRRC, New Mexico Tech

George Hirasaki

Shell Development Co. Houston, TX

Jill Buckley NMPRRC, New Mexico Tech

Norman Wardlaw Univ. of Calgary, Canada

Jill Buckley NMPRRC, New Mexico Tech

Sheila Yeh Chevron 0il Field Research Corp. La Habra, Calif.

Michel Robin Institut Français du Pétrole Paris, France 
Table 7-1. (continued)

Flutd Distribution in Mixed Wettability Rock

Gary Jerauld ARCO 011 and Gas Plano, Texas

Pore Level Trapping of 011 in Single Pores, Norman Wardlaw Pore Doublets, and Pore Networks Univ. of Calgary, Canada

Capillary Phenomena in Foam Flow Through Porous Media

Clay Radke

Univ. of Calif., Berkeley

Results of in situ Measurements of Residual 011 After Waterflood

Harry Deans

Diagenesis, Pore Structure, and Surface Properties of Reservoir Rocks ${ }^{\mathrm{a}}$

Martha Cather

Captllary Properties of Single Pores ${ }^{a}$

Obtaining Samples with Preserved Wettability

Univ. of Wyoming, Laramie NMPRRC, New Mexico Tech

NMPRRC, New Mexico Tech Cheuron 0il Fi Robert Wunderlich Robert Wunderlich
ld Research Corp. La Habra, Calif.

Effect of Drilling Mud Filtrates on Mixed Wettability Rock ${ }^{\mathrm{B}}$

Jia Duo

(Drilling \& Exploitation Research Inst. of Dagang 0il Field, PRC)

Core Analysis Procedures for Evaluation of Reservoir Wettability

Louis Cuiec Institut Français du Pétrole Paris, France

Measurement of Relative Permeabilities

Cliff Black British Petroleum Glasgow, United Kingdom

Laboratory Measurement of Relative Permeability with Reservoir Fluids

Jon Ringen Statoil

Stavanger, Norway

Observations on Slow Rate Displacements for Mixed Wettability Systems

Gerard Glotin/ Alaine Labastie

Elf Aquitaine

Pau, France

Numerical Simulation of Core Floods ${ }^{a}$

Ahmed Ouenes

NMPRRC - Visiting Scientist

(Elf Aquitaine) 
Table 7-1. (continued)

Relative Permeability Measurements on Ninety Samples

from 0il-Bearing Formations of a Single We11

Effect of Brine Composition, Crude 011, and Aging Conditions on Wettability and

011 Recovery

\author{
Ase Scheie \\ Norsk Hydro \\ Bergen, Norway \\ Pudji Jadhunandan \\ NMPRRC, New Mexico Tech
}

a. Presentations on work by the Petrophysics and Surface Chemistry Group at NMPRRC. 

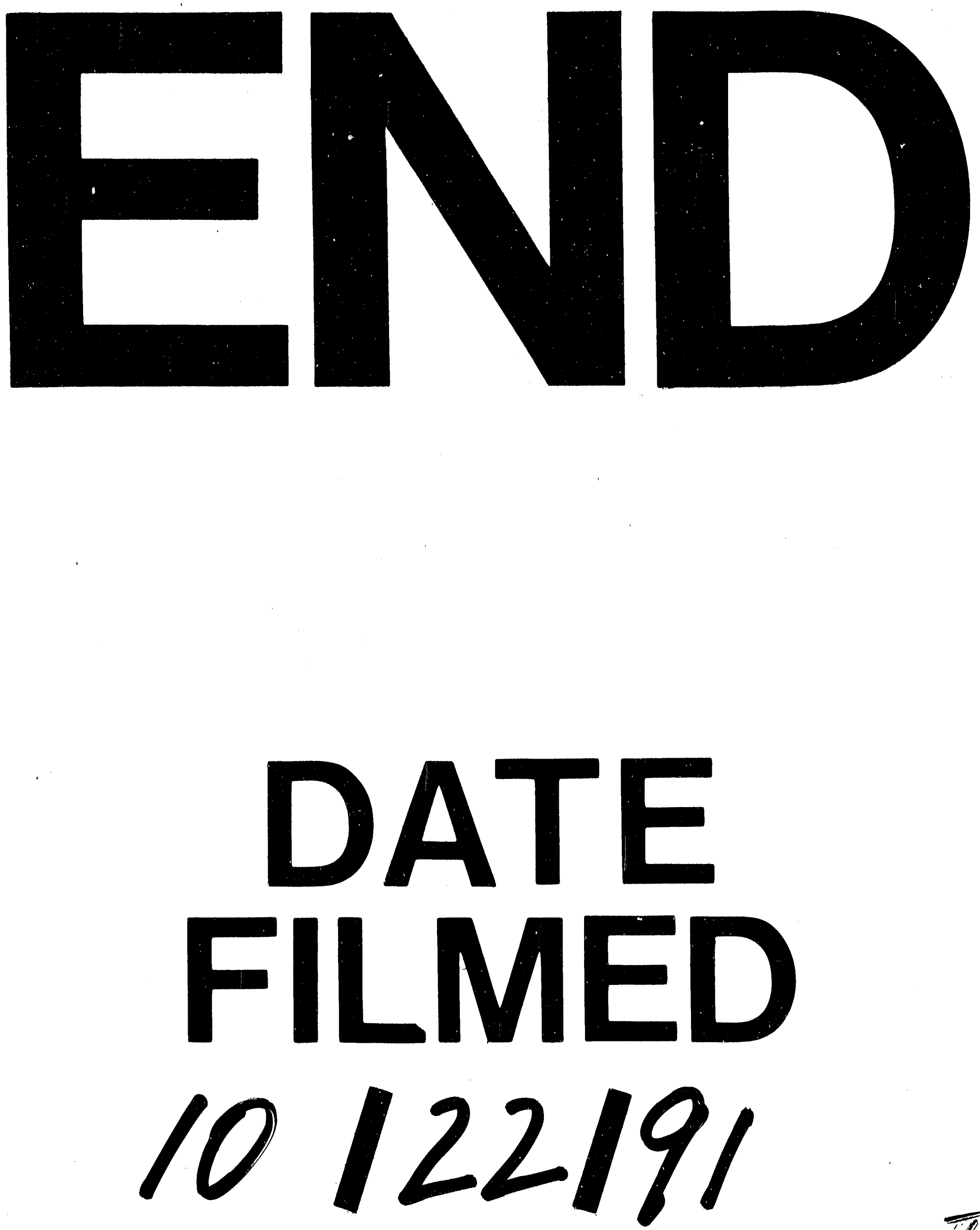

I 
